\title{
Maturação sexual e adiposidade em crianças e adolescentes de duas escolas de São Paulo
}

Jéssica Rodrigues de Oliveira

Dissertação apresentada ao Programa de Pós-Graduação em Nutrição em Saúde Pública da Faculdade de Saúde Pública da Universidade de São Paulo para obtenção do título de Mestre.

Área de concentração: Nutrição em Saúde Pública

Orientadora: Profa. Dra. Ana Maria Dianezi Gambardella

São Paulo 
É expressamente proibida a comercialização deste documento, tanto na sua forma impressa como eletrônica. Sua reprodução total ou parcial é permitida exclusivamente para fins acadêmicos e científicos, desde que na reprodução figure a identificação do autor, título, instituição e ano da dissertação. 
Para minha Família! 


\section{AGRADECIMENTOS}

À professora Dra. Ana Gambardella que com muito carinho, compreensão, competência e respeito me acolheu e me encorajou neste projeto. E pela amizade e liberdade de criação concedida durante todo o processo de orientação.

À amiga e professora Dra. Fernanda Frutuoso pela amizade, parceria e orientação iniciada na graduação. A realização deste sonho não seria possível sem seu apoio e incentivo.

Ao professor Dr. Wolney Conde pelos ensinamentos e contribuições referente as questão metodológicas, e por sempre mostrar-se atencioso e disponível.

À professora Dra. Sonia Buongermino pelas valiosas contribuições durante o exame de qualificação para melhorias desta pesquisa.

À professora Dra. Fátima Marucci pelos almoços acompanhados de prazerosas e estimulantes discussões sobre alimentação e nutrição. E a todos os professores do programa, que contribuíram para minha formação partilhando de suas vivências e conhecimentos.

Aos amigos e companheiros desta jornada: Jaqueline Muller, Fernanda Nascimento, Manuela Ferreira, Daiana Quintilliano, Fernanda Monticelli, Juliana Shibao e Daniela Itinoseki por transformar esse processo de formação em momentos de risadas e descontração; e a Larissa Baraldi, Luis Gobbo e Fernando Adami pelas "discussões estatísticas" durante as manhãs, de grande contribuição neste processo.

À amiga e secretária Alessandra Blaya, pelo auxílio e carinho em todos os momentos de necessidade.

À minha mãe, meu irmão, minha avó, meus padrinhos e primos por acreditarem e contribuírem para a realização deste sonho.

Ao Ricardo pela amizade e pelas incontáveis discussões sobre educação e a todos os meus queridos amigos que me apoiaram e entenderam meus momentos de ausência.

O meu sincero: Muito Obrigada! 
"I know I'm not gonna change the way people think about food, but that doesn't mean I'm gonna let them change the way I think about it."

(autor desconhecido) 


\section{RESUMO}

OLIVEIRA JR. Maturação sexual e adiposidade em crianças e adolescentes de duas escolas de São Paulo [dissertação de Mestrado]. São Paulo: Faculdade de Saúde Pública da Universidade de São Paulo; 2010.

Introdução: Na adolescência ocorre importante período de desenvolvimento sexual e acentuado crescimento corporal, caracterizado por alterações na quantidade e distribuição de gordura e massa magra diferente entre os sexos com importante impacto no estado nutricional, tanto atual como futuro. Objetivo: Analisar a associação entre maturação sexual e adiposidade em crianças e adolescentes. Método: Foi realizado estudo longitudinal com 617 estudantes de 8 a 18 anos de idade de duas escolas do município de São Paulo. Foram realizadas três coletas de dados com intervalo de 6 meses.. Dados de peso, estatura, perímetro da cintura foram coletados. O excesso de peso foi classificado com base nos valores críticos do índice de massa corporal (IMC) para crianças e adolescentes brasileiros. Valores de resistência $(R)$, reactância $(X c)$, ângulo de fase e composição corporal foram obtidos por meio de impedância bioelétrica. O estágio de maturação sexual (EMS) foi auto-avaliado e os indivíduos foram distribuídos em quartis de idade segundo EMS e sexo. Foram comparados os indivíduos com maturação relativamente acelerada com os demais indivíduos. Resultados: Foi observada associação negativa entre escore $z$ do IMC e idade de início da maturação sexual em meninos. A maturação sexual relativamente acelerada se associou com excesso de peso e com maior incremento nos valores de escore $\mathrm{z}$ do IMC. Meninas com maturação relativamente acelerada apresentaram maior adiposidade central. A maturação acelerada se associou a R/E, Xc/E e ângulo de fase e quantidade absoluta de massa magra. Menores vetores de impedância foram observados em meninas com maturação acelerada. Conclusão: A maturação sexual acelerada associouse a alterações nos parâmetros bioelétricos, composição corporal, maior incremento no IMC e obesidade em crianças e adolescentes.

Descritores: Criança, Adolescente, Puberdade precoce, Desenvolvimento sexual, Índice de massa corporal, Composição corporal, Parâmetro bioelétricos, Obesidade 


\begin{abstract}
OLIVEIRA JR. Sexual maturation and adiposity in children and adolescents from two schools in São Paulo [dissertation]. Sao Paulo: Faculdade de Saúde Publica, Universidade de Sao Paulo; 2010.

Introduction: Adolescence is considered an important period of sexual development and an increase body-growth, characterized by changes in the amount and distribution of fat and lean mass distinct between sexes, with a significant impact on nutritional status, current and future. Objective: To evaluate the association between sexual maturation and adiposity in children and adolescents. Method: We conducted a longitudinal study with 617 students 8-18 years old from two schools in São Paulo. Were performed three data collections at intervals of six months. Data on weight, height, waist circumference were collected. Overweight was classified based on cutoffs of body mass index (BMI) for Brazilian children and adolescents. Resistance $(\mathrm{R})$, reactance $\left(\mathrm{Xc}_{\mathrm{c}}\right)$, phase angle $(\mathrm{PA})$ and body composition values were obtained by bioelectrical impedance. The sexual maturation stage (SMS) was self-assessed and subjects were divided into quartiles of age second sex and SMS. We compared the subjects with relatively rapid maturation with other individuals. Results: We observed a negative association between BMI z score and age of onset of sexual maturation in boys. The relatively rapid sexual maturation was associated with overweight and greater increase in the values of $z$ scores of BMI. Girls with relatively rapid maturation had higher central adiposity. The accelerated maturation was associated with $\mathrm{R} / \mathrm{H}, \mathrm{Xc} / \mathrm{H}$ and PA and the absolute amount of lean mass. Lower impedance vectors were observed in girls with accelerated maturation. Conclusion: The accelerated sexual maturation was associated with changes in bioelectrical parameters, body composition, greater increase in BMI and obesity in children and adolescents.
\end{abstract}

Keywords: Child, Adolescent, Precocious puberty, Sexual development, Body mass index, Body composition, Bioelectrical parameter, Obesity 


\section{ÍNDICE}

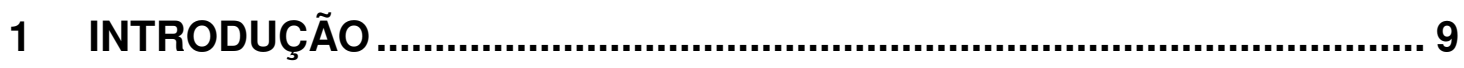

1.1 Crescimento, desenvolvimento e maturação ………............................. 9

1.2 Antropometria e composição corporal na adolescência ........................... 13

1.3 Maturação sexual e estado nutricional .................................................. 15

1.4 Tendência secular do excesso de peso em crianças e adolescentes e o impacto para a saúde pública .................................................................... 20

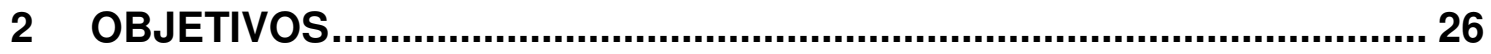

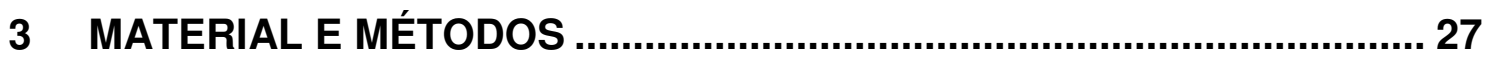

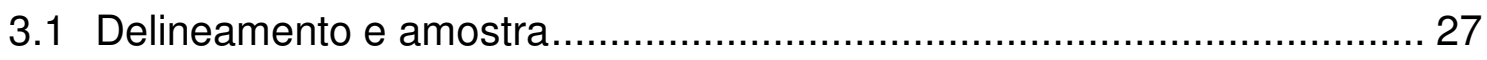

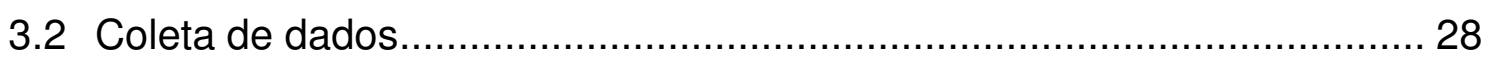

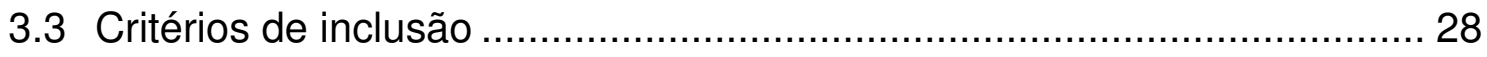

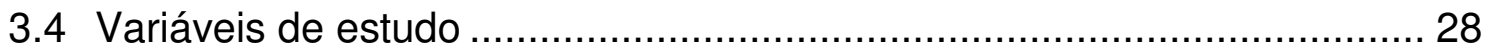

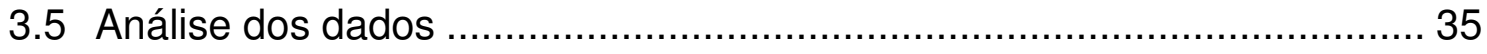

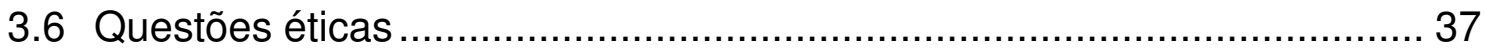

4 RESULTADOS E DISCUSSÃO

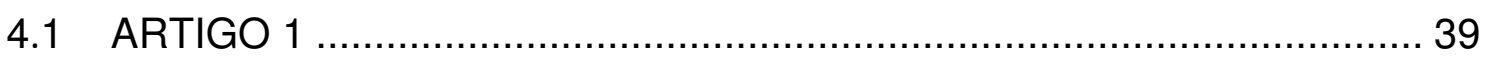

Maturação sexual e idade da menarca no Brasil

\subsection{ARTIGO 2}

Associação entre maturação sexual, excesso de peso e adiposidade central em crianças e adolescentes de duas escolas de São Paulo

4.3 ARTIGO 3

Maturação sexual e sua relação com composição corporal e parâmetros bioelétricos em crianças e adolescentes de duas escolas de São Paulo

5 CONSIDERAÇÕES FINAIS................................................................ 118

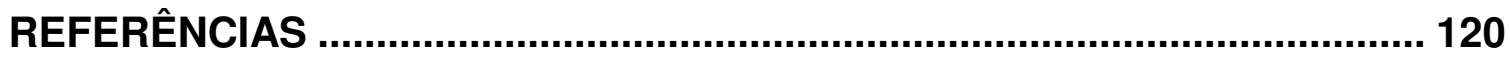

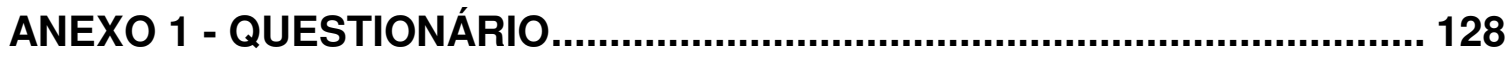

ANEXO 2 - APROVAÇÃO DO COMITÊ DE ÉTICA ….................................. 131

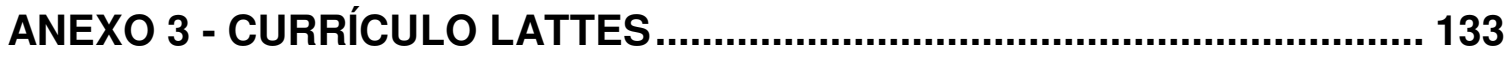




\section{INTRODUÇÃO}

\subsection{Crescimento, desenvolvimento e maturação}

O crescimento é um processo dinâmico decorrente do aumento do número e tamanho das células, resultando em crescimento estatural (longitudinal) e aumento do peso corporal. O padrão de crescimento entre os sexos começa a se diferenciar antes do nascimento. Em geral, os meninos são maiores que as meninas durante toda a gestação, de modo que, meninos a termos são em média 150 gramas mais pesados e de 1 a 2 centímetros maiores que as meninas. Após o nascimento, a maioria das dimensões corporais, tais como estatura, circunferências do corpo e peso, passam a seguir um padrão semelhante de crescimento entre os sexos. Os primeiros anos de vida são marcados por rápido crescimento, seguido por desaceleração ao final da infância. Durante a adolescência ocorre, a partir de condições ambientais (saúde, nutrição, higiene, status socioeconômico, entre outras) favoráveis, a expressão máxima do potencial genético do indivíduo, concluindo o crescimento longitudinal do indivíduo que perdurará por toda idade adulta. Em contrapartida, algumas dimensões corporais como o peso, gordura corporal e massa muscular podem continuar a sofrer alterações durante toda a vida (Bogin 2001).

A avaliação objetiva do crescimento a partir da técnica de mensuração das dimensões lineares, diâmetros e pesos do corpo humano, capaz de 
expressar tais medidas de forma quantitativa, é conhecida como antropometria (Cameron 1986). O médico alemão, Johann Sigismund Elsholtz foi o primeiro a utilizar este termo, quando em 1654 foi publicada a sua tese de graduação intitulada 'Antropometria'. A auxologia por sua vez, é a ciência que estuda o crescimento a partir de sucessivas medidas, podendo ser descrita em dois tipos de curvas capazes de medir a dimensão e a velocidade de crescimento de um indivíduo em determinado período (Tanner 1981).

O desenvolvimento é o processo de sucessivas alterações qualitativas e quantitativas nas estruturas corporais e suas funções. $O$ desenvolvimento envolve diversas mudanças em todo o corpo como o fechamento das fontanelas no crânio de bebê, capacidade cognitiva e neurológica das crianças, erupção dos dentes e a mudança no timbre de voz nos meninos durante a adolescência (Bogin 2001).

A maturação é o processo de desenvolvimento do ser humano para as características do adulto no sentido de tornar o organismo apto à função reprodutiva. A maturação física ocorre desde o momento da concepção, mas os indicadores de maturação tornam-se mais evidentes durante a adolescência. Alterações corporais, desenvolvimento mamário em meninas, desenvolvimento de pêlos pubianos em ambos os sexos, e desenvolvimento da genitália e pelos faciais nos meninos são indicadores visíveis da 
maturação para a aparência do corpo adulto, tornando-os aptos à função reprodutiva (Tanner 1962).

O início e desenrolar de todo o processo de maturação sexual apresenta grandes variações inter e intrageracionais influenciadas por fatores genéticos, responsáveis, em grande parte, pela variação individual dos fenômenos pubertários e, por fatores ambientais que deverão ser favoráveis para possibilitar a expressão máxima do potencial genético do adolescente (WHO 1995, Vitalle et al. 2003, Oliveira \& Veiga 2005, Barbosa et al. 2006).

A cessação do crescimento longitudinal também é considerada um evento maturacional. Embora haja uma associação entre crescimento e maturação, há uma importante distinção entre eles, uma vez que a idade biológica se diferencia da idade cronológica durante a maturação. Assim, crianças do mesmo tamanho podem diferir quanto ao estado de maturação e indivíduos completamente maduros (adultos) podem ter diferentes tamanhos. Isto é mais evidente durante os estágios iniciais da adolescência onde alguns indivíduos encontram-se biologicamente mais avançados (maturação precoce) que outros em relação a sua idade cronológica (Tanner 1962)

Alguns processos de desenvolvimento têm sido avaliados mais ou menos arbitrariamente em fases ou graus de modo que o progresso pode ser medido por meio de etapas. O desenvolvimento dos caracteres sexuais secundários associados à maturação sexual é um exemplo comum, no qual 
o desenvolvimento das mamas nas meninas, a genitália nos meninos e os pelos pubianos para ambos os sexos foi cuidadosamente descrito fases, auxiliando na investigação condições normais e anormais do crescimento e maturação adolescente (Tanner 1962, Colli 1993, WHO 1995, Bini 2000, Wang 2002)

Usualmente, é aceito que $\mathrm{o}$ aparecimento do tecido mamário e o desenvolvimento da genitália nos meninos é o sinal físico de maior confiabilidade da ativação do eixo hipotalâmico-hipofisário-gonadal nas meninas e meninos, respectivamente (gonadarca). $\mathrm{O}$ aparecimento de pêlos pubianos, embora geralmente ocorra aproximadamente o mesmo tempo, é atribuível a um processo hormonal distinto, o início da secreção de androgênios pelas glândulas supra-renais (adrenarca) e, portanto não é um marcador para confiável para a gonadarca (Kaplowitz 1999).

Não há dados recentes que abordam a idade em que normalmente a puberdade ou adrenarca ocorre em uma grande amostra da população. Dados transversais obtidos na década de 1960 em estudo conduzido por Marshall e Tanner (1970) com 192 meninas e 228 meninos brancos britânicos que foram atendidos no consultório em intervalos de 3 meses durante a adolescência, levaram à designação da faixa etária normal de início da puberdade (idade em que $95 \%$ das crianças atingiram o estágio 2 de Tanner para mamas e genitália), entre 8 e 13 anos nas meninas e entre 9 anos e 6 meses e 13 anos 6 meses em meninos. Cada sujeito foi 
fotografado nu durante a visita, e o estadiamento da mama e desenvolvimento e pêlos pubianos foi realizado por meio de exame das fotografias (e não exame físico), utilizando o sistema de classificação desenvolvido por Tanner (1962).

Entretanto, Tanner e Marshall (1970) observaram que as meninas estudadas pertenciam principalmente a classes socioeconômicas menos favorecidas. Eles também observaram que as meninas de seu estudo "não eram representativas da população britânica", especialmente porque elas chegaram a menarca a média de idade de 13,47 anos, quatro meses mais tarde que a população de Londres. No entanto, sua declaração que "o primeiro sinal da puberdade apareceram entre as idades de 8 anos e 13 anos em 95\% dos meninas e, 9 anos e 13 anos nos meninos" parece ter sido amplamente aceito como um padrão normal para o início da puberdade, sendo classificados como precoces àqueles indivíduos que iniciaram o processo de maturação em idades mais jovens e, tardios quando em idades superiores a estas.

\subsection{Antropometria e composição corporal na adolescência}

A adolescência compreende o período da vida que se estende dos 10 aos 19 anos segundo definição da Organização Mundial de Saúde (WHO 1986), representando cerca de $20 \%$ da população mundial. O período de transição gradual da infância para a vida adulta normalmente inicia-se com a 
puberdade (WHO 1995). Este período é marcado por profundas mudanças biopsicossociais nas quais o adolescente começa a definir sua identidade e estabelecer um sistema de valores pessoais mostrando-se especialmente vulnerável aos enormes agravos enfrentados pela maioria das sociedades atuais (WHO 2005).

Durante a adolescência ocorrem diversas alterações psicológicas e fisiológicas no ser humano, caracterizando-se como um dos períodos mais críticos do ciclo vital. Um grande número de mudanças físicas ocorre e muitos padrões adultos são adquiridos nesta fase. Desta maneira, o processo de maturidade biológica ocorrido na adolescência pode oferecer oportunidades para a prevenção de problemas de saúde no adulto (WHO 2005).

$\mathrm{Na}$ adolescência ocorre o estirão pubertário, marcado por um período de rápido e intenso crescimento físico com ganho de aproximadamente $45 \%$ da massa óssea do indivíduo adulto. Esta fase tem duração média de 36 meses sendo que o ganho de estatura é de aproximadamente 10 centímetros por ano no sexo masculino e de 8 a 9 no feminino, podendo ainda haver um acréscimo de 5 a 8 centímetros durante a fase de desaceleração até a parada total do crescimento. É nessa fase que o indivíduo adquire aproximadamente $50 \%$ do seu peso final e 20 a $25 \%$ de sua estatura definitiva (WHO 2005). 
O estirão pubertário ocorre geralmente 2 anos mais cedo no sexo feminino, podendo iniciar entre 9,5 e 14,5 anos nas meninas e entre 10,5 e 16 anos nos meninos (Colli 1993, Barbosa et al. 2006).

Em relação à composição corporal, observa-se aumento gradativo da massa muscular desde o início ao final da adolescência, sendo mais acentuado no sexo masculino e, aumento do tecido adiposo mais acentuado no feminino (Barbosa et al. 2006).

\subsection{Maturação sexual e estado nutricional}

O desenvolvimento puberal segue certa cronologia fisiológica de eventos devido à modificações no padrão de secreção de alguns hormônios. A ativação do eixo hipotalâmico-hipofisário-gonadal desencadeia, sob estímulo das gonadotrofinas, a secreção de esteróides sexuais (predominantemente testosterona nos meninos e estradiol nas meninas) que são responsáveis pelas modificações morfológicas do período puberal (Siervogel et al. 2003, Barbosa et al. 2006).

A Organização Mundial de Saúde - OMS ressalta que, para a avaliação nutricional do adolescente, deve-se considerar as modificações antropométricas e de composição corporal que estão fortemente relacionadas ao estirão puberal. Para tanto, marcadores biológicos do início 
e final do desenvolvimento pubertário possibilitam predizer o estágio em que o adolescente se encontra (WHO 1995).

Tanner (1962) propôs estágios baseados em características secundárias do desenvolvimento sexual para a identificação do estágio de maturação sexual - EMS. A classificação é baseada em graus do desenvolvimento de mamas para o sexo feminino, genitália externa para o sexo masculino e pêlos pubianos para ambos os sexos. O estágio 1 corresponde ao crescimento e desenvolvimento pré-puberal, enquanto os estágios 2 a 5 correspondem à progressão da puberdade até a maturação completa.

O estágio 3 do desenvolvimento da genitália e a mudança no timbre de voz nos meninos e, o segundo estágio do desenvolvimento das mamas e a menarca nas meninas são os marcadores biológicos propostos para o início e final do estirão puberal, respectivamente (WHO 1995).

A avaliação do estado nutricional por meio da antropometria é bem mais complexa em adolescentes do que em crianças. A razão principal desta complexidade decorre da grande variabilidade do crescimento e das dimensões corporais na adolescência, variabilidade esta que depende do estado nutricional dos indivíduos, mas, também, do desempenho do crescimento nas idades anteriores e de fatores hormonais relacionados ao processo da maturação sexual (WHO 2005). 
Os critérios para diagnóstico do estado nutricional na adolescência variam em diferentes estudos. Embora recentemente esteja se consolidando a opção pelo conjunto de curvas para o índice de massa corpórea (IMC = peso/estatura ${ }^{2}$ ) baseados no desfecho da idade adulta para a classificação do estado nutricional de adolescentes, ainda não existe consenso quanto ao melhor ponto de corte (Oliveira et al. 2006, Wang 2002).

Atualmente, os diferentes critérios para a classificação nutricional de adolescentes baseiam-se em valores de referência do IMC segundo idade e sexo, não existindo associação com o estágio de maturação sexual que melhor caracteriza a fase de desenvolvimento desta população. Adicionalmente, as mudanças ocorridas durante a puberdade ocasionam alterações antropométricas e na composição corporal dos adolescentes com impacto importante no estado nutricional (Taylor et al. 2003).

Diversos estudos apontam associação significativa entre IMC e o estágio de maturação sexual com o aumento continuo de 0,5 a $1,3 \mathrm{~kg} / \mathrm{m}^{2}$ no $\mathrm{IMC}$ a cada estágio (Díaz et al. 1996, Vitalle et al. 2003, Oliveira \& Veiga 2005, Barbosa et al. 2006).

Oliveira \& Veiga (2005) observaram associação entre renda e início da maturação sexual ocorrendo mais precocemente em adolescentes de nível socioeconômico mais elevado que em jovens pertencentes a estratos menos favorecidos, sendo mais evidente no sexo feminino. Para alguns autores, o 
estado nutricional é o principal fator envolvido na relação entre renda e maturação sexual (Colli 1993, Saito 1993, Wang 2002, Vitalle et al. 2003, Moreira et al. 2004).

A maturação sexual precoce (aquela iniciada antes dos 8 anos na menina dos 9 anos no menino) constitui fator de risco para o maior percentual de gordura corporal. Por outro lado, os indivíduos com maior percentual de gordura corporal tem maiores chances de maturar precocemente (Bini et al. 2000, Laitinen et al. 2001, Oliveira \& Veiga 2005). Neste contexto, alguns autores afirmam que seria necessário atingir determinado depósito de gordura corporal para a ocorrência do estirão puberal (Frish \& McArthur 1974, Saito 1993, Vitalle 2003, Barbosa et al. 2006).

Daniels et al. (1997) avaliando crianças e adolescentes entre 7 e 17 anos de idade, encontraram maior correlação do IMC com o EMS quando comparado a idade cronológica, mais evidente no sexo feminino. Wang (2002), estudando a influência do início da puberdade e do EMS na adiposidade de adolescentes observou que meninos com a maturação sexual precoce apresentaram menor IMC e percentual de gordura. Em contrapartida, a maturação sexual precoce em meninas associou-se a maiores valores de IMC e percentual de gordura corporal.

Ao estudarem uma amostra de meninas entre 13 e 19 anos de diferentes etnias, participantes do National Longitudinal Study of Adolescent Health, 
Adair \& Gordon-Larsen (2001) observaram prevalência de excesso de peso significativamente maior entre adolescentes que apresentaram maturação sexual precoce, independente da etnia, sendo as maiores prevalências observadas em negras e a maturação sexual precoce dobrou o risco de desenvolver excesso de peso (IMC zpercentil 85) nas adolescentes.

Rosenfield et al. (2009) analisando dados de crianças e adolescentes norteamericanos de 8 a 18 anos de idade, obtidos a partir do NHANES III, por meio de estimativas de modelos probito e logito evidenciaram que o excesso de peso e obesidade são 1,5 e 2,0 vezes mais prevalente em meninas que maturam mais cedo, respectivamente, e que meninas com excesso de peso apresentam uma chance duas vezes maior de alcançar a menarca, comparadas a meninas eutróficas de mesma idade. Tais resultados adicionam à evidência que o curso da epidemia de obesidade infantil parece ser um determinante importante de uma idade mais adiantada de ocorrência dos marcos do início da puberdade nos Estados Unidos nas últimas décadas.

Assim, a ampla variação do início do estirão do crescimento, da velocidade e duração da maturação sexual e o padrão de crescimento associado às diferenças étnicas e socioeconômicas entre os grupos populacionais, impactam na avaliação nutricional baseada nas variáveis antropométricas e de composição corporal em adolescentes. 


\subsection{Tendência secular do excesso de peso em crianças e adolescentes e o impacto para a saúde pública}

O contínuo aumento da prevalência de obesidade em todas as faixas etárias observado em países industrializados e em desenvolvimento é considerado atualmente pela OMS uma epidemia mundial (WHO 2000).

Nos Estados Unidos o excesso de peso em adolescentes dobrou nas duas últimas décadas (Ogden et al. 2002, 2006). Em países da América Latina como Chile, Peru e México, cerca de um quarto das crianças e adolescentes estão acima do peso (PAHO 2002). Segundo a OMS, a tendência secular de aumento da obesidade também é registrada na Europa (Inglaterra, Finlândia, Alemanha, Holanda, Suécia, entre outros) e região central do Pacífico (Austrália e Samoa). Na África e Ásia, a obesidade apresenta baixa prevalência, sendo mais comum em populações urbanas (WHO 2000). 
Figura 1 Prevalência e tendência secular do excesso de peso e obesidade no mundo.

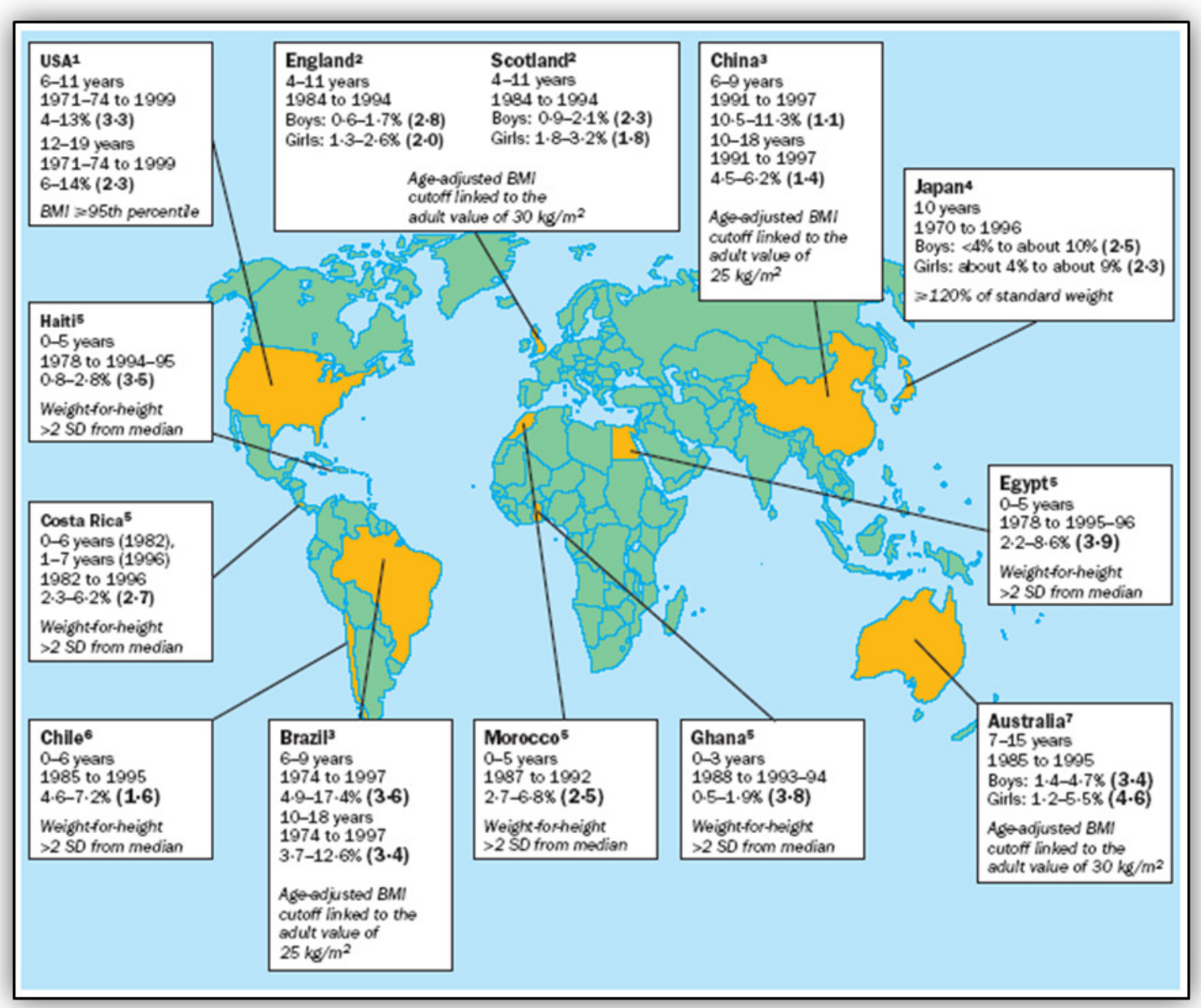

Extraído de Ebelling et al. (2002)

No Brasil, a prevalência de excesso de peso em adolescentes entre 10 e 19 anos aumentou quatro vezes em meninos (de 2,6 para 11,8\%) e triplicou em meninas (de 5,8 para 15,3\%) comparando os dados do Estudo Nacional de Despesa Familiar (ENDEF) e da Pesquisa sobre Padrões de Vida (PPV) conduzidas nos anos de 1974/74 e 1996/97, respectivamente. Maiores prevalências são observadas na região sudeste do país, no sexo feminino e em adolescentes de áreas urbanas (Neutzling et al. 2000, Veiga et al. 2004, Cintra et al. 2007). 


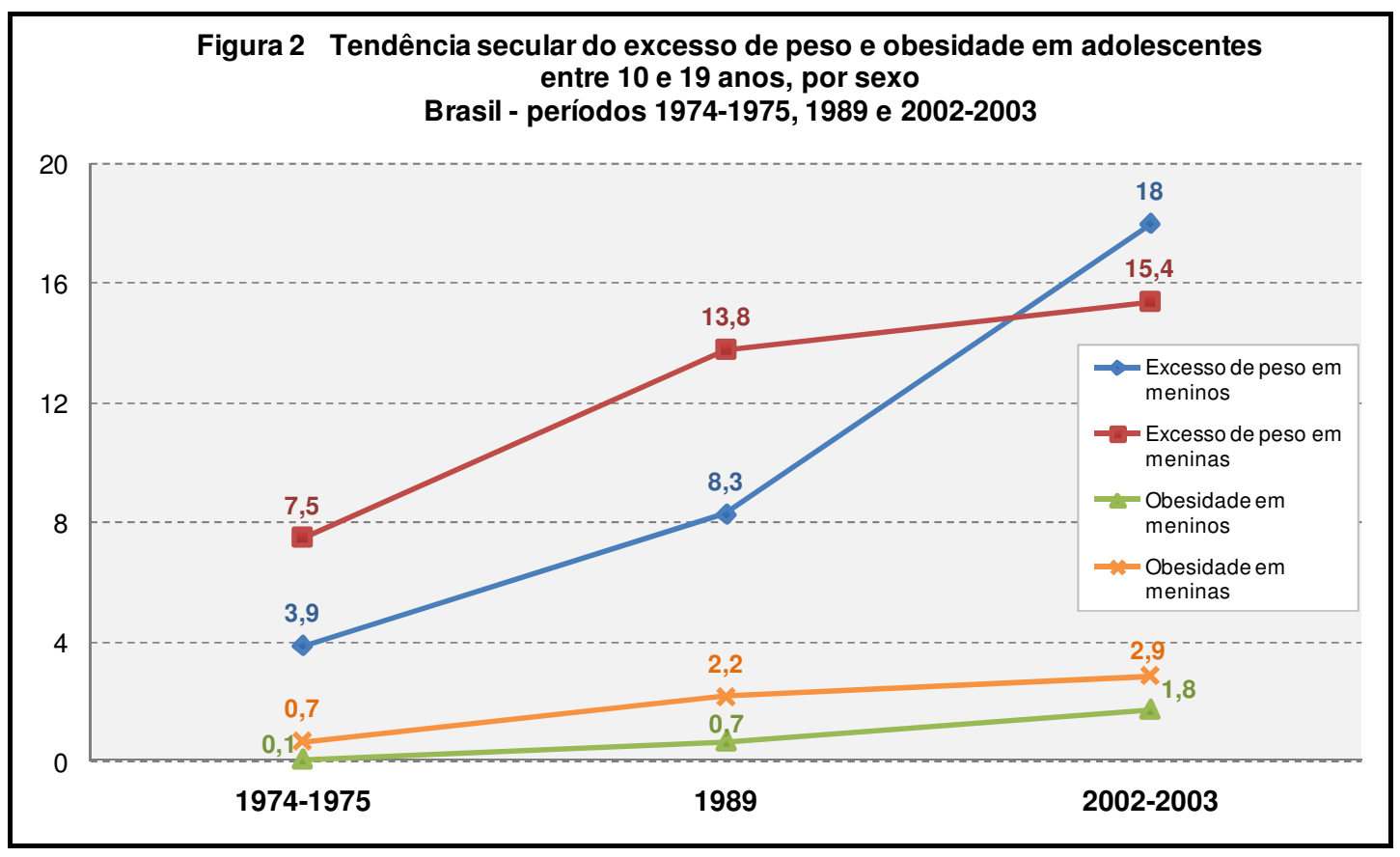

Adaptado de IBGE (2006)

Os últimos dados nacionais sobre o estado nutricional de adolescentes apontam prevalência de excesso de peso de $16,7 \%$ em $2002-2003$, sendo maior em meninos $(17,9 \%)$ do que em meninas $(15,4 \%)$. Em ambos os sexos, a prevalência máxima de excesso de peso entre adolescentes foi observada na faixa etária entre 10 e 11 anos (cerca de 22\%), diminuindo para $12 \%-15 \%$ ao final da adolescência (IBGE 2006).

A prevalência de excesso de peso em adolescentes do sexo masculino foi maior nas regiões Sul $(22,6 \%)$, Sudeste $(21,5 \%)$ e Centro-Oeste $(19,3 \%)$ quando comparadas às regiões Norte $(15,3 \%)$ e Nordeste $(11,8 \%)$. Dentro de cada região, o problema em meninos foi sempre mais freqüente no meio urbano do que no meio rural. Assim como nos meninos, o problema foi apenas ligeiramente mais freqüente nas meninas das regiões Sul (17\%), 
Sudeste (18\%) e Centro-Oeste $(15,6 \%)$ do que nas regiões Norte $(13,9 \%)$ e Nordeste $(11,6 \%)$ e, apenas nas regiões Nordeste e Sudeste, a freqüência foi claramente maior nas áreas urbanas do que nas áreas rurais (IBGE 2006).

Em ambos os sexos, observa-se associação entre renda familiar e excesso de peso em adolescentes. No sexo masculino, há uma associação positiva entre renda e prevalência de excesso de peso, indo de $8,5 \%$ na menor classe de renda (até 0,5 salário mínimo per capita) até $28,2 \%$ na maior classe de renda (5 ou mais salários mínimos per capita). No sexo feminino, o aumento do excesso de peso com a renda ocorre uma associação positiva apenas ao longo das três primeiras classes de renda (de 8,9\% para 16,4\%) pouco se modificando nas três classes seguintes de renda: $15,7 \%, 18 \%$ e 18,4\% (IBGE 2006).

A obesidade têm se tornado um dos mais prevalentes problemas nutricionais do mundo, sendo considerada um importante fator de risco para doenças e agravos não-transmissíveis (DANT) como diabetes mellitus tipo 2, hipertensão arterial, dislipidemias, doenças cardiovasculares, doenças da vesícula, osteoartrites, problemas respiratórios e algumas neoplasias malignas (WHO 2000, Reilly et al. 2003).

Atualmente, sabe-se que a obesidade infanto-juvenil é um importante fator prognóstico para a obesidade na vida adulta. Estudos longitudinais mostram que até $80 \%$ dos adolescentes obesos se converterão em adultos obesos e 
que, um terço dos pré-escolares e metade dos escolares obesos serão adultos obesos e estarão expostos a um alto risco para enfermidades crônicas, além de consequências socioeconômicas e psicológicas deletérias para o indivíduo (WHO 2000, Guo et al. 2002, Stettler 2004, Silveira et al. 2006).

O custo relacionado à obesidade pode ser estimado do ponto de vista econômico. O custo direto corresponde às despesas com prevenção, diagnóstico, tratamento, reabilitação, investigação, formação e investimentos em saúde com a doença e suas consequências, incluindo consultas médicas, consumo de medicamentos, internações hospitalares e cuidados de enfermagem, assim como das doenças associadas, tais como hipertensão arterial, diabetes e aterosclerose. Estima-se que este custo corresponda de 10 a $23 \%$ dos gastos com a saúde nos países industrializados (WHO 2000, Finkelstein et al. 2004).

Estudo norte-americano baseado em dados do National Hospital Discharge Survey (NHDS) realizado com crianças e adolescentes entre 6 e 17 anos, entre os anos de 1979 e 1999, mostrou um aumento de $260 \%$ nos gastos hospitalares relacionados à obesidade e doenças associadas, passando de 35 para 127 milhões de dólares por ano (Wang \& Dietz 2002).

Os custos indiretos estão relacionados ao impacto sobre a qualidade de vida e a produtividade. A qualidade de vida é afetada em função da limitação imposta à oportunidade pessoal em muitos aspectos, como o preconceito 
existente em relação aos obesos e também da dificuldade em desempenhar determinadas atividades físicas e de encontrar empregos, entre outros. Esses representam também, uma medida do valor da produção perdida decorrente dos episódios de doença, incapacidade ou morte prematura, afetando o rendimento nacional por meio de despesas locais, estaduais e dos governos nacionais e que, embora seja difícil de mensurar com precisão, estima-se que estes gastos superem os custos diretos com a doença (WHO 2000).

Considerando a tendência secular de aumento da obesidade, a elevada prevalência da doença, os enormes gastos diretos e indiretos despendidos, o efeito deletério para o indivíduo e que a adolescência constitui um período crítico para o desenvolvimento da obesidade, é fundamental identificar e compreender os fatores envolvidos no surgimento precoce da doença para o incremento de políticas de promoção da saúde, prevenção e tratamento precoce da obesidade. 


\section{OBJETIVOS}

Analisar a associação entre maturação sexual e adiposidade em crianças e adolescentes de duas escolas do município de São Paulo.

\subsection{Objetivos específicos}

- Realizar uma revisão da literatura acerca da maturação sexual com dados sobre a idade da menarca e discussão dos fatores envolvidos no processo

- Avaliar a influência da maturação sexual relativamente acelerado no índice de massa corporal, adiposidade central e composição corporal de crianças e adolescentes;

- Comparar o comportamento dos parâmetros bioelétricos segundo sexo e status de maturação. 


\section{MATERIAL E MÉTODOS}

\subsection{Delineamento e amostra}

Os dados são originários do projeto "Crescimento e composição corporal de adolescentes". Trata-se de um estudo longitudinal com crianças e adolescentes de 8 a 18 anos de idade de ambos os sexos, matriculados em duas escolas, pública e privada do município de São Paulo, com o intuito de obter populações de diferentes status socioeconômicos.

O cálculo do tamanho amostral foi realizado considerando-se um nível de significância de $95 \%$ e um poder amostral (1- $\beta$ ) de $80 \%$. Baseando-se em estudos anteriores que avaliam a maturação precoce, estimou-se uma prevalência de indivíduos com maturação relativamente acelerada de $25 \%$ com valor de OR de 2 em relação ao desfecho (obesidade). Assim, o tamanho da amostra necessária para estimar o risco de obesidade segundo status de maturação sexual foi de 605 indivíduos. Para a análise dos dados contínuos, estimou-se o desvio-padrão e a diferença a ser detectada no percentual de gordura corporal de $6 \%$ e $2,5 \%$, respectivamente, para 0 status de maturação sexual. Considerando um teste de hipótese bicaudal e a mesma prevalência de indivíduos com maturação precoce, o tamanho da amostra para atender a estes critérios foi de 244 indivíduos de cada sexo. Assim, para o presente estudo foram utilizados dados longitudinais de 617 indivíduos, 40,7\% do sexo masculino. 


\subsection{Coleta de dados}

Os estudantes participaram de 3 coletas de dados, durante o período de um ano, com intervalo de 6 meses entre as mesmas. A primeira coleta foi realizada em agosto/setembro de 2001, a segunda, em março/abril e a última, em setembro/outubro, ambas em 2002.

A coleta de dados foi realizada por um entrevistador previamente treinado, por meio de entrevista, mensuração antropométrica e exame de impedância bioelétrica, nas próprias instituições, sendo os dados registrados em formulários pré-testados (Anexo 1).

\subsection{Critérios de Inclusão}

Foram incluídos no estudos adolescentes entre 8 e 18 anos de idade, de ambos os sexos, matriculados nas escolas estudadas, que concordassem participar do estudo e apresentassem o termo de consentimento livre e esclarecido assinado pelos pais ou responsáveis, ou pelo próprio indivíduo quando maior de 18 anos.

\subsection{Variáveis de estudo}

Variáveis Dependentes 
Índice de massa corporal dos adolescentes

Para a mensuração do peso corporal foi utilizada balança eletrônica do tipo plataforma (Tanita ${ }^{\circledR}$ ), com capacidade para $150 \mathrm{~kg}$ e precisão de $100 \mathrm{~g}$, e para a estatura foi utilizado antropômetro $\left(\mathrm{Seca}^{\circledR}\right)$, com escala em milímetro, fixado em suporte de madeira, conforme metodologia proposta por Gordon et al. (1988).

Posteriormente, foi calculado o índice de massa corporal $\left(\right.$ IMC=peso/estatura $\left.{ }^{2}\right)$ de cada indivíduo estudado.

\section{Excesso de peso dos adolescentes}

A presença de sobrepeso e obesidade foi verificada com base nos valores críticos do IMC para crianças e adolescentes brasileiros. Este critério proposto por Conde \& Monteiro (2006) baseia-se em curvas que consideram os indicadores clássicos da população adulta e retroagem para as idades menores, construídas a partir de dados originários da Pesquisa Nacional de Saúde e Nutrição (PNSN).

\section{$\underline{\text { Adiposidade central dos adolescentes }}$}

O perímetro da cintura foi aferido ao final da expiração, com fita métrica inelástica e escala em milímetro $(\mathrm{mm})$, no ponto médio entre a crista ilíaca e a face externa da última costela. Foram realizadas três medidas de perímetro da cintura e considerada a média dos valores obtidos, conforme proposto por Lohman et al. (1988). 
Tabela 1 Valores críticos do IMC proposto para definição de excesso de peso e obesidade em crianças e adolescentes brasileiros, segundo idade

\begin{tabular}{|c|c|c|c|c|}
\hline \multirow[b]{2}{*}{ Idade (meses) } & \multicolumn{2}{|c|}{$\begin{array}{c}\text { Excesso de Peso } \\
\qquad\left(25 \mathrm{~kg} / \mathrm{m}^{2}\right)\end{array}$} & \multicolumn{2}{|c|}{$\begin{array}{l}\text { Obesidade } \\
\left(30 \mathrm{~kg} / \mathrm{m}^{2}\right)\end{array}$} \\
\hline & Homens & Mulheres & Homens & Mulheres \\
\hline 96,5 & 18,16 & 17,49 & 22,69 & 20,44 \\
\hline 102,5 & 18,35 & 17,70 & 23,17 & 20,84 \\
\hline 108,5 & 18,57 & 17,96 & 23,67 & 21,28 \\
\hline 114,5 & 18,82 & 18,27 & 24,17 & 21,78 \\
\hline 120,5 & 19,09 & 18,63 & 24,67 & 22,32 \\
\hline 126,5 & 19,38 & 19,04 & 25,14 & 22,91 \\
\hline 132,5 & 19,68 & 19,51 & 25,58 & 23,54 \\
\hline 138,5 & 20,00 & 20,01 & 25,99 & 24,21 \\
\hline 144.5 & 20,32 & 20,55 & 26,36 & 24,89 \\
\hline 150,5 & 20,65 & 21,12 & 26,69 & 25,57 \\
\hline 156,5 & 20,99 & 21,69 & 26,99 & 26,25 \\
\hline 162,5 & 21,33 & 22,25 & 27,26 & 26,89 \\
\hline 168,5 & 21,66 & 22,79 & 27,51 & 27,50 \\
\hline 174,5 & 22,00 & 23,28 & 27,74 & 28,04 \\
\hline 180,5 & 22,33 & 23,73 & 27,95 & 28,51 \\
\hline 186,5 & 22,65 & 24,11 & 28,15 & 28,90 \\
\hline 192,5 & 22,96 & 24,41 & 28,34 & 29,20 \\
\hline 198,5 & 23,27 & 24,65 & 28,52 & 29,42 \\
\hline 204,5 & 23,56 & 24,81 & 28,71 & 29,56 \\
\hline 210,5 & 23,84 & 24,90 & 28,89 & 29,63 \\
\hline 216,5 & 24,11 & 24,95 & 29,08 & 29,67 \\
\hline 222,5 & 24,36 & 24,96 & 29,28 & 29,70 \\
\hline 228,5 & 24,59 & 24,96 & 29,50 & 29,74 \\
\hline 234,5 & 24,81 & 24,97 & 29,75 & 29,83 \\
\hline 240,0 & 25,00 & 25,00 & 30,00 & 30,00 \\
\hline
\end{tabular}

Fonte: Conde e Monteiro (2006) 


\section{Parâmetros bioelétricos e composição corporal}

Para a obtenção dos valores de resistência $(R)$ e reactância $(X c)$ e determinação dos valores absolutos e relativos de massa magra e gordura corporal foi utilizado aparelho de bioimpedância tetrapolar RJL Systems ${ }^{\circledR}$ adotando-se as técnicas propostas pelo fabricante. A técnica de impedância bioelétrica - BIA consiste na emissão de uma corrente elétrica constante de baixa amplitude $(500$ a $800 \mathrm{~mA})$ e alta freqüência $(50 \mathrm{kHz})$ por meio de eletrodos fixados no corpo e a mensuração da impedância corporal (Z), definida como a oposição de um condutor à passagem de uma corrente. No corpo humano, há uma associação entre a concentração de íons contidos no meio condutor e a condutividade elétrica e resistência dos compartimentos (Lukaski 1987).

O primeiro passo é a determinação da quantidade de água corporal a partir do valor da impedância obtido. A seguir, determina-se a quantidade de massa magra por meio de equações preditivas e o total de gordura corporal, é, posteriormente, obtido pela diferença entre o peso do indivíduo e a quantidade de massa magra calculada (Foster \& Lukaski 1996, Houtkooper et al. 1996).

Foram utilizados valores absolutos $(\mathrm{kg})$ e relativos $(\%)$ de massa magra e gordura corporal. O ângulo de fase foi obtido a partir do arco tangente da reactância/resistência $(\Phi=\operatorname{arc} \tan (\mathrm{Xc} / \mathrm{R}))$. Para transformar o resultado de 
radianos para graus $\left({ }^{\circ}\right)$, multiplicou-se o resultado obtido por $180^{\circ} / \pi$. Essas constituíram variáveis independentes, do tipo contínua.

Variáveis Independentes

Maturação sexual relativamente acelerada

Em publicação sobre a utilização e interpretação de medidas antropométricas para a avaliação do estado nutricional de populações, a Organização Mundial de Saúde aponta diversas opções para o estadiamento sexual de adolescentes. Entre elas: idade óssea, número de dentes permanentes, menarca, espermarca, presença de voz adulta, pico de velocidade de crescimento e desenvolvimento dos caracteres sexuais secundários (WHO 1995).

A escolha do método de avaliação do estágio de maturação sexual - EMS de adolescentes a ser utilizado depende de fatores como recursos humanos, financeiros, facilidade/praticidade na avaliação e fatores culturais. Neste contexto, a auto-avaliação do desenvolvimento dos caracteres secundários constitui alternativa eficiente para o estadiamento sexual em estudos populacionais (WHO 1995).

O EMS foi auto-avaliado pelos indivíduos a partir da comparação com fotos de 5 etapas que caracterizam o desenvolvimento sexual da criança e do adolescente, conforme critério proposto por Tanner (1962). O 
desenvolvimento dos pêlos pubianos (P1, P2, P3, P4, P5) foi avaliado em ambos os sexos, segundo características, quantidade e distribuição. Para o sexo masculino, considerou-se o estágio de desenvolvimentos dos genitais (G1, G2, G3, G4, G5) e para o feminino o desenvolvimento das mamas (M1, M2, M3, M4, M5), avaliados conforme o tamanho, características e forma. O estágio 1 corresponde ao crescimento e desenvolvimento pré-puberal, enquanto os estágios 2 a 4 correspondem à progressão da puberdade até a maturação completa (estágio 5).

As crianças e adolescentes foram distribuídos em grupos pequenos, de mesmo sexo, e receberam informações sobre adolescência, desenvolvimento físico e maturação sexual e, em seguida, explicações sobre a auto-avaliação e o preenchimento do formulário.

Para auxiliar as crianças e adolescentes na auto-avaliação foram fornecidas informações sobre as características que diferenciam os diferentes estágios de maturação sexual, conforme apresentado por Colli et al. (1993). Como exemplo, pode-se citar a diferença entre os estágio M1 e M2 do desenvolvimento das mamas. No segundo, observa-se o broto mamário caracterizado pelo aumento da glândula mamária, com elevação da auréola e papila, formando um pequena saliência, que não é encontrada no primeiro estágio. 
Os indivíduos foram distribuídos em quartis de idade (meses) ajustados para cada estágio de Tanner atual e separados por sexo. O mesmo procedimento foi realizado para as três coletas. Assim, foram considerados indivíduos com maturação relativamente acelerada aqueles que se encontrassem no $1^{0}$ quartil de idade do estágio de maturação sexual em todas as três coletas de dados. Posteriormente, os demais quartis foram agrupados para comparação com o 1ํquartil durante as análises.

Foram realizados procedimentos similares para pêlos pubianos e genitália/mama e verificou-se a concordância entre os dois critérios na classificação da maturação sexual precoce. A concordância e o valor de kappa foi de $79,3 \%$ e 0,46 para os meninos e $86,1 \%$ e 0,64 para as meninas, respectivamente. Assim, optou-se pela utilização dos dados de maturação sexual obtidos na classificação dos estágios de desenvolvimento dos genitais masculinos e mamas para as meninas, uma vez que apresentam maior confiabilidade na detecção da ativação do eixo hipotalâmicohipofisário-gonadal e são recomendados pelo World Health Organization Expert Committee como indicadores da maturação sexual para uso internacional (WHO 2005).

\section{$\underline{\text { Idade dos adolescentes }}$}

A idade foi obtida por meio da diferença entre as datas da entrevista e de nascimento de cada indivíduo. 


\section{Escolaridade materna}

A escolaridade materna foi obtida em anos completos de estudo e foi utilizada como medida indireta do status socioeconômico das crianças e adolescentes.

\subsection{Análise dos dados}

\section{Análise Estatística}

Para a descrição das variáveis serão utilizadas medidas de freqüência, tendência central e dispersão. $O$ testes $t$ de Student foi utilizado para verificar diferenças nas medidas antropométricas, parâmetros bioelétricos e composição corporal entre os indivíduos maturados ou não precocemente. $O$ coeficiente de correlação de Pearson foi utilizado para verificar a relação entre $\mathrm{R} / \mathrm{E}$ e Xc/E.

Foram calculados valores de escore z do IMC para comparação segundo sexo, faixa etária e EMS. Para estes cálculos, utilizaram-se os parâmetros LMS obtidos na construção da curva de referência do IMC para a população brasileira, proposta por Conde e Monteiro (2006). Neste método, os dados são resumidos em três curvas suavizadas ( $L, M$ e S) específicas para a idade. As curvas $\mathrm{M}$ e $\mathrm{S}$ correspondem à mediana e aos coeficientes de variação do IMC em cada estrato. O parâmetro L é o coeficiente (Box-Cox) empregado com o objetivo de obter distribuição normal dos valores do IMC 
em cada estrato (Cole 1992). Assim, foram calculados os valores de escore z para o IMC a partir da equação:

$$
Z=\left[(I M C / M)^{L}-1\right] / L S
$$

Foram realizadas análises de regressão logística verificar a influência da maturação sexual relativamente acelerada no excesso de peso dos adolescentes. A associação maturação relativamente acelerada na variação antropométrica, parâmetros bioelétricos e composição corporal foi analisada utilizando modelos de regressão linear múltipla. Todas análises foram estratificadas por sexo e ajustadas por idade, estatura e escolaridade materna. A colinearidade foi testada examinando-se o fator de inflação da variância (FIV). Nenhuma variável apresentou colinearidade perfeita $(F I V<10)$. Em geral, a correlação entre as variáveis foi menor que 0,15. Para os cálculos estatísticos foi utilizado o programa Stata 10.1 (Statacorp 2007) e nível de significância de 5\%.

Os valores de resistência e a reactância dos indivíduos, corrigidas para a estatura (R/E e Xc/E) foram plotadas como pontos vetores num plano Cartesiano (gráfico $\mathrm{RXc}$ ). Foram calculadas elipses para os vetores médios de impedância (Z) com 95\% de confiança, segundo sexo e status de maturação sexual utilizando software BIVA (Piccoli e Pastori 2002). Para a comparação das diferenças entre as médias dos vetores $Z$ entre os grupos (sexo e status de maturação) foi utilizado o teste $\mathrm{T}^{2}$ de Hotlling. Este teste é 
mais sensível que o teste t de Student, gerando um pequeno risco de rejeitar a hipótese nula erroneamente (Lentner 1982).

\subsection{Questões éticas}

O projeto de pesquisa está de acordo com as normas da resolução 196 de 10/10/1996 do Conselho Nacional de Saúde, que regulamenta as pesquisas envolvendo seres humanos e foi aprovado pelo Comitê de Ética em Pesquisa da Faculdade de Saúde Pública da Universidade de São Paulo (Anexo 2).

Por se tratar de população vulnerável e de autonomia reduzida, solicitou-se, previamente, o consentimento livre e esclarecido da Instituição. Os pais ou responsáveis legais firmaram concordância por escrito. 


\section{RESULTADOS E DISCUSSÃO}

A dissertação foi elaborada no formato de artigos científicos, sendo seus resultados e discussão apresentados em três artigos.

O primeiro artigo intitulado "Maturação sexual e idade da menarca no Brasil" apresenta uma revisão bibliográfica sobre a maturação sexual com dados nacionais sobre a idade da menarca e discussão entorno dos fatores envolvidos no processo.

O segundo artigo intitulado "Associação entre maturação sexual, excesso de peso e adiposidade central em crianças e adolescentes de duas escolas de São Paulo" apresenta uma análise sobre a influência da maturação sexual relativamente acelerada nas variação antropométrica e adiposidade ocorrida no período nas crianças e adolescentes.

Um terceiro artigo intitulado "Maturação sexual e sua relação com composição corporal e parâmetros bioelétricos em crianças e adolescentes de duas escolas de São Paulo" avaliou o comportamento de alguns parâmetros bioelétricos como o ângulo de fase e o vetor de impedância e medidas de composição corporal em crianças e adolescentes com maturação relativamente acelerada comparando-os com os demais. 


\title{
4.1 ARTIGO 1
}

\section{Maturação sexual e idade da menarca no Brasil}

\author{
Sexual maturation and age at menarche in Brazil
}

\section{Resumo}

Este estudo teve por objetivo realizar uma revisão da literatura sobre a maturação sexual, com dados nacionais sobre a idade da menarca e discussão entorno dos fatores envolvidos no processo. Foram selecionados 28 trabalhos cuja coleta de dados foi realizada a partir de 1970. Não observou-se grande variação na idade da menarca nos diferentes estudos. Também não se observa diferenças significativas na idade da menarca nas diferentes regiões do país. Ressalta-se a necessidade de estudos regionais e nacionais representativos da população para melhor visualizar o fenômeno da maturação sexual entre as adolescentes brasileiras, considerando também fatores que possam explicar a variabilidade intra e inter regional.

Palavras-chaves: puberdade, desenvolvimento sexual, menarca, fatores socioeconômicos, transição nutricional 


\section{Introdução}

A adolescência é o período de transição gradual da infância para a vida adulta que se inicia com a pubescência e o aparecimento de caracteres sexuais secundários. Este período é caracterizado por profundas mudanças fisiológicas e psicossociais nas quais o adolescente começa a definir sua identidade e estabelecer um sistema de valores pessoais, mostrando-se especialmente vulnerável aos enormes agravos enfrentados pela maioria das sociedades atuais ${ }^{1}$.

Estas transformações iniciam-se com a ativação do complexo neuroendócrino que desencadeia, sob estímulo das gonadotrofinas, a secreção de esteróides sexuais, predominantemente, a testosterona no sexo masculino e o estradiol nas meninas, responsáveis pelas modificações morfológicas durante o período puberal².

O início e desenrolar dos eventos maturacionais apresentam grandes variações entre indivíduos e populações. Este processo e suas etapas sofrem influências de fatores genéticos e ambientais que incluem condições nutricionais ao nascimento e os períodos iniciais da fase de crescimento ${ }^{3}$.

O conhecimento da idade de ocorrência da maturação sexual em determinada população possibilita a análise de tendência do 
desenvolvimento puberal desta população, além de auxiliar o estabelecimento de padrões normativos para a puberdade ${ }^{4}$.

Desta forma, o presente estudo teve por objetivo realizar uma revisão da literatura sobre a maturação sexual com dados nacionais sobre a idade da menarca e discussão entorno dos fatores envolvidos no processo.

Para a seleção dos artigos utilizou-se como critério os trabalhos cuja coleta de dados foi realizada a partir de 1970 devido à escassez de dados anteriores. Os trabalhos deveriam apresentar a descrição do critério de seleção da amostra ressaltando-se a não inclusão de meninas enfermas ou atletas.

\section{Maturação sexual}

O desenvolvimento puberal apresenta cronologia fisiológica de eventos distinta entre os sexos devido a modificações no padrão de secreção hormonal ${ }^{5,6}$. Em geral, as meninas iniciam a fase de maturação sexual cerca de 1 ano antes dos meninos ${ }^{7}$.

O crescimento e desenvolvimento do aparelho reprodutor e dos caracteres sexuais secundários é um dos fenômenos mais característicos e importantes desta fase, sendo considerado o marco de início da puberdade que é seguida por alterações na quantidade de massa muscular, distribuição da 
gordura corporal, 'estirão' de crescimento e fusão das epífises ósseas como estágio final do crescimento ${ }^{8}$.

Assim como as sucessivas medidas antropométricas e cálculos da velocidade de crescimento são imprescindíveis para caracterizar a fase do crescimento físico do adolescente, algum método de mensuração do grau de maturação sexual também é necessário para se avaliar a progressão pubertal do adolescente uma vez que nesta fase a idade biológica se distingue da idade cronológica ${ }^{8}$.

O aparecimento do tecido mamário e o desenvolvimento da genitália nos meninos é usualmente aceito como sinal físico de maior confiabilidade da ativação do eixo hipotalâmico-hipofisário-gonadal nas meninas e meninos, respectivamente (gonadarca). O aparecimento de pêlos pubianos, embora geralmente ocorra aproximadamente o mesmo tempo, é atribuível ao início da secreção de androgênios pelas glândulas supra-renais (adrenarca). ${ }^{9}$

Neste sentido, Tanner padronizou em 1962, o método difundido mundialmente e mais utilizado até hoje para avaliar o estágio da maturação sexual na adolescência. O estadiamento da maturação sexual proposto por Tanner é feito pela avaliação das mamas e dos pêlos pubianos no sexo feminino, e da genitália e pêlos pubianos no masculino. As mamas e os genitais masculinos são avaliados quanto ao tamanho, forma e características, e os pêlos púbicos por suas características, quantidade e 
distribuição. O estágio 1 corresponde sempre à fase infantil - pré-púbere, e o estágio 5 à fase adulta - pós-púbere ${ }^{10}$.

Não há dados recentes que abordam a idade em que normalmente a puberdade ou adrenarca ocorre em uma grande amostra da população. Marshall e Tanner (1970) em estudo conduzido a partir de dados transversais obtidos na década de 1960, de 192 meninas e 228 meninos brancos britânicos que foram atendidos no consultório em intervalos de 3 meses durante a adolescência, levaram à designação da faixa etária normal de início da puberdade (idade em que 95\% das crianças atingiram o estágio 2 de Tanner para mamas e genitália), entre 8 e 13 anos nas meninas e entre 9 anos e 6 meses e 13 anos 6 meses em meninos. Cada sujeito foi fotografado nu durante a visita, e o estadiamento da mama e desenvolvimento e pêlos pubianos foi realizado por meio de exame das fotografias (e não exame físico), utilizando o sistema de classificação desenvolvido por Tanner (1962). ${ }^{10,11}$

Entretanto, Tanner e Marshall (1970) observaram que as meninas estudadas pertenciam principalmente a classes socioeconômicas menos favorecidas. Observaram também, que as meninas de seu estudo não eram representativas da população britânica, pois chegaram a menarca a média de idade de 13,47 anos, quatro meses mais tarde que a população de Londres. No entanto, sua declaração que "o primeiro sinal da puberdade apareceram entre as idades de 8 anos e 13 anos em 95\% dos meninas e, 9 
anos e 13 anos nos meninos" foi amplamente aceito como um padrão normal para o início da puberdade, sendo classificados como precoces àqueles indivíduos que iniciaram o processo de maturação em idades mais jovens e, tardios quando em idades superiores a estas. ${ }^{11}$

Reconhecendo a falta de dados geográficos e padrões de referências validos para avaliar o início das mudanças da ocorridas durante a puberdade nas meninas, Herman-Giddens (1997) e colaboradores realizaram um grande estudo transversal envolvendo 17000 jovens entre os 3 e os 12 anos de idade nos Estados Unidos que participaram da American Academy of Pediatric's Pediatric Research in Office Settings (PROS). A idade média (DP) para o estágio 2 de Tanner de desenvolvimento mamário foi de 9,96 $(1,82)$ anos em meninas brancas (um ano mais cedo do que a idade citada no estudo anterior) e 8,87 (1,93) anos em meninas afro-americanas (dois anos mais cedo). A idade média (DP) para alcançar o estágio 2 de pêlos pubianos foi de $10,51(1,67)$ anos para meninas brancas e $8,78(2,00)$ anos para afroamericanas, enquanto a idade média da menarca foi 12,88 anos na população. $^{12}$

Rosenfield et al. (2009) ${ }^{13}$ analisaram dados de crianças e adolescentes norte-americanos de 8 a 18 anos de idade, obtidos a partir do NHANES III, e por meio de estimativas de modelos probito e logito apresentaram valores de referência para as idades em que 5\%, 50\% e 95\% dos jovens norteamericanos já atingiram a fase de início puberal, segundo sexo e estado 
nutricional (eutrofia e excesso de peso). O desenvolvimento da mama (fase 2) foi observada em $3,2 \%$ das meninas de 8,0 anos de idade com IMC normal na população norte-americana. A idade média de início de pêlos pubianos em estágio 3 nas meninas com IMC normal foi de 11,6 anos. A pubarca ocorreu mais tarde nos meninos com IMC normal que nas meninas. Apenas $5 \%$ dos meninos norte-americanos iniciaram a maturação antes dos 10,7 anos, enquanto nas meninas a idade foi de 9,3 anos .

\section{Menarca}

A menarca é um fenômeno fisiológico que marca a fase final da maturação sexual nas meninas e caracteriza a capacidade reprodutiva da mulher com o início dos ciclos de ovulação ${ }^{14}$. A menarca ocorre aproximadamente, dois anos após o inicio do processo de maturação sexual e 12 a 18 meses após 0 pico de velocidade de crescimento ${ }^{8}$.

A idade da menarca em uma população pode ser determinada por diferentes métodos, dos quais 3 são os mais utilizados em estudos populacionais ${ }^{12}$. $\mathrm{O}$ primeiro deles e mais utilizado é o método retrospectivo ${ }^{14,17-19}$, que consiste basicamente em uma entrevista sobre a idade (mês e ano) da ocorrência da menarca. Este método, segundo alguns autores conduz a erros de estimativa, principalmente devido a amostragens inadequadas, discrepâncias na seleção da amostra quanto ao nível socioeconômico e faixa etária, além do viés de informação uma vez que os dados fornecidos 
pelas meninas são passíveis de erros, intencionalmente ou não, principalmente se foram inquiridas quando a menarca ocorreu há longo tempo ${ }^{17,20}$.

Outro método que tem obtido a preferência dos autores é o longitudinal ou prospectivo, onde meninas pré-selecionadas, segundo idade e nível socioeconômico são acompanhadas na sua evolução e periodicamente são questionadas a respeito da ocorrência da menarca ${ }^{21-22}$.

Segundo Wyshak \& Frish ${ }^{23}$, esse método é o ideal para a avaliação da idade média da menarca, exigindo apenas pessoal treinado e registros cuidadosos de cada menina desde a admissão até a data em que ocorreu a menarca. Porém este método apresenta certas limitações ou desvantagens como a necessidade de acompanhamento dos casos por um período de aproximadamente seis anos, os riscos de perdas significativas durante 0 seguimento e os custos mais elevados deste tipo de delineamento.

O método conhecido como "statu quo" necessita apenas a idade cronológica da menina na data da investigação, e a informação sobre a ocorrência ou não da menarca. Para manter uma faixa de segurança, além das idades em que se processa o referido evento, os planos de amostragem em geral, incluem meninas de 8 a 16 anos. Baseado nestas informações é a calculada a média da idade de ocorrência da menarca para aquela população em estudo ${ }^{14,24,25}$. Este método têm se mostrado mais acurado na estimação da 
idade da menarca quando comparado ao método retrospectivo uma vez que não depende da memória da adolescente ${ }^{26}$.

\section{Importância da idade da menarca}

A OMS ressalta a importância da identificação de marcadores biológicos de desaceleração do crescimento ${ }^{1,8}$. Neste sentido, a idade de ocorrência da menarca tem sido um parâmetro de maturidade biológica amplamente utilizado para o sexo feminino.

Alguns autores sugerem a utilização da idade da menarca como proxy do início e duração da maturação sexual, além da velocidade de crescimento em grupos populacionais ${ }^{27,28}$.

A idade da menarca também reflete mudanças no desenvolvimento socioeconômico, condições de higiene e de saúde das populações, sendo utilizada como um marcador do desenvolvimento social ${ }^{28-30}$.

Diversos estudos mostram que meninas de status socioeconômico mais elevado apresentam a primeira menstruação mais precocemente que àquelas pertencentes a estratos menos favorecidos, mesmo residentes no mesmo país ou região. Para alguns autores, fatores ambientais relacionados ao estado nutricional são os principais fatores na relação entre renda e maturação sexual ${ }^{9,31,32}$. 
Idade da menarca no Brasil

Diversos autores estudaram a idade da menarca em diferentes populações brasileiras (Tabela 1). Ressalta-se que a maior parte dos estudos baseiamse em amostras pequenas, realizados com populações do Sul e Sudeste brasileiro e a avaliação da idade da menarca baseou-se, em sua maioria, no método retrospectivo.

Os dados nacionais mostram pequena variabilidade quanto à idade de ocorrência da menarca, variando de 12,09 em uma amostra de meninas do município de Londrina/PR ${ }^{46}$ a 13,23 em meninas de Rolândia/PR ${ }^{45}$.

A tendência de redução da idade da menarca é um fenômeno observado em diversos países ${ }^{27,28,49}$. Artigos publicados entre 1912 e 1937, revisados por Hegg \& Levy ${ }^{39}$, reportam a idade de ocorrência da menarca em torno dos 14 anos no Brasil. Kac et al. ${ }^{40}$ ao avaliarem a tendência secular da idade da menarca em 1955 mulheres nascidas entre 1920 e 1979 no Rio de Janeiro, verificaram uma redução de 13,07 para 12,40 anos na ocorrência do fenômeno. 
Tabela 1 Estudos sobre a média (DP) de idade da ocorrência da menarca no Brasil

\begin{tabular}{|c|c|c|c|c|c|}
\hline Autor (ano) & $\begin{array}{l}\text { Região } \\
\text { Cidade/Estado }\end{array}$ & $\begin{array}{l}\text { Método de } \\
\text { avaliação }\end{array}$ & $\mathbf{N}$ & Idade & (anos) \\
\hline PNSN $(1989)^{33}$ & Brasil & Statu quo & 7.087 & 13,20 & $(\mathrm{nd})^{*}$ \\
\hline \multicolumn{6}{|l|}{ Região Norte/Nordeste } \\
\hline Silva et al. (1982) ${ }^{34}$ & São Luís/MA & Retrospectivo & 302 & 12,40 & $(1,20)$ \\
\hline Souza et al. (1996) ${ }^{35}$ & João Pessoa/PB & Retrospectivo & 1066 & 12,10 & $(2,20)$ \\
\hline Silva \& Padez (2006) ${ }^{36}$ & Caboclo/PA & Retrospectivo & 164 & 12,29 & $(1,76)$ \\
\hline \multicolumn{6}{|l|}{ Região Centro-Oeste } \\
\hline Bezerra et al. (1973) ${ }^{3 /}$ & Sobradinho/DF & Retrospectivo & 316 & 12,50 & (nd) \\
\hline \multicolumn{6}{|l|}{ Região Sudeste } \\
\hline Hegg \& Luongo (1976) ${ }^{38}$ & São Paulo/SP & Retrospectivo & 333 & 12,56 & (nd) \\
\hline Hegg \& Levy (1977) ${ }^{39}$ & São Paulo/SP & Retrospectivo & 1850 & 12,27 & $(1,15)$ \\
\hline Scaf et al. (1982) ${ }^{18}$ & Bauru/SP & Retrospectivo & 1.379 & 12,97 & $(1,23)$ \\
\hline Colli (1985) ${ }^{41}$ & São Paulo/SP & Retrospectivo & 2.584 & 12,60 & (nd) \\
\hline Colli $(1985)^{41}$ & Santo André/SP & Retrospectivo & 713 & 12,80 & (nd) \\
\hline Campos et al. (1990) ${ }^{42}$ & Ilha Bela/SP & Retrospectivo & 271 & 12,77 & $(1,33)$ \\
\hline Goldberg et al. (1996) ${ }^{43}$ & Botucatu/SP & Statu quo & 717 & 12,62 & $(1,56)^{*}$ \\
\hline Tavares et al. (1998) ${ }^{25}$ & Barrinha/SP & Statu quo & 1.602 & 12,52 & $(1,47)^{*}$ \\
\hline Fonseca et al. (1998) ${ }^{19}$ & Niterói/RJ & Retrospectivo & 391 & 12,32 & $(1,32)$ \\
\hline Vitalle et al. (2003) ${ }^{33}$ & São Paulo/SP & Longitudinal & 229 & 12,11 & $(1,10)$ \\
\hline Moreira et al. (2004) ${ }^{15}$ & Rio de Janeiro/RJ & Statu quo & 118 & 12,19 & $(1,51)^{*}$ \\
\hline Castilho et al. (2005) ${ }^{22}$ & São Paulo/SP & Longitudinal & 111 & 12,63 & $(1,39)$ \\
\hline Lago et al. (2007) ${ }^{47}$ & Rio de Janeiro/RJ & Retrospectivo & 1.940 & 12,22 & $(1,59)$ \\
\hline \multicolumn{6}{|l|}{ Região Sul } \\
\hline Violato \& Matsudo (1983) ${ }^{45}$ & Rolândia/PR & Retrospectivo & 440 & 13,23 & (nd) \\
\hline Petroski et al. (1983) ${ }^{48}$ & Florianópolis/SC & Retrospectivo & 146 & 12,93 & $(1,20)$ \\
\hline Petroski et al. (1999) ${ }^{20}$ & Florianópolis/SC & Retrospectivo & 1070 & 12,56 & $(1,15)$ \\
\hline Borges \& Pires Júnior (2000) ${ }^{46}$ & Londrina/PR & Statu quo & 160 & 12,09 & $(1,07)^{*}$ \\
\hline Borges \& Schwarztbach (2003) ${ }^{47}$ & Cândido Rondon/PR & Statu quo & 290 & 12,21 & $(0,81)^{*}$ \\
\hline Silva et al. (2008) ${ }^{19}$ & Pelotas/RS & Longitudinal & 2.082 & 12,21 & $(1,52)$ \\
\hline
\end{tabular}

* mediana da idade; $\mathrm{nd}=$ não divulgado

\section{A Pesquisa Nacional sobre Saúde e Nutrição - PNSN realizada em $1989{ }^{33}$,} que baseou-se em uma amostra nacional de 62 mil pessoas de todas regiões do país (exceto Norte rural), com objetivo de apurar os indicadores do estado nutricional da população brasileira, verificou também a ocorrência 
da menarca pelo método statu quo. A mediana da idade da menarca observado naquele período no Brasil foi de 13,2 anos. Como esta foi a única pesquisa nacional que avaliou a idade de ocorrência da menarca, torna-se difícil a comparação, uma vez que os estudos apresentam amostras pequenas e não representativas das populações em estudo.

\section{Fatores associados à maturação sexual e idade da menarca no Brasil}

Evidências apontam que a idade da menarca é influenciada por fatores genéticos e ambientais. Dentre estes fatores, a genética seria o mais óbvio, porém não explica a tendência secular observada no Brasil, uma vez que os genes não tiveram tempo suficiente para este decréscimo na idade da menarca ${ }^{27}$.

Dentre os outros fatores que afetam a puberdade pode-se citar a priori a associação da idade da menarca e status socioeconômico. Estudo realizado por Colli et al. ${ }^{41}$ no município de Santo André/SP mostrou relação entre nível socioeconômico e idade da menarca, mais baixa nas adolescentes de melhor nível socioeconômico. No Nordeste, estudo realizado em João Pessoa/PB com 1.066 escolares pertencentes a classes socioeconômicas média e baixa da cidade, observou a ocorrência da menarca aos 12,1 anos em média ${ }^{31}$. 
Tavares et al., ${ }^{25}$ ao estudarem escolares no município de Barrinha, interior de São Paulo, observaram associação negativa entre a idade da menarca e classe social, outras condições como a situação de emprego do pai também mostraram associação com a idade da menarca, sendo esta maior nas meninas cujos pais estavam desempregados. Os autores não observaram relação entre o número de irmãos na família e a mediana da idade da menarca.

Em 2003, ao analisarem prontuários de adolescentes paulistanas de baixo nível socioeconômico atendidas entre 1992 e 1999, Vitalle et al. ${ }^{32}$ observaram maiores valores do índice de massa corporal no grupo de meninas com menarca quando comparadas as que não haviam apresentado o fenômeno ainda. Observaram ainda, uma relação entre sobrepeso e obesidade com o grupo com menarca e de desnutrição e eutrofia no grupo sem menarca.

Em estudo longitudinal com meninas em condições desfavoráveis incluindo carências sociais, econômicas e nutricionais do município do Rio Branco/AC, os autores observaram que a média de idade de ocorrência da menarca foi de 12,70 anos e presença de desnutrição em quase metade da amostra estudada ${ }^{37}$.

O rápido crescimento econômico do Brasil nos últimos anos provocou uma diminuição marcante na proporção de brasileiros na pobreza - de $32 \%$ em 
1992/3 para $23 \%$ em $1996{ }^{51}$. Recentemente, entre 2001 e 2004, houve uma forte redução na desigualdade de renda no país, sendo considerada a menor dos últimos 30 anos ${ }^{52}$.

Analisando o estado nutricional da população infantil brasileira baseado em três inquéritos domiciliares realizados nas décadas de 70, 80 e 90, BatistaFilho \& Rissin ${ }^{53}$ observaram rápido declínio da prevalência de desnutrição e acelerada elevação da prevalência de sobrepeso/obesidade, fator que para alguns autores, estaria contribuindo para o declínio da idade da menarca no mundo uma vez que a ocorrência do fenômeno está relacionada com o estado nutricional da adolescente ${ }^{30}$.

Alguns autores têm apontado um possível relação entre o peso da criança na infância e período pré-puberal e a idade da menarca - 'hipótese do peso crítico'. Outro fator considerado importante por alguns autores é o peso ao nascer e a nutrição no período pré e/ou pós-natal. ${ }^{27,50,54}$

Ao passo que os fatores genéticos exercem suas influências de maneira acentuada no processo de maturação sexual, as diferenças individuais e as características físicas determinadas geneticamente sofrem sucessivas mudanças ao longo do processo em função do ambiente, cuja influência pode acelerar ou retardar este fenômeno. Assim, ficam evidentes as dificuldades existentes para estabelecer uma causa principal para este 
fenômeno, uma vez que grupos populacionais recebem e processam diferentemente as influências de fatores externos.

\section{Considerações finais}

Ressalta-se a necessidade de estudos regionais e nacionais representativos da população para melhor visualizar o fenômeno da maturação sexual entre as adolescentes brasileiras, considerando também fatores que possam explicar a variabilidade intra e inter regional. Estes resultados poderiam prover subsídios para se avaliar o desenvolvimento das condições de saúde da população.

Atualmente, não há uma definição consensual de um padrão normativo para a idade de ocorrência da menarca devido à influência dos inúmeros fatores genéticos e ambientais que afetam de forma diferente as populações, tornando-se difícil estabelecer uma média mundial. Neste sentido, destacase também a dificuldade de comparação dos valores entre populações devido a fatores como status socioeconômico da população, delineamento e metodologia do estudo.

Outro aspecto importante é a associação entre a idade da menarca e sobrepeso nas adolescentes, uma vez que a menarca tem sido considerada um marco importante no aumento dos depósitos de gordura nas meninas brasileiras. Deste modo, fica evidenciada a necessidade de estudos 
transversais e longitudinais com adolescentes para melhor compreender esta relação.

\section{Referências}

1. World Health Organization. Nutrition in adolescence - Issues and challenges for the health sector. Geneva; 2005 (WHO discussion papers on adolescence).

2. Patton GC, Viner R. Pubertal transitions in health. Lancet 2007; 369:1130-9.

3. Luo ZC. Cheung YB, He Q, Albertsson-Wikland K, Karlberg J. Growth in early life and its relation to pubertal growth. Epidemiology 2003; 14:65-73.

4. Wu T, Mendola P, Buck GM. Ethnic differences in the presence of secondary sex characteristics and menarche among US girls: the third national health and nutrition examination survey, 1988-1994. Pediatrics $2002 ; 110: 752-7$

5. Sievorgel RM, Demerath EW, Schuber C, Remsberg KE, Chumlea WC, Sun S, Czernwinski SA, Towne B. Puberty and body composition. Horm Res 2003; 60:36-45. 
6. Barbosa KBF, Franceschini SCC, Priore SE. Influência dos estágios de maturação sexual no estado nutricional, antropometria e composição corporal de adolescentes. Rev Bras Saúde Matern Infant 2006; 6(4):37582.

7. Rogol AD, Roemmich JN, Clark PA. Growth at puberty. J Adolesc Health 2002; 31(1):192-200.

8. World Health Organization. Physical status: the use and interpretation of anthropometry. Geneva; 1995 (Technical Report Series, 854).

9. Kaplowitz PB, Oberfield SE, Drug and Therapeutics nd Executive Committees of the Lawson Wilkins Pediatric Endocrine Society. Reexamination of the age limit for defining when puberty is precocious in girls in the United States: implications for evaluation and treatment. Pediatrics 1999; 104:936-941.

10. Tanner JM. Growth at adolescence. $2^{\text {nd }}$ Ed. Oxford: Blackwell; 1962. 340 p.

11. Marshall WA, Tanner JM. Variations in the pattern of pubertal changes in boys. Arch Dis Child 1970; 45:13-23 
12. Herman-Giddens ME, Slora EJ, Wasserman RC, et al. Secondary sexual characteristics and menses in young girls seen in office practice: a study from the Pediatric Research in Office Settings Network. Pediatrics 1997;99:505-12.

13. Rosenfield RL, Lipton RB, Drum ML. Thelarche, Pubarche, and Menarche attainment in children with normal and elevate body mass index. Pediatrics 2009;123:84-8.

14. Colli AS, Coates V, Guimarães EMB. Monitoração do crescimento e desenvolvimento físico. In: Coates V et al.. Medicina do adolescente. São Paulo: Sarvier; 1993.

15. Moreira DM, Fragoso MIJ, Oliveira Júnior AV. Níveis maturacionais e socioeconômico de jovens sambistas no Rio de Janeiro. Rev Bras Med Esporte 2004; 10(1):16-23.

16. Fechner PY. Gender differences in puberty. J Adolesc Health 2002; $30 S: 44-8$.

17. Baxter-Jones ADG, Eisenmann JC, Sherar LB. Controlling for maturation in pediatric exercise science. Peditric Exercise Science 2005; 17:18-30. 
18. Scaf G, Freitas JAS, Damante JH. Comparação entre dois métodos para estimar as idades de pubescência e menarca. J Pediat (São Paulo) 1983; $5: 42-8$.

19. Fonseca VM, Sichieri R, Veiga GV. Fatores associados à obesidade em adolescentes. Rev Saude Publica 1998; 32:541-9.

20. Petroski EL, Velho NM, Bem MFL de. Idade da menarca e satisfação com o peso corporal. Rev Bras Cineantropom Desempenho Hum 1999; $1(1): 30-6$.

21. Frisancho AA, Garin SM, Rohmann CG. Age at menarche: a new method of prediction and retrospective assessment based on hand $X$ rays. Hum Biol 1969; 41(1):42-50.

22. Castilho SD, Barros Filho AA. Crescimento pós-menarca em uma coorte de meninas brasileiras. Arq Bras Endocrinol Metab 2005;49:971-7.

23. Wyshak G, Frisch RE. Evidence for a secular trend in age of menarche. N Engl J Med 1982; 306:1033-5.

24. Henneberg M, Louw GJ. Average menarcheal age of higher socioeconomic status urban Cape coloured girls assessed by means of status quo and recall methods. Am J Phys Antropol 1995; 96:1-5. 
25. Tavares CH, Haeffner LS, Barbieri MA, Bettiol H, Barbieri MR, Souza L. Idade da menarca em escolares de uma comunidade rural do Sudeste do Brasil. Cad Saude Publica 2000;16:709-15.

26. Koo MM, Rohan TE. Accuracy of short-term recall of age at menarche. Ann Hum Biol 1997; 24:61-4.

27. Cole TJ. Secular trends in growth. Proc Nutrition Society. 2000; 59:31724.

28. Keizer-Schrama AMPFM, Mul D. Trends in pubertal development in Europe. Hum Reprod Update 2001; 7(3):287-91.

29. Biro FM, Lucky AW, Simbartl LA, Barton BA, Saniels SR, Striegel-Moore R, Kronsberg S, Morrison J. Pubertal maturation in girls and the relationship to anthropometric changes: pathways through puberty. $J$ Pediatr 2003; 142:643-6.

30. Kac G, Velásquez-Meléndez G, Valente JG. Menarca, gravidez precoce e obesidade em mulheres brasileiras selecionadas em um Centro de Saúde de Belo Horizonte, Minas Gerais, Brasil. Cad Saúde Pública $2003 ; 19(1): 111-8$. 
31. Wang $Y$. Is obesity associated with early sexual maturation? A comparison of the association in American boys versus girls. Pediatrics $2002 ; 110(5): 903-10$.

32. Vitalle MSS, Tomioka CY, Juliano Y, Amancio OMS. Índice de massa corporal, desenvolvimento puberal e sua relação com a menarca. Rev Assoc Med Bras 2003; 49(4):429-33.

33. Instituto Nacional de Alimentação e Nutrição- INAN. Perfil de Crescimento da População Brasileira de 0 a 25 anos. Pesquisa Nacional sobre Saúde e Nutrição. Brasília: MS; 1990.

34. Silva TMA, Nascimento DV, Silva PTN, Matsudo VKR. Idade de menarca das escolares maranhenses. In: Anais do X Simpósio de Ciências do Esporte, 1982. São Caetano do Sul: p. 17.

35. Souza EAC, Medeiros Filho JG, Souza ESM. Estudo da maturação sexual em escolares do sexo feminino no Município de João Pessoa Paraíba. Pediatria (S.Paulo) 1996;18:59-6.

36. Silva HP, Padez C. Secular trends in age at menarche among Caboclo populations from Pará, Amazonia, Brazil: 1930-1980. Am J Hum Biol 2006;18:83-92. 
37. Bezerra VL, Campos D, Salomon JBR. Crescimento e desenvolvimento adolescente. Arch Latinoam Nutr1973; 23: 465-483.

38. Hegg TV, Luongo J. Medidas antropométricas e desenvolvimento pubertário em escolares paulistanos de oito a dezesseis anos de idade. [dissertação]. São Paulo: USP; 1976.

39. Hegg RV, Levy MSF. Estudo sobre a menarca-1974. Rev Assoc Med Bras 1977; 23:431-5.

40.Kac G, Coel ASC, Velasquez-Melendez G. Secular trend in age at menarche for women born between 1920 and 1979 in Rio de Janeiro, Brazil. Ann Hum Biol 2000; 27:423-8.

41. Colli AS. Crescimento e desenvolvimento físico. Pediatria Básica. $7^{\mathfrak{a}}$ ed. São Paulo: Sarvier; 1985.

42. Campos MAS, França NM Matsudo VKR. Idade de menarca em escolares de Ilha Bela. In: Anais do XVII Simpósio Internacional de Ciências do Esporte, 1990. São Paulo: p. 85.

43. Goldberg TBL, Colli AS, Curi PR. Relação entre área do braço, área do músculo, área de gordura do braço e a menarca em adolescentes do município de Botucatu. J Pediatr(Rio J). 1996; 72(2):85-92. 
44. Lago MJ do, Faerstein E, Sichieri R, Lopes CS, Werneck GL. Associação entre idade da menarca e estatura definitiva no Estudo Pró-Saúde. Rev Assoc Med Bras 2007;53(1):20-24.

45. Violato PRS, Matsudo VKR. Menarca em escolares da rede de ensino de Rolândia-PR. Rev Bras Cien Esp 1983;5:26-9.

46. Borges GA, Pires-Júnior R. Idade da menarca em adolescentes de Londrina - PR. Rev Bras Ativ Fis Saúde 2000;5(3): 05-11.

47. Borges GA, Schwarztbach C. Idade da menarca em adolescentes de Marechal Cândido Rondon - PR. Rev Bras Cineantropom Desempenho Hum 2003; 5(2):15-21.

48. Petroski EL, Duarte MFS, Matsudo VKR. Idade de menarca em escolares catarinenses. Rev Ed Fís 1983; 4: 3-6.

49. Lee PA, Guo SS, Kulin HE. Age of puberty: data from the United States of America. Acta Pathol Microbiol et Immunol Scand 2001; 109:81-8.

50. Frisch RE, Revelle R. Height and weight at menarche and a hypothesis of critical body weights and adolescent events. Science 1970; 169; 397-99. 
51. Instituto de Pesquisa Econômica Aplicada - IPEA. A evolução recente do bem-estar social, da pobreza e da desigualdade. Brasília: IPEA; 1997, n.71.

52. Instituto de Pesquisa Econômica Aplicada - IPEA. Conseqüências e causas imediatas da queda recente da desigualdade de renda brasileira. Rio de Janeiro: IPEA; 2006, n.1201.

53. Batista-Filho M, Rissin A. A transição nutricional no Brasil: tendências regionais e temporais. Cad Saúde Pública 2003; 19(1):S181-91.

54. Tam CS, Zegher F, Garnett SP et al. Opposing influences of prenatal and postnatal growth on the timing of menarche. J Clin Endocrinol Metab $2006 ; 91: 4369-73$. 


\title{
4.2 ARTIGO 2
}

\author{
Associação entre maturação sexual, excesso de peso e \\ adiposidade central em crianças e adolescentes de duas \\ escolas de São Paulo
}

Sexual maturation and its association with overweight and central adiposity in child and adolescents from two schools, São Paulo

Resumo

Objetivo: Analisar a associação entre maturação sexual relativamente acelerada, excesso de peso e adiposidade central em crianças e adolescentes.

Método: Estudo longitudinal com 617 crianças e adolescentes de 8 a 18 anos de idade. Foram realizadas três coletas de dados de peso, estatura, perímetro da cintura. $\mathrm{O}$ excesso de peso foi classificado com base nos valores críticos do índice de massa corporal (IMC) para crianças e adolescentes brasileiros. O estágio de maturação sexual (EMS) foi autoavaliado nas três coletas pelas crianças e adolescentes. Os indivíduos foram distribuídos em quartis de idades segundo EMS e sexo. Foram comparados os indivíduos com maturação relativamente acelerada com os demais 
indivíduos. Os dados foram analisados por meio de análises de regressão linear e logística

Resultados: Foi observada associação negativa entre escore z do IMC e idade de início da maturação sexual em meninos, não sendo observada associação no sexo feminino. A maturação sexual relativamente acelerada se associou positivamente com excesso de peso e com maior incremento nos valores de escore $z$ do IMC. Meninas com maturação relativamente acelerada apresentaram maior adiposidade central.

Conclusão: A maturação sexual acelerada associou-se com o excesso de peso e maior incremento no IMC em ambos os sexos. Assim, recomenda-se a identificação do estágio de maturação sexual na avaliação nutricional de crianças e adolescentes.

Palavras-chaves: Criança; Adolescente; Puberdade precoce, Desenvolvimento sexual, Índice de massa corporal, Sobrepeso, Obesidade, Gordura abdominal 


\section{Introdução}

Atualmente, observa-se no Brasil um elevado número de indivíduos obesos em praticamente todos os estratos de idade e ainda pode-se constatar tendência de concentração entre indivíduos de classes sociais menos favorecidas. Projeções realizadas no início da década pela Organização Mundial de Saúde (OMS) indicavam a obesidade como maior problema de saúde pública da atualidade e desde então, tem atraído cada vez mais, a atenção de especialistas preocupados com a alta incidência da doença ${ }^{1}$. Adolescentes são alvos de estudos em todo o mundo devido às profundas mudanças biopsicossociais ocorridas nesta fase e à proximidade com a maturidade biológica, podendo oferecer assim oportunidades para a prevenção de problemas de saúde na idade adulta.

A tendência secular de aumento da obesidade era registrada na Europa (Inglaterra, Finlândia, Alemanha, Holanda, Suécia, entre outros) e região central do Pacífico (Austrália e Samoa) já no início da década. Na África e Ásia, a obesidade apresentava baixa prevalência, sendo mais comum em populações urbanas ${ }^{1}$.

Em 2002, a Organização Panamericana de Saúde apontava que cerca de um quarto das crianças e adolescentes de países da América Latina como Chile, Peru e México estavam acima do peso ${ }^{2}$. Dados mais recentes apontam que o excesso de peso em adolescentes norte-americanos dobrou 
nas duas últimas décadas ${ }^{3,4}$. No Brasil, a prevalência de excesso de peso em adolescentes entre 10 e 19 anos triplicou nos últimos 30 anos ${ }^{5-7}$.

O índice de massa corporal (IMC) é amplamente utilizado na avaliação nutricional de indivíduos e populações devido à sua praticidade e baixo custo, quando comparado a outros métodos. Atualmente, os diferentes critérios para a classificação nutricional de adolescentes baseiam-se em valores de referência do IMC segundo idade e sexo, não existindo associação com o estágio de maturação sexual que melhor caracteriza a fase de desenvolvimento desta população. Adicionalmente, as mudanças ocorridas durante a puberdade ocasionam alterações antropométricas e na composição corporal dos adolescentes com impacto importante no estado nutricional $^{8}$.

O desenvolvimento puberal segue cronologia fisiológica de eventos devido à modificações no padrão de secreção de alguns hormônios. A ativação do eixo hipotalâmico-hipofisário-gonadal desencadeia, sob estímulo das gonadotrofinas, a secreção de esteróides sexuais (predominantemente testosterona nos meninos e estradiol nas meninas) que são responsáveis pelas modificações morfológicas do período puberal. A produção destes hormônios resulta no aparecimento de caracteres sexuais secundários marcando o início da puberdade ${ }^{9}$. 
$\mathrm{Na}$ década de 70 , com base em estudos populacionais sobre a idade de ocorrência da menarca, Frish \& Revelle ${ }^{10}$ sugeriram que um peso de aproximadamente $48 \mathrm{~kg}$ fosse necessário para o desenvolvimento normal e, particularmente para o início do processo pubertário e o evento da menarca ("hipótese do peso crítico"). Desde então, pesquisas em todo o mundo tem buscado associar o processo de maturação sexual com variáveis antropométricas e estado nutricional, porém os resultados são controversos.

Classicamente, tem-se definido puberdade precoce como o aparecimento de caracteres sexuais antes dos 8 anos de idade na menina e dos 9 anos no menino ${ }^{11,12}$. Adair \& Gordon-Larsen ${ }^{13}$, estudando uma amostra de meninas entre 13 e 19 anos de diferentes etnias, participantes do National Longitudinal Study of Adolescent Health, observaram prevalência de excesso de peso significativamente maior entre adolescentes que apresentaram maturação sexual precoce. A maturação sexual precoce dobrou o risco de desenvolver excesso de peso nestas adolescentes.

No entanto, um número limitado de estudos foi realizado com meninos para verificar a relação entre maturação sexual precoce e obesidade. Este fato pode ser atribuído basicamente a dificuldade de mensuração da maturação sexual em meninos nos estudos epidemiológicos. A idade da menarca é o indicador de maturação sexual mais utilizado em estudos populacionais pela facilidade na obtenção e seu baixo custo. Em contrapartida, meninas mais jovens e meninos em todas as faixas etárias não podem ser incluídos no 
estudo. Segundo alguns autores, este método ainda conduz a erros de estimativa, uma vez que a idade de ocorrência é coletada em anos e os dados fornecidos pelas meninas são passíveis de erros, principalmente se foram inquiridas quando a menarca ocorreu a longo tempo ${ }^{14,15}$.

Identificar e compreender a influência da maturação sexual no desenvolvimento da obesidade é fundamental para o incremento de políticas de prevenção e tratamento nesta faixa etária, além de auxiliar no desenvolvimento de referências antropométricas apropriadas para a avaliação do estado nutricional de crianças e adolescentes. Neste sentido, o presente trabalho teve por objetivo analisar a influência da maturação sexual relativamente acelerada no excesso de peso e adiposidade central em crianças e adolescentes.

\section{Métodos}

Foi realizado um estudo longitudinal com estudantes de 8 a 18 anos de idade, de ambos os sexos, que participaram de 3 coletas de dados, durante o período de um ano, com intervalo de 6 meses entre as mesmas. A primeira coleta foi realizada em agosto/setembro de 2001, a segunda, em março/abril e a última, em setembro/outubro, ambas em 2002. Foram estudados indivíduos matriculados em uma escola pública e uma privada do Município de São Paulo, com o intuito de obter populações de diferentes níveis sócioeconômicos. 
O cálculo do tamanho amostral foi realizado considerando-se um nível de significância de 95\% e um poder da amostra (1- $\beta$ ) de $80 \%$. Baseando-se em estudos anteriores, estimou-se uma prevalência de indivíduos com maturação precoce de $25 \%$ com um valor de OR de 2 em relação ao desfecho (obesidade). Assim, tamanho da amostra para atender os critérios estimados foi de 605 indivíduos. Foram acrescentados ainda, aproximadamente $10 \%$ para compensar possíveis perdas na amostra.

A coleta de dados foi realizada por uma única pesquisadora, por meio de entrevistas e por mensuração antropométrica, nas próprias instituições, sendo os dados registrados em formulários pré-testados. A escolaridade materna foi obtida em anos completos de estudo, por meio de questionário enviado aos pais junto com o Termo de Consentimento.

A idade foi calculada em meses, mediante a diferença entre a data de nascimento e a data da entrevista. Para a mensuração do peso corporal foi utilizada balança eletrônica do tipo plataforma com capacidade para $150 \mathrm{~kg}$ e precisão de $100 \mathrm{~g}\left(\right.$ Tanita TFB-521 $\left.{ }^{\circledR}\right)$. A estatura foi mensurada utilizando-se estadiômetro $\left(\mathrm{Seca}^{\circledR}\right)$ fixado à parede com escala em milímetros $(\mathrm{mm})$. O perímetro da cintura foi aferido ao final da expiração, com fita métrica inelástica e escala em milímetros $(\mathrm{mm})$, no ponto médio entre a crista ilíaca e a face externa da última costela. Foram realizadas duas medidas de estatura e três de perímetro da cintura e considerada a média dos valores obtidos, 
conforme proposto por Lohman et al. ${ }^{16}$. Calculou-se o IMC dividindo-se o peso pela estatura ao quadrado de cada indivíduo.

A presença de sobrepeso e obesidade foi verificada com base nos valores críticos do IMC para crianças e adolescentes brasileiros. Este critério proposto por Conde \& Monteiro ${ }^{17}$ baseia-se em curvas que consideram os indicadores clássicos da população adulta e retroagem para as idades menores, construídas a partir de dados originários da Pesquisa Nacional de Saúde e Nutrição (PNSN) de 1989.

O estágio de maturação sexual foi auto-avaliado pelos indivíduos a partir da comparação com fotos de 5 etapas que caracterizam o desenvolvimento sexual da criança e do adolescente, conforme critério proposto por Tanner ${ }^{18}$. O desenvolvimento dos pêlos pubianos (P1, P2, P3, P4, P5) foi avaliado em ambos os sexos, segundo características, quantidade e distribuição. Para o sexo masculino, considerou-se o estágio de desenvolvimentos dos genitais (G1, G2, G3, G4, G5) e para o feminino o desenvolvimento das mamas (M1, M2, M3, M4, M5), avaliados conforme o tamanho, características e forma. $\mathrm{O}$ estágio 1 corresponde ao crescimento e desenvolvimento pré-puberal, enquanto os estágios 2 a 4 correspondem à progressão da puberdade até a maturação completa (estágio 5).

Os indivíduos foram distribuídos em quartis de idade (meses) ajustados para cada estágio de Tanner, separados por sexo. Assim, considerou-se com 
maturação relativamente acelerada aqueles que se encontrassem no $1^{\circ}$ quartil de idade para cada estágio de maturação sexual durante as três coletas de dados. Posteriormente, os demais quartis foram agrupados para comparação com o $1^{\circ}$ quartil durante as análises.

Foram realizados procedimentos similares para pêlos pubianos e genitália/mama e verificou-se a concordância entre os dois critérios na classificação da maturação sexual precoce. A concordância e o valor de kappa foi de $79,3 \%$ e 0,46 para os meninos e $86,1 \%$ e 0,64 para as meninas, respectivamente. Assim, optou-se pela utilização dos dados de maturação sexual obtidos na classificação dos estágios de desenvolvimento dos genitais masculinos e mamas para as meninas, uma vez que apresentam maior confiabilidade na deteç̧ão da ativação do eixo hipotalâmicohipofisário-gonadal e são recomendados pelo World Health Organization Expert Committee como indicadores da maturação sexual para uso internacional ${ }^{19}$.

\section{$\underline{\text { Análise estatística }}$}

A prevalência de sobrepeso e obesidade foi avaliada segundo sexo e status de maturação sexual (relativamente acelerada ou não). O teste t de Student foi utilizado para verificar diferenças nas medidas antropométricas entre os indivíduos maturados ou não precocemente. 
Foram calculados valores de escore $\mathrm{z}$ do IMC para comparação segundo sexo, faixa etária e EMS. Para estes cálculos, utilizaram-se os parâmetros LMS obtidos na construção da curva de referência do IMC para a população brasileira, proposta por Conde e Monteiro (2006). Neste método, os dados são resumidos em três curvas suavizadas ( $L, M$ e $S$ ) específicas para a idade. As curvas $\mathrm{M}$ e $\mathrm{S}$ correspondem à mediana e aos coeficientes de variação do IMC em cada estrato. O parâmetro L é o coeficiente (Box-Cox) empregado com o objetivo de obter distribuição normal dos valores do IMC em cada estrato ${ }^{21}$. Assim, foram calculados os valores de escore $z$ para 0 IMC a partir da equação:

$$
Z=\left[(I M C / M)^{L}-1\right] / L S
$$

Foram realizadas análises de regressão logística para verificar a relação entre a maturação relativamente acelerada e o sobrepeso e obesidade dos indivíduos. Posteriormente, utilizando a regressão linear múltipla, observouse a associação entre a maturação sexual relativamente acelerada e IMC e perímetro da cintura. Todas análises foram estratificadas por sexo e ajustadas por idade, estatura e escolaridade materna. A colinearidade foi testada examinando-se o fator de inflação da variância (FIV). Nenhuma variável apresentou colinearidade perfeita $(F I V<10)$. Em geral, a correlação entre as variáveis foi menor que 0,15. Para os cálculos estatísticos foi utilizado o programa Stata $10.1^{22}$ e nível de significância de $5 \%$. 
O presente estudo encontra-se de acordo com as normas da Resolução $n^{\circ}$. 196 de 10/10/1996 do Conselho Nacional de Saúde, que regulamenta as pesquisas envolvendo seres humanos, e foi aprovado pelo Comitê de Ética em Pesquisa da Faculdade de Saúde Pública da Universidade de São Paulo.

\section{Resultados}

Foram coletados inicialmente dados de 660 crianças e adolescentes. Após a terceira coleta, foram acompanhados um total 617 crianças e adolescentes, sendo 40,7\% ( $n=251)$ meninos e 59,3\% ( $n=366)$ meninas. Observou-se maior perda entre o sexo masculino quando comparada ao feminino e as perdas foram, em sua maioria, de alunos que saíram da escola.

As características da população estudada estão apresentadas na Tabela 1. Meninos apresentaram maior ganho de peso e estatura no período estudado, com diferenças estatisticamente significante entre os sexos. Alisando o estado nutricional dos estudantes no início do estudo, observa-se maior prevalência de excesso de peso no sexo feminino $(27,4 \%$ vs. $23,8 \%$ no sexo masculino). Em contrapartida, meninos apresentaram maior prevalência de obesidade ( $8,5 \%$ vs. $7,3 \%$ em meninas). Maior aumento das prevalências de excesso de peso e obesidade, no intervalo entre as coletas, também foi observado no sexo masculino. 
Tabela 1 Amostra e variações antropométricas da terceira para a primeira coleta de dados das crianças e adolescentes

\begin{tabular}{|c|c|c|c|c|c|}
\hline \multirow[b]{2}{*}{ Amostra } & \multicolumn{2}{|c|}{ Meninos } & \multicolumn{2}{|c|}{ Meninas } & \multirow[t]{2}{*}{$p$} \\
\hline & $\mathbf{N}$ & $\%$ & & & \\
\hline Crianças (8|-10) & 10 & $4,0 \%$ & 17 & $4,6 \%$ & 0,693 \\
\hline Adolescentes (10|-18) & 241 & $96,0 \%$ & 349 & $95,4 \%$ & \\
\hline Idade (anos) & 153,5 & $(19,78)$ & 154,6 & $(21,64)$ & 0,504 \\
\hline Características & $3^{\mathrm{a}}-1^{\mathrm{a}}$ coleta $(\Delta)$ & DP & $3^{\mathrm{a}}-1^{\mathrm{a}}$ coleta $(\Delta)$ & DP & \\
\hline Estatura $(\mathrm{cm})$ & 4,2 & $(2,00)$ & 3,6 & $(2,40)$ & 0,002 \\
\hline Peso (Kg) & 4,9 & $(1,98)$ & 4,1 & $(1,93)$ & 0,001 \\
\hline $\operatorname{IMC}\left(\mathrm{Kg} / \mathrm{m}^{2}\right)$ & 0,5 & $(0,76)$ & 0,4 & $(0,88)$ & 0,818 \\
\hline Perímetro da Cintura $(\mathrm{cm})$ & 0,5 & $(2,08)$ & 0,7 & $(2,04)$ & 0,257 \\
\hline Prevalência (\%) & \multicolumn{2}{|c|}{$3^{\mathrm{a}-1} \mathbf{1}^{\mathrm{a}}$ coleta $(\Delta)$} & \multicolumn{2}{|c|}{$3^{\mathrm{a}-1} \mathbf{1}^{\mathrm{a}}$ coleta $(\Delta)$} & \\
\hline Excesso de Peso** & \multicolumn{2}{|l|}{$4,1 \%$} & \multicolumn{2}{|l|}{$2,3 \%$} & \\
\hline Obesidade & \multicolumn{2}{|l|}{$1,4 \%$} & \multicolumn{2}{|l|}{$0,3 \%$} & \\
\hline
\end{tabular}

Comparados com os maturados mais tardiamente, os meninos com maturação relativamente acelerada eram significativamente $(p<0,05)$ mais baixos $(149,3 \mathrm{~cm}$ vs. $157,9 \mathrm{~cm})$ e menos pesados $(46,8 \mathrm{~kg}$ vs. $51,8 \mathrm{~kg})$ no inicio do estudo. Em relação às meninas, assim como observado entre os meninos, as que apresentaram maturação relativamente acelerada eram significativamente mais baixas $(152,2 \mathrm{~cm}$ vs. $154,8 \mathrm{~cm})$, porém não apresentaram diferenças significativas em relação ao peso $(48,1 \mathrm{~kg}$ vs. 49,5kg). Em ambos os sexos, os indivíduos que maturaram relativamente mais cedo apresentaram maior ganho de peso e estatura no período. Menores valores de IMC também forma observados em meninos com maturação relativamente acelerada. Não foram observadas diferenças estatísticas entre sexos para os valores de perímetro da cintura (Tabela 2). 
Tabela 2 Média (desvio padrão) de idade e das diferenças nas variáveis antropométricas no período de estudo, segundo sexo e status de maturação sexual

\begin{tabular}{lcccccc}
\hline & \multicolumn{2}{c}{ Meninos } & \multicolumn{4}{c}{ Meninas } \\
\hline Características & $\begin{array}{c}\text { Sem } \\
\text { maturação } \\
\text { acelerada }\end{array}$ & $\begin{array}{c}\text { Com } \\
\text { maturação } \\
\text { acelerada }\end{array}$ & $\mathbf{p}$ & $\begin{array}{c}\text { Sem } \\
\text { maturação } \\
\text { acelerada }\end{array}$ & $\begin{array}{c}\text { Com } \\
\text { maturação } \\
\text { acelerada }\end{array}$ & $\mathbf{p}$ \\
Idade (anos) & $154,41(19,39)$ & $132,94(7,80)$ & $\mathbf{0 , 0 0 0}$ & $158,71(20,57)$ & $134,56(11,52)$ & $\mathbf{0 , 0 0 0}$ \\
Estatura (cm) & $4,83(1,97)$ & $6,52(1,49)$ & $\mathbf{0 , 0 0 3}$ & $3,95(1,93)$ & $4,80(1,72)$ & $\mathbf{0 , 0 0 1}$ \\
Peso $(\mathrm{Kg})$ & $4,09(1,94)$ & $5,64(2,71)$ & $\mathbf{0 , 0 0 6}$ & $3,56(2,47)$ & $3,84(2,08)$ & 0,390 \\
IMC $\left(\mathrm{Kg} / \mathrm{m}^{2}\right)$ & $0,45(0,73)$ & $1,10(1,09)$ & $\mathbf{0 , 0 0 2}$ & $0,49(0,88)$ & $0,34(0,90)$ & 0,215 \\
PC $(\mathrm{cm})$ & $0,42(2,02)$ & $1,42(3,05)$ & 0,105 & $0,70(1,94)$ & $0,48(2,45)$ & 0,413 \\
\hline
\end{tabular}

A Figura 1 apresenta as médias de escore $z$ do IMC segundo estágio de desenvolvimento sexual e sexo. Observa-se que entre os meninos púberes e pós-púberes há um declínio dos valores médios de escore $z$ com o aumento da idade. Meninos que iniciaram a maturação sexual em idades mais jovens apresentam maiores valores de escore $z$ do IMC (2,67 DP). Em contrapartida, os meninos que não iniciaram o processo de maturação sexual apresentam valores médios semelhantes de escore z do IMC independente da idade (0,93DP na faixa etária de 8 a 10 anos; 0,81DP de 10 a 12 anos e 0,84DP de 12 a 14 anos). No sexo feminino esta tendência não apresenta-se tão evidente, uma vez que meninas púberes e pós-púberes apresentam maiores valores de escore $z$ nas idades mais jovens (1,37 DP) e os menores valores são observados nas meninas com faixa etária entre 10 e 12 anos (0,94 DP). Em relação às meninas pré-puberes, assim como nas demais, os valores mais baixos de escore z são na faixa etária entre 10 e 12 anos (0,05 DP). 


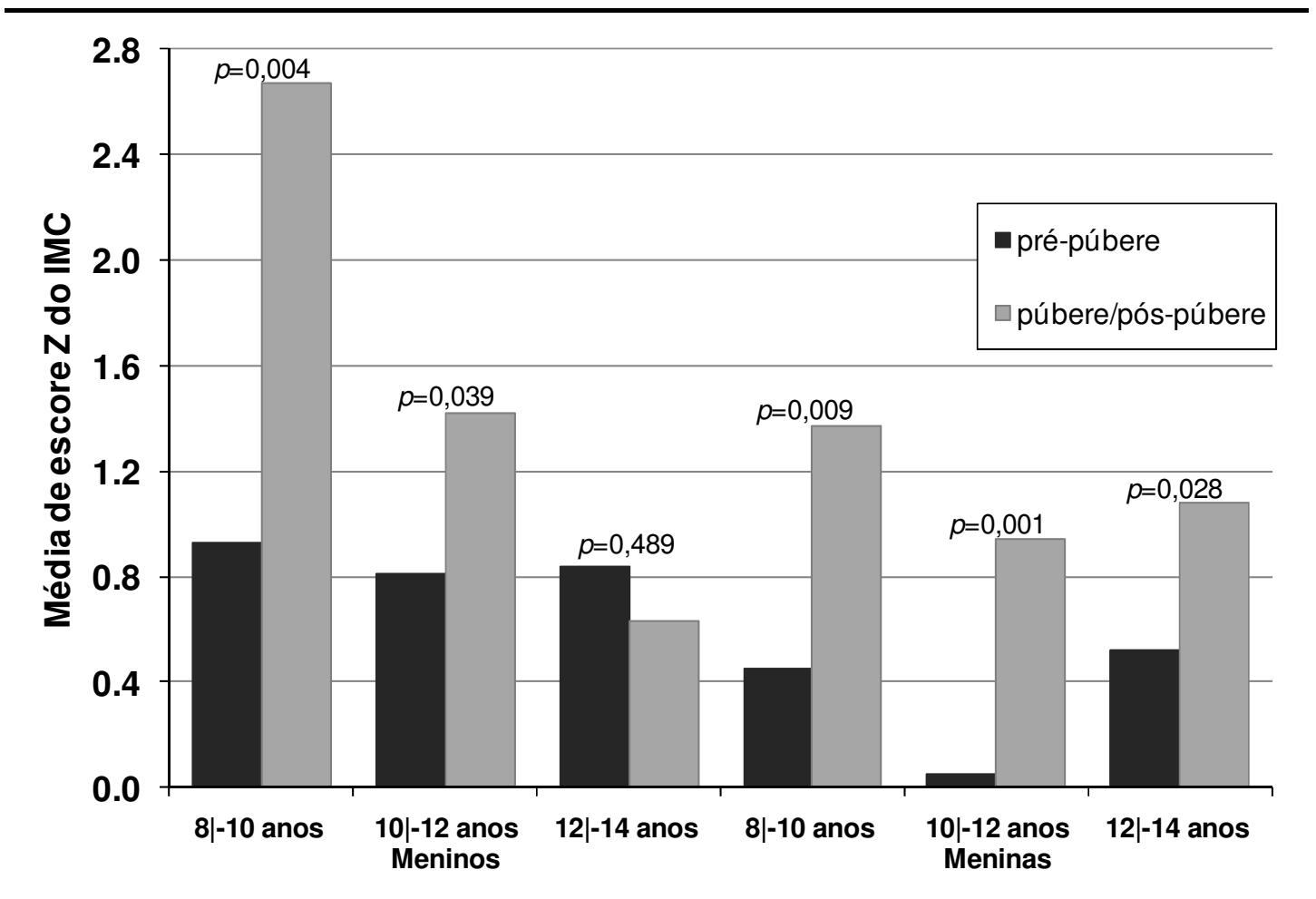

Figura 1 Média de escore $\mathrm{z}$ do IMC segundo sexo e estágio de maturação sexual

$\mathrm{Na}$ análise de regressão logística observa-se que a maturação sexual relativamente acelerada está associada com o aumento do risco para sobrepeso e obesidade em ambos os sexos. Quando ajustado por idade, a maturação sexual perdeu sua significância como fator de risco para o desenvolvimento de sobrepeso no sexo masculino (Tabela 3). 
Tabela 3 Associação entre maturação sexual precoce e sobrepeso e obesidade

\begin{tabular}{|c|c|c|c|c|c|c|}
\hline & \multicolumn{3}{|c|}{ Meninos } & \multicolumn{3}{|c|}{ Meninas } \\
\hline & OR & IC(95\%) & $\boldsymbol{P}$ & OR & IC(95\%) & $\boldsymbol{P}$ \\
\hline \multicolumn{7}{|l|}{ Modelo 1: Sobrepeso } \\
\hline Sem maturação acelerada* & 1,00 & & & 1,00 & & \\
\hline Maturado acelerada & 1,63 & {$[0,51-5,26]$} & 0,293 & 2,54 & {$[1,37-4,71]$} & 0,003 \\
\hline \multicolumn{7}{|l|}{ Modelo 2: Obesidade } \\
\hline Sem maturação acelerada* & 1,00 & & & 1,00 & & \\
\hline Maturação acelerada & 2,27 & {$[1,07-4,74]$} & 0,043 & 2,86 & {$[1,44-5,65]$} & 0,002 \\
\hline
\end{tabular}

A Tabela 4 apresenta os resultados da regressão linear múltipla. Adolescentes que apresentam maturação sexual relativamente acelerada apresentaram, em média, maior incremento no escore $Z$ do IMC e no perímetro da cintura no período de estudo, com significância estatística apenas no sexo feminino.

Tabela 4 Associação entre maturação sexual precoce ${ }^{*}$ e antropometria

\begin{tabular}{|c|c|c|c|c|c|c|}
\hline & \multicolumn{3}{|c|}{$\begin{array}{l}\text { Escore } Z \text { do IMC }\left(\mathrm{kg} / \mathrm{m}^{2}\right) \\
\qquad 3^{\mathrm{a}-1^{\mathrm{a}}} \text { coleta }(\Delta)\end{array}$} & \multicolumn{3}{|c|}{$\begin{array}{c}\text { PC }(\mathrm{cm}) \\
\text { 3-.1 }^{\mathrm{a}} \text { coleta }(\Delta)\end{array}$} \\
\hline & $\bar{\beta}$ & EP & $p$ & B & EP & $P$ \\
\hline \multicolumn{7}{|l|}{ Meninos } \\
\hline Maturação acelerada & 0,013 & 0,014 & 0,344 & 0,010 & 0,008 & 0,212 \\
\hline \multicolumn{7}{|l|}{ Meninas } \\
\hline Maturação acelerada & 0,042 & 0,015 & 0,025 & 0,070 & 0,021 & 0,014 \\
\hline
\end{tabular}

*Grupo de referência: não maturados precoces. Todos os modelos foram ajustados pela estatura, idade e escolaridade materna. IMC, índice de massa corporal; PC, perímetro da cintura 


\section{Discussão}

Atualmente, o índice de massa corpórea (IMC) tem sido amplamente utilizado para a identificação de adiposidade em adolescentes por ser de fácil obtenção, baixo custo e apresentar boa correlação com a gordura corporal, sendo recomendado pela OMS ${ }^{1}$. Entretanto, ainda não existe consenso em relação ao ponto de corte do IMC mais adequado para a classificação do estado nutricional nesta faixa etária ${ }^{23}$. Neste sentido, no presente trabalho optou-se pela utilização da referência nacional por se tratar de curvas delineadas a partir de um conjunto de dados originários de uma pesquisa de representatividade nacional.

Outro ponto importante é a utilização do método LMS na modelagem das curvas tornando-as menos arbitrárias e internacionalmente mais aceitas, além de considerarem os pontos de corte utilizados na classificação de sobrepeso e obesidade na idade adulta (IMC $\geq 25$ e $30 \mathrm{~kg} / \mathrm{m}^{2}$, respectivamente) e retroagem para as idades mais jovens ${ }^{24}$.

No caso de crianças e adolescentes brasileiros, a utilização dos centis 85 e 95, ao invés daqueles baseados no desfecho do IMC adulto, implicaria em obter, valores mais altos para a prevalência de obesidade nas meninas e, prevalências de desnutrição, excesso de peso e obesidade maiores no sexo masculino ${ }^{25}$. 
A classificação da maturação sexual suscita alguns aspectos para discussão. Um primeiro ponto seria a auto-avaliação do estágio de maturação sexual. A simplicidade do método, aliada a situações que dificultam a avaliação objetiva realizada pelo examinador, fez com que um elevado número de pesquisas com a finalidade de correlacionar a autoavaliação com o exame feito por profissionais treinados, fossem realizadas. Todavia, a auto-avaliação não apresenta consenso na literatura no que diz respeito à confiabilidade para a determinação do EMS, uma vez que o método implica em possíveis erros de classificação, intencionais ou não. Estudos nacionais e internacionais apontam valores de kappa (concordância) entre a auto-avaliação e a avaliação objetiva de 0,34 a 0,81 (48 a $86 \%$ ) para as meninas 0,29 a 0,88 (51 a $76 \%$ ) para os meninos ${ }^{26-31}$.

Neste sentido, para melhorar a acurácia da auto-avaliação da maturação sexual, as crianças e adolescentes foram distribuídos em grupos pequenos, de mesmo sexo, e receberam informações sobre adolescência, desenvolvimento físico e maturação sexual e, em seguida, explicações sobre a auto-avaliação e o preenchimento do formulário que foi feito de forma individual. Com o intuito de facilitar e auxiliar na auto-avaliação, foram fornecidas informações sobre as características que diferenciam os estágios de maturação sexual.

Outro ponto a ser discutido é a classificação da maturação sexual precoce. O ponto de corte clássico para a avaliação da puberdade precoce foi 
definido com base numa distribuição normal da idade de início da maturação e um intervalo de $95 \%$ de confiança de estudos epidemiológicos realizados com crianças britânicas há 40 anos ${ }^{11,12}$. Todavia, a incidência de puberdade precoce difere bastante entre os sexos. Muitas meninas, mas um número muito reduzido de meninos apresentam o desenvolvimento de caracteres sexuais secundários antes dos 8 e 9 anos, respectivamente. Esta diferença pode ser atribuída a inúmeras razões como às características inerentes ao sexo e a fisiologia dos indivíduos, à tendência secular de diminuição da idade de início da maturação sexual, mais evidente no sexo feminino, constatada pela diminuição da idade da menarca em populações de países industrializados e em desenvolvimento ${ }^{32}$.

Alguns autores e órgãos internacionais têm proposto uma revisão destes parâmetros de idade e a utilização do percentil 25 da distribuição de idade do início da maturação da própria população para classificação de puberdade precoce ${ }^{32-34}$.

A ausência de informações referentes ao início do processo de maturação sexual de todos indivíduos impediu a utilização dos pontos de corte existentes. Neste sentido, o presente estudo, de delineamento longitudinal, optou pela classificação de indivíduos com "maturação relativamente acelerada", realizada a partir de quartis de idade. Por não se tratar de uma amostra representativa da população, o método status quo também não pode ser empregado. 
A variabilidade inter e intraindividual em relação ao tempo de maturação sexual também pode promover erros na classificação da maturação precoce, uma vez que um indivíduo maturado precoce pode apresentar uma progressão compensatória e não ser classificado como precoce nos estágios mais avançados, assim como indivíduos não maturados precoce podem apresentar um progresso mais lento da maturação e ser classificado como precoce no estágio seguinte. Assim, para cada coleta, a divisão em quartis da idade para cada estágio de maturação segundo sexo foi um método viável a ser utilizado onde foram classificados com maturação relativamente acelerada àqueles jovens que se encontrassem no $1^{\circ}$ quartil de idade para seu EMS atual nas três coletas, sendo os demais classificados sem maturação relativamente acelerada.

No presente estudo foram observados maiores valores de escore $z$ do IMC entre os jovens púberes ou pós-púberes independente da idade ou sexo. Este fator poderia ser explicado pelo elevado incremento no peso e estatura que ocorre durante o processo de maturação sexual. $O$ inicio da maturação em idades mais jovens também se associou a valores mais elevados de escore $z$ do IMC, principalmente no sexo masculino.

Em relação ao sexo feminino, os achados do presente estudo reforçam o que os diversos trabalhos que a literatura nacional e internacional já evidenciavam, que meninas maturadas precocemente apresentam maiores valores de peso e estatura e maior risco de sobrepeso/obesidade. Wang ${ }^{14}$ 
ao analisar dados de uma amostra representativa de crianças de adolescentes norte-americanos de 8 a 14 anos participantes do Third National Health and Nutrition Examination Survey (NHANES III) realizado entre os anos de 1988 e 1994, observou que a maturação sexual precoce associou-se positivamente ao risco de sobrepeso (OR=1,59 [1,05 - 2,42]) e a obesidade $(\mathrm{OR}=1,96[1,11-3,47])$ em meninas.

Ribeiro et al. ${ }^{15}$ ao estudarem adolescentes portugueses entre 10 e 15 anos, verificaram que meninas maturadas precoces tinham uma chance 2 vezes maior de apresentarem excesso de peso quando comparadas as não precoces. Outro estudo com meninas afro-americanas encontrou um risco de 3,6 vezes de desenvolver sobrepeso entre meninas maturadas precoces, comparadas as que apresentavam maturação normal ou tardia ${ }^{35}$.

Ao estudarem uma amostra de meninas entre 13 e 19 anos de diferentes etnias, Adair \& Gordon-Larsen ${ }^{13}$ observaram que a maturação sexual

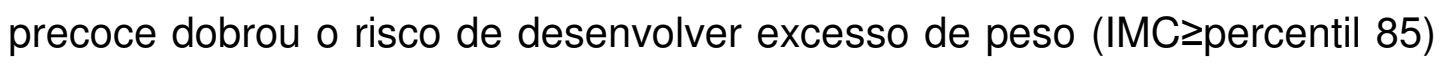
nas adolescentes. As prevalências de excesso de peso encontradas eram significativamente maior entre adolescentes que apresentaram maturação sexual precoce, independente da etnia, sendo as maiores prevalências em meninas negras.

Em contraste com o grande número apontando para a relação entre obesidade e maturação precoce em meninas, os estudos com meninos são 
escassos e apresentam resultados distintos. Assim como ressaltado entre as meninas, os meninos portugueses maturados precocemente mostraram chance 2 vezes maior de sobrepeso quando comparado aos demais ${ }^{15}$. Em contrapartida, Wang ${ }^{14}$ observou situação inversa, em que a maturação precoce apresentou-se como fator protetor para o sobrepeso $(\mathrm{OR}=0,65[0,44$ - 0,98]) e obesidade $(\mathrm{OR}=0,40[0,20-0,82])$ nos meninos.

Wang ${ }^{14}$ também verificou que meninas norte-americanas maturadas precocemente apresentam em média um incremento de $3,48 \mathrm{~cm}$ na estatura, $5,87 \mathrm{~kg}$ no peso e $1,50 \mathrm{~kg} / \mathrm{m}^{2}$ no IMC. Valores semelhantes, porém em menor proporção, foram encontrados no presente estudo, com um incremento de $2,04 \mathrm{~cm}$ na estatura, $4,64 \mathrm{~kg}$ no peso e $1,44 \mathrm{~kg} / \mathrm{m}^{2}$ no IMC. Todavia, no sexo masculino foram observados neste estudo, valores inversos dos meninos norte-americanos $(2,55 \mathrm{~cm}$ vs. $-2,47 \mathrm{~cm}$ de estatura; $0,45 \mathrm{~kg}$ vs. $-2,51 \mathrm{~kg}$ de peso; $0,61 \mathrm{~kg} / \mathrm{m}^{2}$ vs. $0,98 \mathrm{~kg} / \mathrm{m}^{2}$ do $\left.\mathrm{IMC}\right)$. Ressalta-se que embora a influência da maturação sexual precoce na obesidade caminhe na mesma direção em ambos os sexos, a influência no incremento das medidas antropométricas ocorrem de formas distintas entre os meninos e meninas.

Bratberg et al. ${ }^{36}$ em estudo longitudinal com 1605 adolescentes noruegueses, apontaram que a combinação da adiposidade central com a maturação sexual precoce aumentou o risco de sobrepeso em meninas ao final da adolescência. Entre os meninos, nenhuma associação foi encontrada. 
No presente estudo, observou-se que meninas e meninos com maturação relativamente acelerada apresentavam em média, maiores valores de perímetro da cintura $(3,10 \mathrm{~cm}$ e $1,73 \mathrm{~cm}$, respectivamente) ao final do estudo, porém com significância estatística apenas no sexo feminino ( $p=0,004)$. Este aumento da adiposidade central em crianças e adolescentes que apresentam maturação acelerada parece estar associada a outros de riscos à saúde. Estudos recentes apontam associação entre maturação precoce e aumento da pressão arterial ${ }^{37}$ e hiperinsulinemia e resistência à insulina ${ }^{38}$. Todavia, nestes estudos o perímetro da cintura não foi avaliado nas crianças e adolescentes para verificar uma possível relação causal.

O início e desenrolar de todo o processo de maturação sexual é influenciado por fatores genéticos, responsáveis, em grande parte, pela variação individual dos fenômenos pubertários e, por fatores socioambientais que deverão ser favoráveis para possibilitar a expressão máxima do potencial genético do adolescente. No entanto, ainda são desconhecidos como tais fatores interagem entre si e influenciam no processo de maturação sexual e este por sua vez, no desenvolvimento da obesidade. Assim, ressalta-se a necessidade de pesquisas e estudos longitudinais que acompanhem os indivíduos da infância à idade adulta para maior elucidação destas relações.

Em conclusão, o presente estudo mostrou uma associação positiva entre maturação sexual relativamente acelerada e excesso de peso nos adolescentes, mais evidente no sexo feminino. Ressalta-se que embora esta 
influência caminhe na mesma direção em ambos os sexos, a influência no incremento das medidas antropométricas ocorrem de forma distinta entre os sexos, com acúmulo importante de adiposidade abdominal somente nas meninas destacando assim, a importância de se considerar a maturação sexual na avaliação do estado nutricional de crianças e adolescentes.

\section{Referências}

1.World Health Organization. Obesity: preventing and managing the global epidemic. Geneva, 2000 (Technical Report Series, 894).

2. Pan American Health Organization. Globesity: The crisis of growing proportions. Perspec Health Mag. 2002; 7:6-11.

3. Ogden $\mathrm{CL}$, Flegal $\mathrm{KM}$, Carroll $\mathrm{MD}$, et al.. Prevalence and trends in overweight among US children and adolescents, 1999-2000. J Am Med Assoc 2002; 288:1728-1732.

4. Ogden CL, Carroll MD, Curtin LR, et al.. Prevalence of overweight and obesity in United States 1999-2004. J Am Med Assoc 2006; 295:1549-1555.

5. Neutzling MB, Taddei JAAC, Rodrigues EM, et al.. Overweight and obesity in Brazilian adolescents. Int J Obes 2000; 24:869-874. 
6. Veiga GV, Cunha AS, Sichieri R. Trends in overweight among adolescents living in the poorest and richest regions of Brazil. Am J Public Health 2004; 94:1544-1548.

7. Cintra IP, Passos MAS, Fisberg M, et al.. Evolução de duas séries históricas do índice de massa corporal em adolescentes. J Pedatr (Rio J) 2007; 83:157-162.

8. Taylor RW, Falorni A, Jones IE, et al.. Indentifying adolescents with high percentage body fat: a comparison of BMI cutoffs using age and stage of pubertal development compared with BMI cutoffs using age alone. Eur J Clin Nutr 2003;57:764-769.

9. Sievorgel RM, Demerath EW, Schuber C, Remsberg KE, et al.. Puberty and body composition. Horm Res 2003; 60:36-45.

10. Frisch RE, Revelle R. Height and weight at menarche and a hypothesis of critical body weights and adolescent events. Science 1970;169:397-379.

11. Marshall WA, Tanner JM. Variations in pattern of pubertal changes in girls. Arch Dis Child 1969; 44:291-303.

12. Marshall WA, Tanner JM. Variations in the pattern of pubertal changes in boys. Arch Dis Child 1970; 45:13-23. 
13. Adair LS, Gordon-Larsen P. Maturational timing and overweight prevalence in US adolescent girls. Am J Public Health 2001:91:642-644.

14. Wang $\mathrm{Y}$. Is obesity associated with early sexual maturation? A comparison of the association in American boys versus girls. Pediatrics 2002;110:903-910.

15. Ribeiro J, Santos P, Duarte J, et al.. Association between overweight and early sexual maturation in Portuguese boys and girls. Ann Hum Biol 2006; 33:55-63.

16. Lohman TG, Roche AF, Martorell R. Anthropometric standardization reference manual. Illinois: Human Kinetics Books 1988.

17. Conde WL, Monteiro CA. Body mass index cutoff points for evaluation of nutritional status in Brazilian children and adolescents. J Pediatr (Rio J). 2006; 82:266-272.

18. Tanner J. Growth at adolescence. 2nd ed. Oxford: Blackwell Scientific Publications, 1962; 36-39.

19. World Health Organization. Physical status: the use and interpretation of anthropometry. Geneva, 1995 (Technical Report Series, 854). 
20. de Onis M, Onyango AW, Borghi E, Siyam A, Nishida C, Siekmann J. Development of a WHO growth reference for school-aged children and adolescents. Bull World Health Organ. 2007;85:660-7.

21. Cole TJ, Green P J. Smoothing reference centile curves: the LMS method and penalized likelihood. Stat Med 1992;11:1305-1319.

22. Statacorp LP. Stata Statistical Software: Release 10.1. College Station, TX: Stata Corporation, 2007.

23. Chinn S, Rona RJ. International definitions of overweight and obesity for children: a lasting solution? Ann Hum Biol 2002;29:306-313.

24. Cole TJ, Bellizzi MC, Flegal KM, et al.. Establishing a standard definition for child overweight and obesity worldwide: international survey. $\mathbf{B r}$ Med $\mathbf{J}$ 2000;320:1-6.

25. Wang $\mathrm{Y}$, Wang JQ. A comparison of international references for the assessment of child and adolescent overweight and obesity in different populations. Eur J Clin Nutr 2002;56:973-982.

26. Duke PM, Litt IF, Gross RT. Adolescents' self-assessment of sexual maturation. Pediatrics1980; 66:918-920. 
27. Saito MI. Maturação sexual: auto-avaliação do adolescente. Pediatr (Sao Paulo). 1984;6:111-5.

28. Bonat S, Pathomvanich A, Keil MF, et al.. Self-assessment of pubertal stage in overweight children. Pediatrics 2002;110:743-747.

29. Desmangles JC, Lappe JM, Lipaczewski G, et al.. Accuracy of pubertal Tanner staging self-reporting. J Pediatr Endocrinol Metab 2006;19:213221.

30. Chan N, Sung RY, Kong AP, et al.. Reliability of pubertal self-assessment in Hong Kong. J Pediatr Child Health 2008; 44:353-358.

31. Stephen MD, Bryant WP, Wilson DP. Self-assessment of sexual maturation in children and adolescents with diabetes mellitus. Endocr Pract $2008 ; 14: 840-845$.

32. Papadimitriou A, Pantsiotou S, Douros K, et al.. Timing of pubertal onset in girls: evidence for non-Gaussian distribuition. J Clin Endocrinol Metab 2008; 93:4422-4425.

33. Kaplowitz PB, Oberfield SE, Drug and Therapeutics nd Executive Committees of the Lawson Wilkins Pediatric Endocrine Society. Reexamination of the age limit for defining when puberty is precocious in girls 
in the United States: implications for evaluation and treatment. Pediatrics $1999 ; 104: 936-941$.

34. Pantsiotou S, Papadimitriou A, Douros K, et al.. Maturational tempo differences in relation to the timing of the onset of puberty in girls. Acta Paediatr 2008; 97:217-220.

35. Himes JH, Obarzanek E, Baranowski T, et al.. Early sexual maturation, body composition, and obesity in African-American girls. Obes Res 2004;12:64-72S.

36. Bratberg GH, Nilsen TI, Holmen TL, et al.. Early sexual maturation, central adiposity and subsequent overweight in late adolescence. A four-year follow-up of 1605 adolescent Norwegian boys and girls: the Young HUNT study. BMC Public Health 2007; 7:54-60.

37. Chen $\mathrm{X}$, Wang $\mathrm{Y}$. The influence of sexual maturation on blood pressure and body fatness in African-American adolescent girls and boys. Am J Hum Biol. 2009; 21:105-112.

38. Slyper $\mathrm{AH}$. The pubertal timing controversy in the USA, and a review of possible causative factors for the advance in timing of onset of puberty. Clinical Endocrinology. 2006;65:1-8. 


\title{
4.3 ARTIGO 3
}

\section{Maturação sexual e sua relação com composição corporal e parâmetros bioelétricos em crianças e adolescentes de duas escolas de São Paulo}

\begin{abstract}
Sexual maturation and relationship with corporal composition and bioelectric parameters in child and adolescents from two schools, São
\end{abstract}

\section{Paulo}

Resumo

Objetivo: Analisar a relação entre maturação sexual e composição corporal e comparar o comportamento dos parâmetros bioelétricos em crianças segundo status de maturação sexual

Método: A resistência $(\mathrm{R})$, reactância $(\mathrm{Xc})$ e valores de composição corporal foram obtidos por meio de aparelho de bioimpedância tetrapolar, de 617 crianças e adolescentes de 8 a 18 anos de idade. $O$ ângulo de fase (AF) foi obtido a partir da $\arctan \left(\mathrm{Xc}_{\mathrm{c}} / \mathrm{R}\right)$. $\mathrm{R}$ e $\mathrm{Xc}$ (padronizados pela estatura; R/E e $\mathrm{Xc} / \mathrm{E})$ e o AF definiram o vetor de impedância biolética (Z). O estágio de maturação sexual (EMS) foi auto-avaliado pelos indivíduos. Os indivíduos foram divididos em quartis de idades do EMS, segundo sexo. Vetores médios de indivíduos com e sem maturação relativamente acelerada (separados por sexo), com elipses de 95\% de confiança foram plotados. 
Resultados: Indivíduos com maturação acelerada apresentaram maiores valores de R/E, Xc/E e ângulo de fase e maiores quantidades absolutas e relativas de massa magra e gordura corporal, comparados aos demais, significante apenas no sexo feminino. Meninas com maturação acelerada apresentaram menores vetores de impedância, comparada com as demais.

Conclusão: A maturação precoce associou-se com os parâmetros bioelétricos e composição corporal, mais evidente no sexo feminino.

Palavras-chaves: Criança; Adolescente; Maturação Sexual, Desenvolvimento sexual, Composição corporal, Parâmetros bioelétricos 


\section{Introdução}

Há três décadas tem-se observado um aumento exponencial do número de crianças e adolescentes obesos. Atualmente, sabe-se que a obesidade infanto-juvenil é um importante fator prognóstico para a obesidade e morbimortalidade na vida adulta e associa-se ao aumento do risco de enfermidades crônicas, além de conseqüências socioeconômicas e psicológicas deletérias para o indivíduo. ${ }^{1-3}$

Face da dificuldade de se utilizar métodos mais avançados para medir gordura corporal em estudos epidemiológicos e serviços de saúde, o Índice de Massa Corpórea $\left(\mathrm{IMC}=\right.$ peso $(\mathrm{kg}) /$ estatura $\left.^{2}(\mathrm{~m})\right)$ tem sido uma alternativa amplamente utilizada na classificação da adiposidade. Todavia, o IMC é incapaz de distinguir os diferentes componentes corporais como massa magra e gordura corporal, constituindo uma medida indireta da obesidade, patologia definida como acúmulo excessivo ou anormal de gordura, sob forma de tecido adiposo, ocasionando prejuízos à saúde do indivíduo. ${ }^{3}$

Assim, para o diagnóstico adequado de obesidade necessita-se de método de mensuração da composição corporal. Neste sentido, a impedância bioelétrica (BIA) ressalta-se como importante instrumento para quantificação dos diferentes componentes corporais (massa magra e tecido adiposo) por ser um método seguro, reprodutível, portátil, de natureza não invasiva e de 
custo e complexidade inferiores quando comparada a outros equipamentos como a pesagem hidrostática e DEXA. ${ }^{4}$

As mudanças morfo-fisiológicas ocorridas durante a adolescência ocasionam alterações corporais com importante impacto no estado nutricional. Neste contexto, a validade do IMC para o diagnóstico de obesidade no período puberal apresenta-se comprometida devido às rápidas e contínuas modificações na composição corporal e crescimento estatural, necessitando assim de métodos que permitam maior acurácia na avaliação do estado nutricional, a partir composição corporal, evitando erros na classificação destes indivíduos. ${ }^{5}$

Na década de 70, baseado em estudos sobre a associação entre puberdade e estado nutricional, foi proposto a "hipótese do peso crítico" na qual um peso mínimo seria necessário para o início do processo pubertário. ${ }^{6}$ Posteriormente, esta hipótese foi reformulada propondo-se que seria necessário atingir determinado depósito de gordura corporal para o início e manutenção do processo. $^{7}$

Estudos mais recentes apontam que o aparecimento de caracteres sexuais secundários como o desenvolvimento das mamas e pêlos pubianos antes dos 8 anos na menina e genitália e pêlos pubianos antes dos 9 anos no menino, caracterizando tradicionalmente a maturação sexual precoce, constitui um fator de risco para o maior percentual de gordura corporal. Por 
outro lado, os indivíduos com elevado percentual de gordura corporal têm maiores chances de maturar precocemente. ${ }^{5,8,9}$

A puberdade é o período de transição gradual da infância para a vida adulta e é marcada por mudanças em todos aspectos do ser humano, caracterizando-se como um dos períodos mais críticos do ciclo vital. ${ }^{10} \mathrm{Um}$ grande número de mudanças físicas ocorre e muitos padrões adultos são adquiridos neste período. Desta maneira, a proximidade da adolescência à maturidade biológica oferece oportunidades para a prevenção de problemas de saúde na vida adulta. ${ }^{11}$

Assim, torna-se indispensável a compreensão da influência do processo de maturação sexual iniciado precocemente na adiposidade e composição corporal de crianças e adolescentes para o desenvolvimento de referências adequadas para a avaliação nutricional destes indivíduos, além de auxiliar na adoção de medidas eficazes de prevenção e tratamento da doença nesta faixa etária.

Diante da ausência de estudos sobre o comportamento dos parâmetros bioelétricos durante a puberdade e a escassez de investigações sobre a associação entre maturação sexual e medidas de composição corporal em meninos, o objetivo deste trabalho é analisar a relação entre maturação sexual e composição corporal e comparar o comportamento dos parâmetros 
bioelétricos em crianças e adolescentes de 8 a 18 anos, de duas escolas do município de São Paulo.

\section{Metodologia}

\section{Delineamento e Amostra}

Este estudo é parte de um projeto cujo objetivo é analisar o crescimento e composição corporal de crianças e adolescentes. Trata-se de um estudo longitudinal com estudantes de 8 a 18 anos de idade, de ambos os sexos, de duas escolas, pública e privada, do município de São Paulo com intuito de obter populações de diferentes status socioeconômico.

O cálculo do tamanho amostral foi realizado considerando-se um nível de significância de 95\% e um poder amostral (1- $\beta$ ) de $80 \%$. Baseando-se em estudos anteriores, estimou-se o desvio-padrão e a diferença a ser detectada no percentual de gordura corporal de $6 \%$ e $2,5 \%$, respectivamente, para o status de maturação sexual. Considerando um teste de hipótese bicaudal e a prevalência de indivíduos com maturação precoce de $25 \%$, o tamanho da amostra para atender os critérios estimados foi de 244 indivíduos de cada sexo. 


\section{Coleta de dados}

Foram realizadas 3 coletas de dados, durante o período de um ano, com intervalo de 6 meses entre as mesmas. A primeira coleta foi realizada em agosto/setembro de 2001, a segunda, em março/abril e a última, em setembro/outubro, ambas em 2002.

A coleta de dados foi realizada por uma única pesquisadora, por meio de entrevistas, mensuração antropométrica e exame de impedância bioelétrica nas próprias instituições, sendo os dados registrados em formulários prétestados. A escolaridade materna foi obtida em anos completos de estudo, por meio de questionário enviado aos pais junto com o Termo de Consentimento.

A idade foi calculada em meses, mediante a diferença entre a data de nascimento e a data da entrevista. Para a mensuração do peso corporal foi utilizada balança eletrônica do tipo plataforma com capacidade para 150kg e precisão de 100g (Tanita TFB-521 ${ }^{\circledR}$ ). A estatura foi mensurada utilizando-se estadiômetro $\left(\operatorname{Seca}^{\circledR}\right)$ fixado à parede com escala em milímetros $(\mathrm{mm})$. Foram realizadas duas medidas de estatura e considerada a média dos valores obtidos, conforme proposto por Lohman et al. ${ }^{12}$

Para obtenção dos valores de resistência $(R)$, reactância $(X c)$ e avaliação da composição corporal, foi utilizado aparelho de impedância bioelétrica 
tetrapolar RJL Systems ${ }^{\circledR}$ adotando-se as técnicas propostas pelo fabricante. A técnica de impedância bioelétrica consiste na emissão de uma corrente elétrica constante de baixa amplitude (500 a $800 \mathrm{~mA}$ ) e alta freqüência $(50 \mathrm{kHz})$ por meio de eletrodos fixados no corpo e a mensuração da impedância corporal (Z), definida como a oposição de um condutor à passagem de uma corrente. No corpo humano, há uma associação entre a concentração de íons contidos no meio condutor e a condutividade elétrica e resistência dos compartimentos. ${ }^{13}$

No sentido de minimizar a interferência de fatores que afetam o estado de hidratação do indivíduo e os resultados obtidos por meio da bioimpedância ${ }^{14}$, as crianças e adolescentes foram instruídos a realizarem o exame após esvaziamento da bexiga e não fazerem atividade física moderada à intensa na manhã do dia do exame.

Foram utilizados os valores absolutos $(\mathrm{kg})$ e relativos (\%) de massa magra e gordura corporal. O ângulo de fase foi obtido a partir do arco tangente da reactância/resistência $(\Phi=\operatorname{arc} \tan (\mathrm{Xc} / \mathrm{R}))$. Para transformar o resultado de radianos para graus $\left({ }^{\circ}\right)$, multiplicou-se o resultado obtido por $180^{\circ} / \pi$. Essas constituíram variáveis independentes, do tipo contínua.

Os indivíduos auto-avaliaram o estágio de maturação sexual (EMS) conforme critério proposto por Tanner. ${ }^{15}$ Considerou-se 0 estágio de desenvolvimentos dos genitais e mamas para os meninos e meninas, 
repectivamente, avaliados conforme o tamanho, características e forma. $\mathrm{O}$ desenvolvimento dos pêlos pubianos foi avaliado em ambos os sexos, segundo características, quantidade e distribuição. O estágio 1 corresponde ao crescimento e desenvolvimento pré-puberal, enquanto os estágios 2 a 4 correspondem à progressão da puberdade até a maturação completa (estágio 5).

\section{$\underline{\text { Análise dos Dados }}$}

Para a classificação do status de maturação (relativamente acelerada ou não), os indivíduos foram agrupados, segundo sexo, em quartis de idade (meses) para cada estágio atual de Tanner. Aqueles que estavam no $1^{\circ}$ quartil de idade para cada EMS em todas as coletas de dados, foram considerados com maturação relativamente acelerada e os demais quartis foram agrupados para comparação com o $1^{\circ}$ quartil durante as análises.

Estas classificações foram realizadas para pêlos pubianos/mamas nas meninas e pêlos pubianos/genitália nos meninos, verificando-se a concordância entre os dois critérios na classificação da maturação sexual precoce, para cada sexo. A concordância e o valor de kappa foram de $79,3 \%$ e 0,46 para os meninos e $86,1 \%$ e 0,64 para as meninas. Optou-se pela utilização estágios de desenvolvimento dos genitais masculinos e mamas para as meninas considerando que a World Health Organization Expert Committee os recomenda como indicadores da maturação sexual 
para uso internacional e apresentam maior confiabilidade na detecção da ativação do eixo hipotalâmico-hipofisário-gonadal ${ }^{10,16}$

Para a descrição das variáveis foram utilizadas medidas de tendência central (média) e dispersão (desvio-padrão). O teste t de Student foi utilizado para verificar diferenças entre as médias dos grupos (sexo e status de maturação). O coeficiente de correlação de Pearson foi utilizado para verificar a relação entre $\mathrm{R} / \mathrm{E}$ e Xc/E.

Foram realizadas análises de regressão linear múltipla para verificar a associação entre a maturação sexual relativamente acelerada e as variações na composição corporal (massa magra e gordura corporal) e parâmetros bioelétricos ( $R, X c$ e ângulo de fase) estratificadas por sexo e ajustadas por estatura, idade e escolaridade materna. Foi testada a interação entre idade e status de maturação. O fator de inflação da variância (FIV) foi utilizado para examinar a colinearidade entre as variáveis independentes. Nenhuma variável apresentou colinearidade perfeita $(F I V<10)$. Para os cálculos foi utilizado o pacote estatístico Stata $10.1^{17}$ e nível de significância de $5 \%$.

Os valores de resistência e a reactância dos indivíduos na última coleta foram corrigidas para a estatura $(\mathrm{R} / \mathrm{E}$ e $\mathrm{Xc} / \mathrm{E})$ e plotadas como pontos vetores num plano Cartesiano (gráfico RXc). Foram calculadas elipses para os vetores médios de impedância (Z) com 95\% de confiança, segundo sexo e status de maturação sexual utilizando software BIVA. ${ }^{18}$ Para a comparação 
das diferenças entre as médias dos vetores $Z$ entre os grupos (sexo e status de maturação) foi utilizado o teste $T^{2}$ de Hotlling. Este teste é mais sensível que o teste t de Student, gerando um pequeno risco de rejeitar a hipótese nula erroneamente. ${ }^{19}$

O presente estudo encontra-se de acordo com as normas da Resolução $n^{\circ}$. 196 de 10/10/1996 do Conselho Nacional de Saúde, que regulamenta as pesquisas envolvendo seres humanos no país, e foi aprovado pelo Comitê de Ética em Pesquisa.

\section{Resultados}

Inicialmente, foram coletados dados de 660 crianças e adolescentes. Após a terceira coleta, foram acompanhados um total 617 crianças e adolescentes, sendo $40,7 \%(n=251)$ meninos e 59,3\% ( $n=366)$ meninas. Verificou-se maior perda de indivíduos entre o sexo masculino, em sua maioria, de alunos que saíram da escola.

A tabela 1 apresenta as características da população estudada. Os indivíduos avaliados não apresentaram diferenças estatísticas para as variáveis antropométricas, segundo sexo. Meninos apresentaram maior incremento no peso e estatura no período. A correlação entre a resistência e 
a reactância corrigidas pela altura foi maior no sexo masculino $(r=0,75)$ quando comparado ao sexo feminino $(r=0,64)$.

Tabela 1 Amostra e diferenças médias nos parâmetros bioelétricos e composição corporal das crianças e adolescentes no período estudado

\begin{tabular}{|c|c|c|c|c|c|}
\hline & \multicolumn{2}{|c|}{ Meninos } & \multicolumn{2}{|c|}{ Meninas } & $\boldsymbol{P}$ \\
\hline \multicolumn{6}{|l|}{ Amostra (n , \%) } \\
\hline Crianças (8|-10 anos) & 10 & $4,0 \%$ & 17 & $4,6 \%$ & \\
\hline Adolescentes (10|-18 anos) & 241 & $96,0 \%$ & 349 & $95,4 \%$ & \\
\hline Idade $^{\star}$ (meses; $x$, DP) & 153,5 & $(19,78)$ & 154,6 & $(21,64)$ & 0,504 \\
\hline Antropometria (x, DP) & \multicolumn{2}{|c|}{$3^{\mathrm{a}-1^{\mathrm{a}}}$ coleta $(\Delta)$} & \multicolumn{2}{|c|}{$3^{\mathrm{a}-1} 1^{\mathrm{a}}$ coleta $(\Delta)$} & \\
\hline Estatura (cm) & 4,2 & $(2,00)$ & 3,6 & $(2,40)$ & 0,002 \\
\hline Peso $(\mathrm{Kg})$ & 4,9 & $(1,98)$ & 4,1 & $(1,93)$ & 0,001 \\
\hline Parâmetros BIA (x, DP) & \multicolumn{2}{|c|}{$3^{\mathrm{a}}-1^{\mathrm{a}}$ coleta $(\Delta)$} & \multicolumn{2}{|c|}{$3^{\text {a }-1} 1^{\text {a }}$ coleta $(\Delta)$} & \\
\hline $\mathrm{R}(\Omega)$ & 22,9 & $(37,16)$ & 16,8 & $(38,49)$ & 0,005 \\
\hline $\mathrm{Xc}(\Omega)$ & 2,2 & $(8,32)$ & 5,4 & $(8,65)$ & $<0,001$ \\
\hline $\mathrm{R} / \mathrm{E}(\Omega / \mathrm{m})$ & 2,3 & $(25,19)$ & $-0,1$ & $(26,93)$ & 0,285 \\
\hline $\mathrm{Xc} / \mathrm{E}(\Omega / \mathrm{m})$ & $-0,1$ & $(5,43)$ & 2,2 & $(5,73)$ & $<0,001$ \\
\hline Ângulo de fase $\left({ }^{\circ}\right)$ & $-0,1$ & $(0,89)$ & 0,3 & $(0,79)$ & $<0,001$ \\
\hline$r(R, X c)$ & \multicolumn{2}{|c|}{0,75} & \multicolumn{2}{|c|}{0,64} & \\
\hline \multicolumn{6}{|l|}{ Composição Corporal (x, DP) } \\
\hline Massa magra (kg) & 0,9 & $(2,51)$ & 1,4 & $(2,30)$ & 0,018 \\
\hline Massa magra (\%) & $-4,5$ & $(3,35)$ & $-2,7$ & $(2,77)$ & $<0,001$ \\
\hline Gordura corporal (kg) & 3,3 & $(2,24)$ & 2,3 & $(1,71)$ & $<0,001$ \\
\hline Gordura corporal (\%) & 4,5 & $(3,32)$ & 2,8 & $(2,73)$ & $<0,001$ \\
\hline
\end{tabular}

IMC, índice de massa corporal; $x$, média; DP, desvio-padrão; BIA, impedância bioelétrica; R, resistência; Xc, reactância; $R / E$, resistência corrigida pela estatura; $X_{c} / E$, reactância corrigida pela estatura; $r$, correlação entre $R$ e Xc. *Idade na primeira coleta

Os indivíduos com maturação acelerada eram significativamente $(p<0,05)$ mais baixos que os demais $(149,3 \mathrm{~cm}$ vs. $157,9 \mathrm{~cm}$ para os meninos; $152,2 \mathrm{~cm}$ vs. 154,8 para as meninas). Não foram observadas diferenças estatísticas entre indivíduos com ou sem maturação relativamente acelerada para os valores de peso $(46,8 \mathrm{~kg}$ vs. $51,8 \mathrm{~kg}, \mathrm{p}=0,156$ para os meninos; $48,1 \mathrm{~kg}$ vs. $49,5 \mathrm{~kg}, \mathrm{p}=0,528$ para as meninas). 
Com relação aos parâmetros bioelétricos, meninos com maturação relativamente acelerada apresentaram, na média, menor incremento na resistência bioelétrica. Entre as meninas, nenhum parâmetro bioelétrico apresentou diferenças significativas segundo status de maturação (Tabela 2). Analisando a composição corporal, meninos com maturação relativamente acelerada apresentaram, em média, incremento de $2,7 \mathrm{~kg}$ a mais na quantidade relativa de massa magra em relação aos sem maturação acelerada. Entre as meninas, valores semelhantes de composição corporal foram observados, independente do status de maturação.

Tabela 2 Média de variação dos parâmetros bioelétricos e composição corporal segundo sexo e status de maturação em crianças e adolescentes no período estudado.

\begin{tabular}{|c|c|c|c|c|c|c|}
\hline & \multicolumn{2}{|c|}{ Meninos } & \multirow[b]{2}{*}{$p$} & \multicolumn{2}{|c|}{ Meninas } & \multirow[b]{2}{*}{$p$} \\
\hline & $\begin{array}{c}\text { Sem maturação } \\
\text { acelerada }\end{array}$ & $\begin{array}{c}\text { Maturação } \\
\text { acelerada }\end{array}$ & & $\begin{array}{c}\text { Sem maturação } \\
\text { acelerada }\end{array}$ & $\begin{array}{l}\text { Maturação } \\
\text { acelerada }\end{array}$ & \\
\hline \multicolumn{7}{|l|}{ Parametros BIA } \\
\hline $\mathrm{R}(\Omega)$ & 24,4 & $-4,9$ & 0,005 & 15,3 & 23,7 & 0,109 \\
\hline $\mathrm{Xc}(\Omega)$ & 2,1 & 4,5 & 0,313 & 5,3 & 6,0 & 0,536 \\
\hline $\mathrm{R} / \mathrm{E}(\Omega / \mathrm{m})$ & 3,5 & $-21,6$ & 0,000 & $-0,7$ & 2,8 & 0,333 \\
\hline $\mathrm{Xc} / \mathrm{E}(\Omega / \mathrm{m})$ & $-0,1$ & 1,1 & 0,449 & 2,2 & 2,5 & 0,702 \\
\hline Ângulo de fase $\left({ }^{\circ}\right)$ & $-0,8$ & 0,4 & 0,071 & 0,3 & 0,3 & 0,903 \\
\hline$r(R, X c)$ & 0,63 & 0,77 & & 0,71 & 0,62 & \\
\hline \multicolumn{7}{|l|}{ Composição Corporal } \\
\hline Massa magra (kg) & 0,8 & 3,5 & 0,000 & 1,3 & 1,5 & 0,466 \\
\hline Massa magra (\%) & $-4,6$ & $-3,0$ & 0,088 & $-2,7$ & $-2,9$ & 0,801 \\
\hline Gordura corporal (kg) & 3,4 & 2,9 & 0,457 & 2,2 & 2,4 & 0,578 \\
\hline Gordura corporal (\%) & 4,6 & 3,0 & 0,094 & 2,7 & 2,9 & 0,844 \\
\hline
\end{tabular}

$\mathrm{BIA}$, impedância bioeletrica; R, resistencia; Xc, reactância; R/E, resistência ajustada pela estatura; Xc/E, reactância ajustada pela estatura; $r$, correlação entre $R$ e Xc 
$\mathrm{Na}$ análise de regressão linear múltipla verifica-se associação entre status de maturação sexual e os parâmetros bioelétricos e de composição (Tabela 3). Meninas com maturação sexual relativamente acelerada tenderam a apresentar em média maiores incrementos na resistência e reactância (corrigidas para a estatura). Em contrapartida, meninos apresentaram, em média, menores incrementos de resistência e maior incremento no ângulo de fase (medida indireta de massa magra). Em relação à quantidade absoluta de massa magra, meninos com maturação relativamente acelerada apresentaram maior incremento, ocorrendo o inverso entre as meninas.

Tabela 3 Associação entre status da maturação e alterações nos parâmetros bioelétricos e composição corporal no intervalo de 1 ano.

\begin{tabular}{|c|c|c|c|c|c|c|}
\hline & \multicolumn{3}{|c|}{ Meninos } & \multicolumn{3}{|c|}{ Meninas } \\
\hline & $\Delta$ & EP & $p$ & $\Delta$ & EP & $P$ \\
\hline \multicolumn{7}{|l|}{ Parâmetros da BIA } \\
\hline $\mathrm{R}(\mathrm{Ohms})$ & $-34,53$ & 11,83 & 0,004 & 12,76 & 5,80 & 0,029 \\
\hline Xc (Ohms) & 4,40 & 2,75 & 0,111 & 2,24 & 1,30 & 0,086 \\
\hline $\mathrm{R} / \mathrm{E}(\mathrm{Ohms} / \mathrm{m})$ & $-25,19$ & 8,08 & 0,002 & 11,63 & 3,96 & 0,004 \\
\hline $\mathrm{Xc} / \mathrm{E}(\mathrm{Ohms} / \mathrm{m})$ & 2,80 & 1,76 & 0,115 & 1,72 & 0,85 & 0,044 \\
\hline Ângulo de fase $\left({ }^{\circ}\right)$ & 0,68 & 0,29 & 0,020 & 0,09 & 0,12 & 0,434 \\
\hline \multicolumn{7}{|l|}{ Composição corporal } \\
\hline Massa magra (kg) & 1,79 & 0,76 & 0,019 & $-0,82$ & 0,32 & 0,011 \\
\hline Massa magra (\%) & 0,74 & 0,96 & 0,439 & $-0,40$ & 0,42 & 0,342 \\
\hline Gordura corporal (kg) & 0,46 & 0,73 & 0,532 & 0,28 & 0,26 & 0,282 \\
\hline Gordura corporal (\%) & $-0,72$ & 0,95 & 0,452 & 0,40 & 0,41 & 0,330 \\
\hline
\end{tabular}

Comparando os vetores médios de impedância (obtidos na última coleta) por meio do teste $\mathrm{T}^{2}$ de Hotelling com $95 \%$ de confiança, observa-se diferença 
estatisticamente significativa nos vetores médios de impedância entre os sexos $(p<0,001)$. Analisando o impacto da maturação sexual nos vetores médios (corrigidos pela idade das crianças e adolescentes), não foram observadas diferenças estatísticas nos vetores segundo status de maturação $(p=0,410)$ no sexo masculino. Em contrapartida, meninas maturadas precoces apresentam menores valores de $\mathrm{R} / \mathrm{E}$ e $\mathrm{XC} / \mathrm{E}$, com diferença estatisticamente significante entre os vetores médios de impedância $(p<0,001)$, comparadas às meninas não maturadas precoces (Figuras 1 e 2 ).

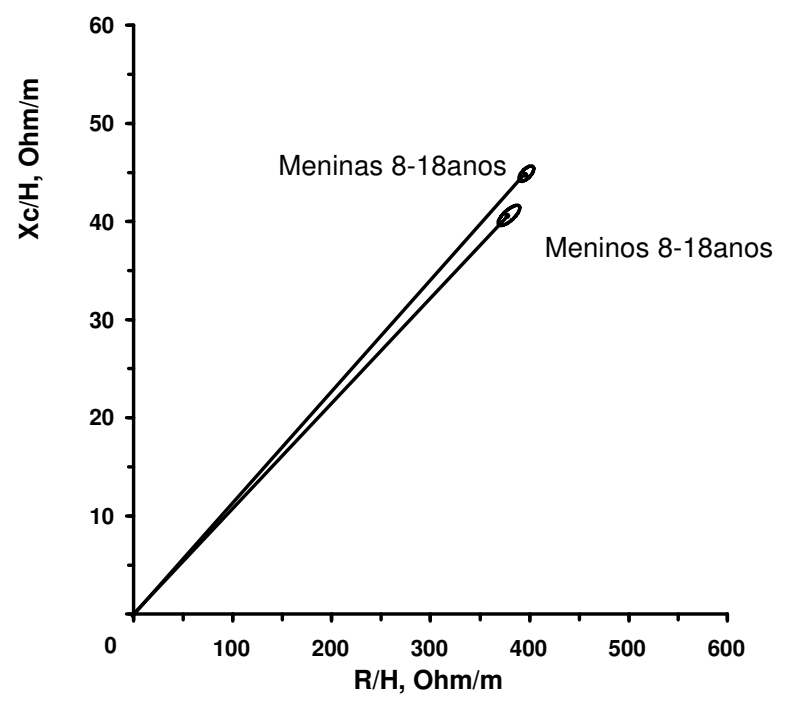

Figura 1 Vetores de impedância médios com elipses de $95 \%$ de confiança das crianças e adolescentes segundo sexo. 

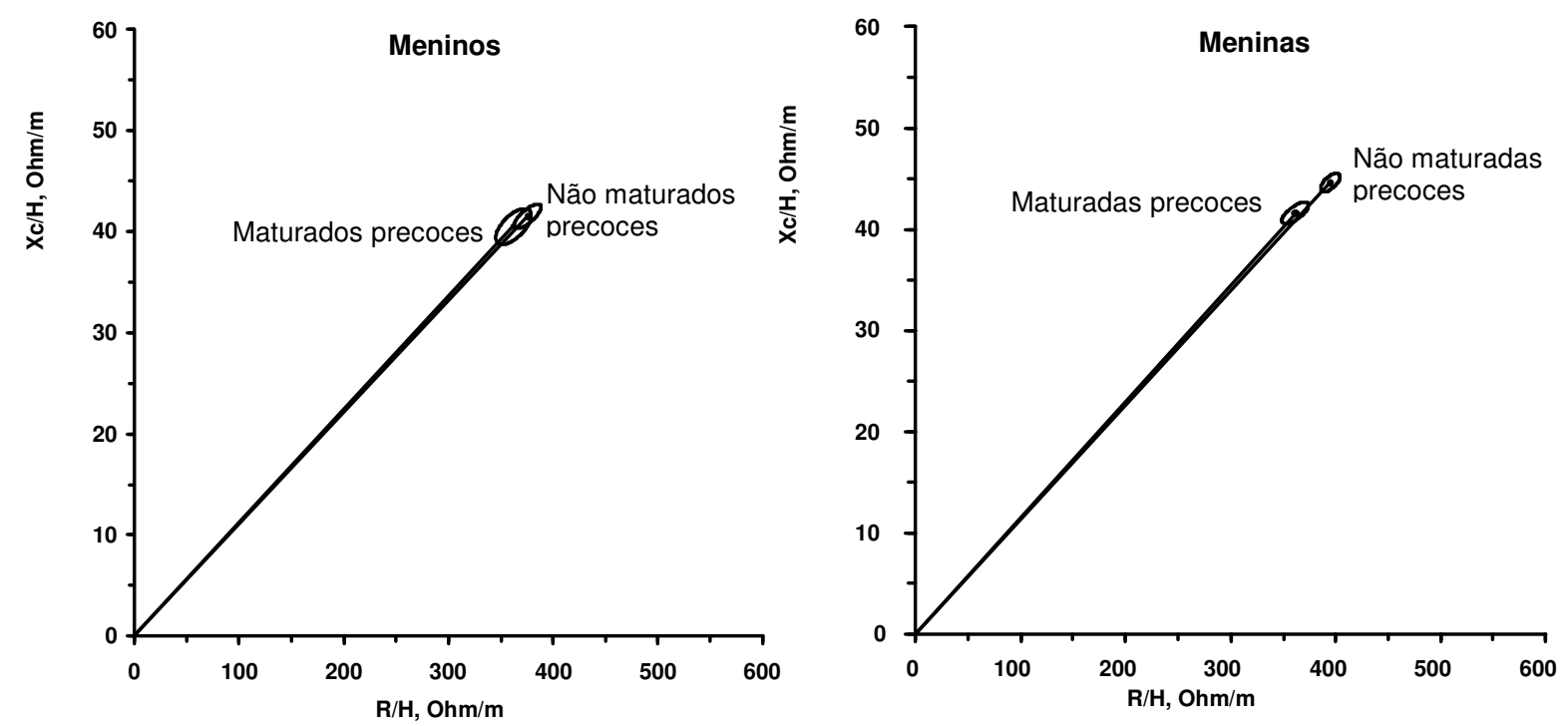

Figura 2 Vetores de impedância médios (ajustados para o efeito da idade) com elipses de confiança de $95 \%$, segundo sexo e status de maturação sexual.

\section{Discussão}

Neste estudo, foram observadas diferenças nos valores de composição corporal e nos parâmetros bioelétricos entre indivíduos que apresentaram maturação sexual relativamente acelerada, quando comparados aos demais. A remoção do efeito da idade dos indivíduos a partir da inclusão desta variável nas análises acentuou tais diferenças estatísticas.

O delineamento do estudo impediu a utilização dos pontos de corte existentes para classificação da maturação sexual precoce dado que a idade de início da maturação era desconhecida. Entretanto, a definição dos pontos de corte clássicos para a avaliação da maturação precoce (desenvolvimento 
de caracteres sexuais secundários antes dos 8 anos nas meninas e dos 9 anos nos meninos) baseou-se numa distribuição normal da idade de início da maturação e um intervalo de $95 \%$ de confiança de estudos epidemiológicos realizado com crianças britânicas há 40 anos. ${ }^{20,21} \mathrm{Em}$ estudo recente sobre o início da maturação sexual em meninas, Papadimitriou et al. ${ }^{22}$ observaram que a idade de início do processo de maturação não apresenta uma distribuição normal na população. Neste contexto, alguns autores e órgãos internacionais têm proposto uma revisão destes parâmetros de idade e a utilização do percentil 25 da distribuição de idade do início da maturação da própria população para classificação de puberdade precoce. ${ }^{22-24}$

Erros na classificação da maturação sexual podem ser decorrentes da variabilidade inter e intraindividual em relação ao tempo de maturação sexual, dado que um indivíduo maturado precoce pode compensar a velocidade de maturação e não ser classificado como precoce nos estágios mais avançados, enquanto um indivíduo não maturado precoce pode apresentar lentidão no processo de maturação e ser classificado como precoce no estágio seguinte.

Assim, a classificação da maturação sexual foi realizada a partir de quartis de idade para cada estágio de maturação segundo sexo, onde foram classificados com maturação relativamente acelerada os indivíduos que se 
encontrassem no $1^{\circ}$ quartil de idade do EMS em todas as três coletas, sendo os demais classificados como sem maturação relativamente acelerada.

Embora a auto-avaliação não apresente consenso na literatura no que diz respeito à confiabilidade para a determinação do EMS, estudos nacionais e internacionais apontam valores de kappa (concordância) entre a autoavaliação e a avaliação objetiva realizada por profissionais treinados de 0,34 a 0,81 (48 a $86 \%$ ) para as meninas e 0,29 a 0,88 (51 a $76 \%$ ) para os meninos. Estes autores também afirmam que a acurácia destas informações são maiores quando alguns cuidados são tomados. ${ }^{25-30}$ Neste sentido, os indivíduos foram distribuídos em grupos pequenos de mesmo sexo, e receberam informações sobre adolescência, desenvolvimento físico e maturação sexual. Foram fornecidas informações sobre as características e diferenças entre os estágios de maturação sexual, e o preenchimento do formulário foi feito individualmente.

A determinação da composição corporal por meio de equações preditivas e o uso dos vetores de impedância mostram-se métodos eficazes na avaliação das alterações corporais ocorridas durante a puberdade, e mais especificamente em relação à maturação acelerada. Os vetores de impedância apresentam um potencial uso na prática clínica por ser um método mais sensível a variações de hidratação e na estrutura corporal, facilitando o monitoramento de indivíduos e a intervenção precoce para 
prevenção de obesidade, principalmente em períodos de rápidas mudanças na composição corporal como a puberdade.

Estudos anteriores mostraram que os valores de composição corporal e os parâmetros de bioimpedância começam a se diferenciar entre os sexos após o início do processo de maturação sexual. Meninos e meninas pós-púberes apresentam menores valores de resistência e reactância em relação à prépúberes. ${ }^{39,40}$

Buffa et al.$^{40}$ avaliando o efeito da puberdade na distribuição dos vetores de impedância em meninas de 10 a 15 anos, observaram diferenças evidentes nos parâmetros bioelétricos entre meninas pré e pós-puberes independente da idade. Meninas pós-púberes apresentaram menores vetores de impedância (valores mais baixo de R/E e $\mathrm{XC} / \mathrm{E}$ ) e maior ângulo de fase, quando comparadas as meninas pré-púberes.

Wang ${ }^{41}$ estudando a influência do início do estágio de maturação sexual na adiposidade de adolescentes, observou que meninos com maturação sexual precoce apresentaram menores valores de dobra triciptal e de somatória de dobras. Em contrapartida, a maturação sexual precoce se associou com maiores valores de dobras em meninas.

Os achados do presente estudo corroboram com os dados da literatura mostrando que indivíduos com maturação relativamente acelerada 
apresentam modificações no padrão de composição corporal com um incremento na quantidade relativa de gordura corporal e redução da quantidade relativa de massa magra, no sexo feminino, ocorrendo o oposto entre os meninos. Todavia, não foram encontrados estudos na literatura que avaliem os parâmetros bioelétricos em crianças e adolescentes com maturação precoce, impossibilitando a comparação dos dados.

O início e duração do processo de maturação sexual sofrem influências genéticas e ambientais ainda desconhecidas. A adolescência é o último período para expressão máxima do potencial genético necessitando de fatores socioambientais favoráveis, havendo assim uma interação entre genética e ambiente. No entanto, como tais fatores interagem entre si e influenciam no processo pubertário e a relação existente entre obesidade e maturação sexual são fatores que ainda necessitam de elucidações.

Um componente significante das diferenças observadas parece ser a variação nas propriedades condutivas dos tecidos que ocorrem durante o processo de maturação. Tais variações afetariam principalmente a determinação da gordura corporal, uma vez que foram encontradas menores diferenças nos valores de ângulo de fase entre os indivíduos com maturação acelerada. A maturação precoce também não se associou aos valores absolutos de massa magra em ambos os sexos. 


\section{Conclusão}

Os resultados do presente estudo mostram uma associação entre maturação relativamente acelerada e parâmetros bioelétricos e composição corporal. Neste sentido, a identificação do estágio de maturação sexual na avaliação nutricional de crianças e adolescentes auxiliaria no entendimento das alterações na composição corporal ocorridas durante a puberdade e identificação precoce de alterações potencialmente patológicas e intervenção nestes indivíduos.

\section{Referências}

1. Ebbeling CB, Pawlak DB, Ludwig DS. Childhood obesity: public-health crisis, common sense cure. Lancet 2002;360:473-482.

2. Stettler N. Comment: the global epidemic of childhood obesity: is the role for the paediatrician? Obes Rev 2004; 5 Suppl 1:1-3.

3. World Health Organization (WHO). Obesity: preventing and managing the global epidemic. Geneva, 2000 (Technical Report Series, 894).

4. Chumlea WC, Guo SS, Kuczmarski RJ et al.. Body composition estimates from NHANES III bioelectrical impedance data. Int J Obes 2002; 26:1596-1609. 
5. Sievorgel RM, Demerath EW, Schuber C, et al.. Puberty and body composition. Horm Res 2003; 60:36-45.

6. Frisch RE, Revelle R. Height and weight at menarche and a hypothesis of critical body weights and adolescent events. Science 1970;169:397-379.

7. Frisch RE, McArthur JW. Menstrual cycles: fatness as a determinant of minimum weight for height necessary for their maintenance or onset. Science 1974;185:949-951.

8. Bini V, Celi F, Berioli MG, Bacosi ML et al.. Body mass índex in children and adolescents according to age pubertal stage. Eur $\mathbf{J}$ Clin Nutr 2000;54(3):214-8.

9. Laitinen J, Power C, Jarvelin M. Family social class, maternal body mass index, childhood body mass index and age at menarche as predictors of adult obesity. Am J Clin Nutr 2001; 74(3):287-94.

10.World Health Organization (WHO). Physical status: the use and interpretation of anthropometry. Geneva, 1995. (Technical Report Series, 854).

11. World Health Organization (WHO). Nutrition in adolescence - Issues and challenges for the health sector. Geneva, 2005 (WHO discussion papers on adolescence). 
12.Lohman TG, Roche AF, Martorell R. Anthropometric standardization reference manual. Illinois: Human Kinetics Books 1988.

13.Lukaski HC. Methods for the assessment of human body composition: traditional and new. Am J Clin Nutr 1987; 46: 537-56.

14. Dehgan M, Merchant AT. Is bioelectrical impedance accurate for use in large epidemiological studies? Nutrition J 2008; 7:26-32.

15.Tanner J. Growth at adolescence. 2nd ed. Oxford: Blackwell Scientific Publications, 1962; 36-39.

16. Biro FM, Lucky AW, Simbartl LA et al.. Pubertal maturation in girls and the relationship to anthropometric changes: pathways through puberty. $\mathbf{J}$ Pediatr 2003;142:643-646.

17.StataCorp LP. Stata Statistical Software: Release 10.1. College Station, TX: Stata Corporation, 2009.

18. Piccoli A, Pastori G. BIVA software. Department of Medical and Surgical Sciences, University of Padova, Padova, Italy, 2002. 
19.Lentner C. Introduction to statistics, Statistical tables, Methematical formulae. In: Lentner C. Geigy Scientific Tables $8^{\text {th }}$ ed. Vol. 2. Basle: Ciba-Geigy; 1982; 215-218.

20. Marshall WA, Tanner JM. Variations in pattern of pubertal changes in girls. Arch Dis Child1 1969; 44:291-303.

21. Marshall WA, Tanner JM. Variations in the pattern of pubertal changes in boys. Arch Dis Child 1970; 45:13-23.

22. Papadimitriou A, Pantsiotou S, Douros K, et al.. Timing of pubertal onset in girls: evidence for non-Gaussian distribuition. J Clin Endocrinol Metab 2008; 93:4422-4425.

23. Kaplowitz PB, Oberfield SE, Drug and Therapeutics nd Executive Committees of the Lawson Wilkins Pediatric Endocrine Society. Reexamination of the age limit for defining when puberty is precocious in girls in the United States: implications for evaluation and treatment. Pediatrics 1999; 104:936-941.

24.Pantsiotou S, Papadimitriou A, Douros K, et al.. Maturational tempo differences in relation to the timing of the onset of puberty in girls. Acta Paediatr 2008; 97:217-220. 
25. Duke PM, Litt IF, Gross RT. Adolescents' self-assessment of sexual maturation. Pediatrics1980; 66:918-920.

26. Saito MI. Maturação sexual: auto-avaliação do adolescente. Pediatr (Sao Paulo). 1984;6:111-5.

27.Bonat S, Pathomvanich A, Keil MF, et al.. Self-assessment of pubertal stage in overweight children. Pediatrics 2002;110:743-747.

28. Desmangles JC, Lappe JM, Lipaczewski G, et al.. Accuracy of pubertal Tanner staging self-reporting. J Pediatr Endocrinol Metab 2006;19:213221.

29. Chan N, Sung RY, Kong AP, et al.. Reliability of pubertal self-assessment in Hong Kong. J Pediatr Child Health 2008; 44:353-358.

30.Stephen MD, Bryant WP, Wilson DP. Self-assessment of sexual maturation in children and adolescents with diabetes mellitus. Endocr Pract 2008; 14:840-845.

31. Barbosa-Silva MCG, Barros AJD, Wang J, et al.. Bioelectrical impedance analysis: population reference values for phase angle by age and sex. Am J Clin Nutr 2005; 82:49-52. 
32. Foster KR \& Lukaski HC. Whole-body impedance - what does it measure? Am J Clin Nutr 1996; 64 (suppl): 388S-96S.

33. Houtkooper LB, Lohman TG, Going SB, Howell WH. Why bioelectrical impedance analysis should be used for estimating adiposity. Am J Clin Nutr 1996; 64(suppl): 436S-48S.

34. Roubenoff R. Applications of bioelectrical impedance analysis for body composition to epidemiologic studies. Am J Clin Nutr 1996; 64(Suppl):459-62.

35. Rogol AD, Roemmich JN, Clark PA. Growth at puberty. J Adolesc Health 2002; 31: 192-200.

36. Goran MI. Measurement issues related to studies of childhood obesity: assessment of body composition, body fat distribution, physical activity, and food intake. Pediatrics 1998;101:505-18.

37.Piccoli A, Rossi B, Pillon L, Bucciante G: A new method for monitoring body fluid variation by bioimpedance analysis: the RXc graph. Kidney Int $1994 ; 46: 534-539$. 
38. Piccoli A, Nigrelli S, Caberlotto A, Bottazzo S, Rossi B, Pillon L, Maggiore Q. Bivariate normal values of the bioelectrical impedance vector in adult and elderly populations. Am J Clin Nutr 1995; 61:269-270.

39. De Palo T, Messina G, Edefonti A, Perfumo F, Pisanello L, Peruzzi L, Di Iorio B, Mingozzi M, Vienna A, Conti G, Penza R, Piccoli A: Normal values of the bioelectrical impedance vector in childhood and puberty. Nutrition 2000;16:417-424.

40.Buffa R, Floris G, Marini E. Bioelectrical impedance vector in pre- and postmenarcheal females. Nutrition 2002; 18:474-478.

41.Wang $Y$. Is obesity associated with early sexual maturation? A comparison of the association in American boys versus girls. Pediatrics 2002;110:903-910. 


\section{CONSIDERAÇÕES FINAIS}

Atualmente, não há uma definição consensual de um padrão normativo para o início do processo de maturação devido à influência de inúmeros fatores genéticos e ambientais que afetam de forma diferente as populações, destacando-se assim a dificuldade de classificação da maturação precoce e a comparação entre populações devido à fatores como delineamento e metodologia de estudo.

Dentre os principais achados do presente estudo pode-se destacar: 1) associação entre maturação sexual relativamente acelerada e obesidade em ambos os sexos; 2) indivíduos maturados precoces tendem a apresentar maior incremento de estatura, quando comparados aos demais; 3) meninas com maturação relativamente acelerada apresentaram, em média, maior incremento no escore $Z$ do IMC e maior acúmulo de gordura na região abdominal; 4) meninos que iniciaram a maturação sexual em idades mais jovens apresentam maiores valores de escore $z$ do IMC; 5) associação entre maturação relativamente acelerada e parâmetros bioelétricos; 6) associação entre massa magra absoluta e maturação acelerada, ocorrendo de foma distinta entre os sexos; 7) meninas maturadas em idades mais jovens apresentaram menores vetores de impedância (Z), comparadas as demais.

Neste sentido, a identificação dos estágios de maturação sexual durante a avaliação do estado nutricional de crianças e adolescentes facilitaria a 
compreensão das alterações na composição corporal ocorridas durante a puberdade, além de auxiliar a identificação precoce de alterações potencialmente patológicas e intervenções nestes indivíduos.

Assim, ressalta-se a necessidade de estudos regionais e nacionais, representativos da população, que realizem a avaliação da maturação sexual e estimem a prevalência de maturação sexual precoce em crianças e adolescentes brasileiros, considerando também fatores que possam explicar a variabilidade intra e inter regional e novos delineamentos que auxiliam no entendimento do processo saúde-doença. 


\section{REFERÊNCIAS}

Adair LS, Gordon-Larsen P. Maturational timing and overweight prevalence in US adolescent girls. Am J Publc Health 2001:91(4):642-4.

Barbosa KBF, Franceschini SCC, Priore SE. Influência dos estágios de maturação sexual no estado nutricional, antropometria e composição corporal de adolescentes. Rev Bras Saúde Matern Infant 2006; 6(4):37582.

Bini V, Celi F, Berioli MG, Bacosi ML, Stella P, Giglio P, et al.. Body mass índex in children and adolescents according to age pubertal stage. Eur $\mathbf{J}$ Clin Nutr 2000;54(3):214-8.

Bogin B. Patterns of Human Growth. $2^{\text {nd }}$ ed. Cambridge: Cambrdige University Press; 2001. 455p.

Cameron N. The methods of auxological antropometry. In: Falkner F, Tanner JM. Human growth: a comprehensive treatise. New York \& London: Plenum Press; 1986. p.3-43.

Cintra IP, Passos MAS, Fisberg M, Machado HC. Evolução de duas séries históricas do índice de massa corporal em adolescentes. J Pedatr (Rio J) 2007; 83(2):157-62. 
Cole TJ, Green P J. Smoothing reference centile curves: the LMS method and penalized likelihood. Stat Med 1992;11:1305-1319.

Cole TJ, Bellizi MC, Flegal KM, Dietz WH. Establishing a standard definition for child overweight and obesity worldwide: international survey. BMJ 2000; $320: 1240-3$

Colli AS, Coates V, Guimarães EMB. Monitoração do crescimento e desenvolvimento físico. In: Coates V et al.. Medicina do adolescente. São Paulo: Sarvier; 1993. p. 51-59.

Conde WL, Monteiro CA. Body mass index cutoff points for evaluation of nutritional satatus in Brazilian children and adolescents. J Pediatr (Rio J). 2006:82(4):266-72.

Daniels SR, Khoury PR, Morrison JÁ. The utility of body mass index as a measure of body fatness in children and adolescents: diferences by race and gender. Pediatrics 1997:99(6):804-7 .

Díaz EB, Burrowa RA, Muzzo SB, Galgani JF, Rodriguez RR. Evaluación nutricional de adolescentes mediante índice de massa corporal para etapa puberal. Rev Chil Pediatr 1996; 67(1):153-8. 
Ebbeling CB, Pawlak DB, Ludwig DS. Childhood obesity: public-health crisis, common sense cure. Lancet 2002; 360(9331):473-82.

Finkelstein EA, Fiebelkorn IC, Wang G. State-level estimates of annual medical expenditures attributable to obesity. Obesity Research 2004; 12(1): 18-24.

Foster KR \& Lukaski HC. Whole-body impedance - what does it measure? Am J Clin Nutr 1996; 64 (suppl): 388S-96S.

Frisch RE, McArthur JW. Menstrual cycles: fatness as a determinant of minimum weight for height necessary for their maintenance or onset. Science 1974;185:949-951.

Gordon CC, Chumlea WC, Roche AF. Stature, recumbent lenght, and weight. In: Lohman TG, Roche AF, Martorell R. Anthropometric standardization reference manual. Champaign: Human Kinetics Books; 1988. p. 3-8.

Guo SS, Wu W, Chumlea WC, Roche AF. Predicting overweight and obesity in adulthood from body mass index values in childhood and adolescence. Am J Clin Nutr 2002; 76:653-8. 
Houtkooper LB, Lohman TG, Going SB, Howell WH. Why bioelectrical impedance analysis should be used for estimating adiposity. Am J Clin Nutr 1996; 64(suppl): 436S-48S.

[IBGE] Instituto Brasileiro de Geografia e Estatística. Pesquisa de Orçamentos Familiares - POF 2002-2003. Antropometria e análise do estado nutricional de crianças e adolescentes no Brasil. Rio de Janeiro: IBGE. 2006; 140p.

Kaplowitz PB, Oberfield SE. Reexamination of the age limit for defining when puberty is precocious in girls in the United States: implications for evaluation and treatment. Pediatrics 1999;104:936-41.

Laitinen J, Power C, Jarvelin M. Family social class, maternal body mass index, childhood body mass index and age at menarch as predictors of adult obesity. Am J Clin Nutr 2001; 74(3):287-94.

Lentner C. Introduction to statistics, Statistical tables, Methematical formulae. In: Lentner C. Geigy Scientific Tables $8^{\text {th }}$ ed. Vol. 2. Basle: Ciba-Geigy; $1982 ; 215-218$.

Lohman TG, Roche AF, Martorell R. Anthropometric standardization reference manual. Illinois: Human Kinetics Books; 1988. 
Lukaski HC. Methods for the assessment of human body composition: traditional and new. Am J Clin Nutr 1987; 46:537-56.

Marshall WA, Tanner JM. Variations in the pattern of pubertal changes in boys. Arch Dis Child 1970; 45:13-23

Moreira DM, Fragoso MIJ, Oliveira Júnior AV. Níveis maturacional e socioeconômico de jovens sambistas no Rio de Janeiro. Rev Bras Med Esporte 2004; 10 (1): 16-23.

Neutzling MB, Taddei JAAC, Rodrigues EM, Sigulem DM. Overweight and obesity in Brazilian adolescents. Int J Obes 200; 24:869-74.

Ogden CL, Flegal KM, Carroll MD, Johnson CL. Prevalence and trends in overweight among US children and adolescents, 1999-2000. JAMA 2002; 288(14):1728-32.

Ogden CL, Carroll MD, Curtin LR, McDowell MA, Tabak CJ, Flegal KM. Prevalence of overweight and obesity in United States 1999-2004. JAMA 2006; 295(13):1549-55.

Oliveira CS, Veiga GV. Estado nutricional e maturação sexual de adolescentes de uma escola pública e de uma escola privada do Município do Rio de Janeiro. Rev Nutr 2005;18(2):183-91. 
Oliveira FLC, Taddei JAAC, Escrivão MAS et al.. Accuracy of obesity diagnosis in Brazilian adolescents: comparison of Cole et al. and Must et al. criteria with DXA percentage of fat mass. Nutr Hosp. 2006; 21(4):484-90.

[PAHO] Pan American Health Organization. Globesity: The crisis of growing proportions. Perspective in Health Magazine. 2002; 7(3):6-11.

Piccoli A, Pastori G. BIVA software. Department of Medical and Surgical Sciences, University of Padova, Padova, Italy, 2002.

Reilly JJ, Methven E, McDowell ZC, Haking B, Alexander D, Stewart L, Kelnar CJH. Health consequences of obesity. Arch Dis Child 2003; 88:748-52.

Rogol AD, Roemmich JN, Clark PA. Growth at puberty. J Adolesc Health 2002; 31(1): 192-200.

Saito MI, A avaliação nutricional na adolescência: a escolha de um referencial. J Pediatr 1993; 69(3):165-75.

Sievorgel RM, Demerath EW, Schuber C, Remsberg KE, Chumlea WC, Sun S, Czernwinski SA, Towne B. Puberty and body composition. Horm Res 2003; 60:36-45. 
Silveira D, Taddei JAAC, Escrivão MAMS, Oliveira FLC, Ancona-Lopez F. Risk factors for overweight among Brazilian adolescents of low-income families: a case control study. Public Health Nutr 2006; 9(4):421-8.

Statacorp LP. Stata Statistical Software: Release 10.1. College Station, TX: Stata Corporation, 2007.

Stettler N. Comment: the global epidemic of childhood obesity: is the role for the paediatrician? Obes Rev 2004; 5 Suppl 1:1-3.

Tanner JM. Growth at adolescence. $2^{\text {nd }}$ Ed. Oxford: Blackwell; 1962.340 p.

Tanner JM. A history of the study of human growth. Cambridge: Cambridge University Press; 1981. 499p.

Taylor RW, Falorni A, Jones IE, Goulding A. Indentifying adolescents with high percentage body fat: a comparasion of BMI cutoffs using age and stage of pubertal development compared with BMI cutoffs using age alone. Eur $\mathbf{J}$ Clin Nutr 2003;57:764-9.

Veiga GV, Cunha AS, Sichieri R. Trends in overweight among adolescents living in the poorest na richest regions of Brazil. Am J Public Health 2004; $94(4): 1544-8$. 
Vitalle MSS, Tomioka CY, Juliano Y, Amancio OMS. Índice de massa corporal, desenvolvimento puberal e sua relação com a menarca. Rev Assoc Med Bras 2003; 49(4):429-33.

Wang Y. Is obesity associated with early sexual maturation? A comparison of the association in American boys versus girls. Pediatrics 2002; 110(5):90310.

Wang G, Dietz WH. Economic burden of obesity in youth aged 6 to 17 years: 1979-1999. Pediatrics 2002; 109(5):86-91.

[WHO] World Health Organization. Young people's health: a challenge for society. Geneva, 1986 (Technical Report Series, 731).

[WHO] World Health Organization. Physical status: the use and interpretation of anthropometry. Geneva, 1995 (Technical Report Series, 854).

[WHO] World Health Organization. Obesity: preventing and managing the global epidemic. Geneva, 2000 (Technical Report Series, 894).

[WHO] World Health Organization. Nutrition in adolescence - Issues and challenges for the health sector. Geneva, 2005 (WHO discussion papers on adolescence). 


\section{FORMULÁRIO}

Pesquisa: Antropometria e composição corporal de crianças e adolescentes

\begin{tabular}{|c|c|c|c|}
\hline $\begin{array}{l}\text { 1. Data: } 1 / 1 \\
M \quad() F \\
\text { 4. Nome: }\end{array}$ & $\frac{\text { IDENTIFICAÇÃOO }}{\text { 2. Data de nascimento }}$ & 1 & 3. Sexo: ( ) \\
\hline $\begin{array}{l}\text { 5. Idade: } \\
\text { 7. Nome do pai: }\end{array}$ & 6. Série: & Telefone: & \\
\hline 8. Nome da mãe: & & & \\
\hline
\end{tabular}

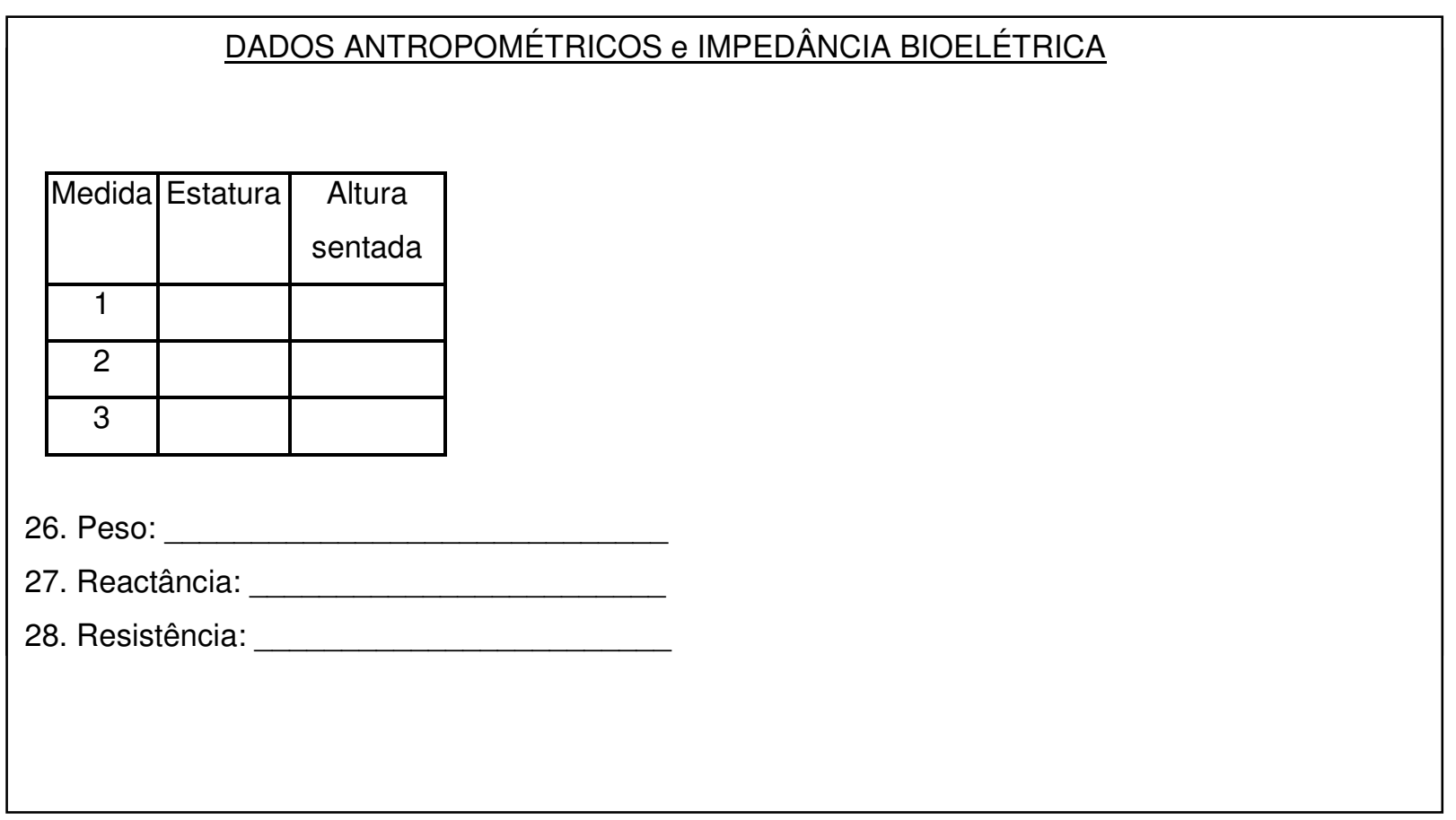




\section{QUESTIONÁRIO}

Este questionário faz parte da pesquisa "Antropometria e composição corporal de crianças e adolescentes" e é de grande importância a obtenção das informações abaixo. Peço a colaboração dos senhores pais e/ou responsáveis no preenchimento das questões e que, por favor, envie-as pelos seus (suas) filhos (as). Atenciosamente, Maria Fernanda.

\section{Identificação:}

1. Nome do filho (a):

2. Qual a data de nascimento do seu filho: 1

3. Endereço completo:

4. Nome do pai:

5. Nome da mãe:

Dados sobre a saúde de Sr (Sra) e de seu (sua) filho (a):

6. Com quantos quilos seu (sua) filho (a) nasceu?

7. O seu filho foi amamentado ao peito? ( ) sim ( ) não

8. Em caso afirmativo, por quantos meses?

9. Qual o peso da mãe? 10. E a altura?

11 Qual o peso do pai? 12. E a altura?

Nível sócio-econômico:

13. Quantas pessoas vivem em sua casa?

14. Qual a escolaridade materna? (informe até qual série)

15. Qual a escolaridade paterna?

16. Qual a ocupação materna?

17. Qual a ocupação paterna?

18. Somando o salário de todas as pessoas que trabalham em sua casa, qual a renda familiar total mensal? 
FORMULÁRIO DE ESTADIAMENTO SEXUAL

IDENTIFICACÃ̃O

Data:

Série:

Nome:

MATURAĊÃO SEXUAL - MENINOS

29. Desenvolvimento dos pêlos pubianos

\begin{tabular}{|l|l|l|l|l|}
\hline P1 & P2 & P3 & P4 & P5 \\
\hline
\end{tabular}

30. Desenvolvimento dos genitais

\begin{tabular}{|l|l|l|l|l|}
\hline G1 & G2 & G3 & G4 & G5 \\
\hline
\end{tabular}

\section{IDENTIFICAÇÃO}

Data:

Série:

Nome:

\section{MATURAÇÃO SEXUAL - MENINAS}

31. Você já teve a primeira menstruação? ( ) Sim ( ) Não

32. Se sim, com que idade? anos

33. Desenvolvimento dos pêlos pubianos

\begin{tabular}{|l|l|l|l|l|}
\hline P1 & P2 & P3 & P4 & P5 \\
\hline
\end{tabular}

34. Desenvolvimento das mamas

\begin{tabular}{|l|l|l|l|l|}
\hline M1 & M2 & M3 & M4 & M5 \\
\hline
\end{tabular}




\title{
ANEXO 2 - APROVAÇÃO COMITÊ DE ÉTICA EM PESQUISA
}

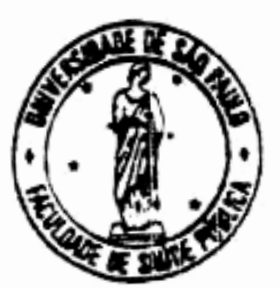

\author{
UNIVERSIDADE DE SÃO PAULO \\ FA, CULDADE DE SAÚDE PÚBLICA \\ COMITE DE ÉTICA EM PESQUISA-COEP \\ Av. Dr. Arnaldo, 715 - Cerqueira César \\ Sào Paulo-SP - CEP: 01246-904
}

Telefone: (0xx11) 3066-7779-e-mail: mdgracavâusp.br

Of.COEP/034/01

21 de março de 2001

Pelo presente, informo que o Comitè de Ética em Pesquisa da Faculdade de Saúde Pública da Universidade de São Paulo-COEP, analisou e aprovou, em sua 2. $\%$ Sessão Ordinária, de 20.03.01, de acordo com os requisitos da Resolução CNS/196/96, o Protocolo de Pesquisa n. 427, intitulado: "CRESCIMENTO E COMPOSIÇÃO CORPORAL DE ADOLESCENTES", apresentado pela pesquisadiora Maria Fernanda Petroli Frutuoso.

Atenciosamente,

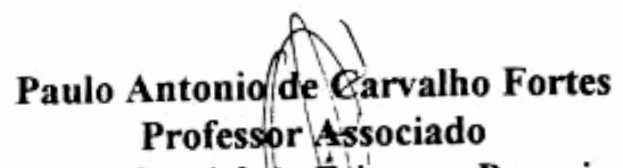

Vice-Coordenador do Comitê de Ética em Pesquisa da FSP-COEP 


\section{COMITÊ DE ÉTICA EM PESQUISA - COEP/FSP \\ Universidade de São Paulo \\ Faculdade de Saúde Pública}

Of.COEP/ $269 / 08$

Protocolo

Projeto de Pesquisa

Pesquisador(a)
1860

A INFLUÊNCIA DO ESTÁGIO DE MATURAÇĀO SEXUAL NO EXCESSO DE PESO DE ADOLESCENTES

Jéssica Rodrigues de Oliveira

24 de OUTUBRO de 2008.

\section{Prezado(a) Orientador(a),}

O Comitê de Ética em Pesquisa da Faculdade de Saúde Pública da Universidade de São Paulo - COEP analisou, em sua 9.\%/08 Sessão ORDINÁRIA, realizada em 17/10/2008, de acordo com os requisitos da Resolução CNS/196/96 e suas complementares, o protocolo de pesquisa acima intitulada e o considerou APROVADO.

Cabe lembrar que conforme Resoluçâo CNS/196/96 sẫo deveres do (a) pesquisador (a): 1. Comunicar, de imediato, qualquer alteraçăo no projeto e aguardar manifestaçăo deste CEP (Comitê de Ética em Pesquisa), para dar continuidade à pesquisa;

2. Manter sob sua guarda e em local seguro, pelo prazo de 5 (cinco) anos, os dados da pesquisa, contendo fichas individuais e todos os demais documentos recomendados pelo CEP, no caso eventual auditoria;

3. Comunicar, formalmente a este Comitê, quando do encerramento deste projeto;

4. Elaborar e apresentar relatórios parciais e final;

5. Justificar, perante o CEP, interrupção do projeto ou a não publicaçăo dos resultados.

Atenciosamente,

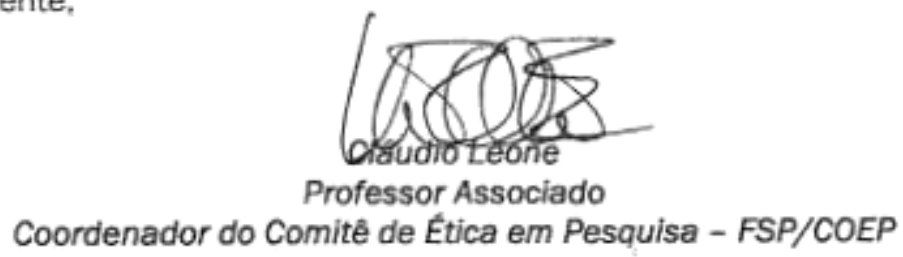

IIm. Sr."

Prof." Dr." ANA MARIA DIANEZI GAMBARDELLA

DEPARTAMENTO DE NUTRIÇĀO

FACULDADE DE SAÚDE PÚBLICA

UNIVERSIDADE DE SĀO PAULO 


\section{ANEXO 3 - CURRÍCULO LATTES}

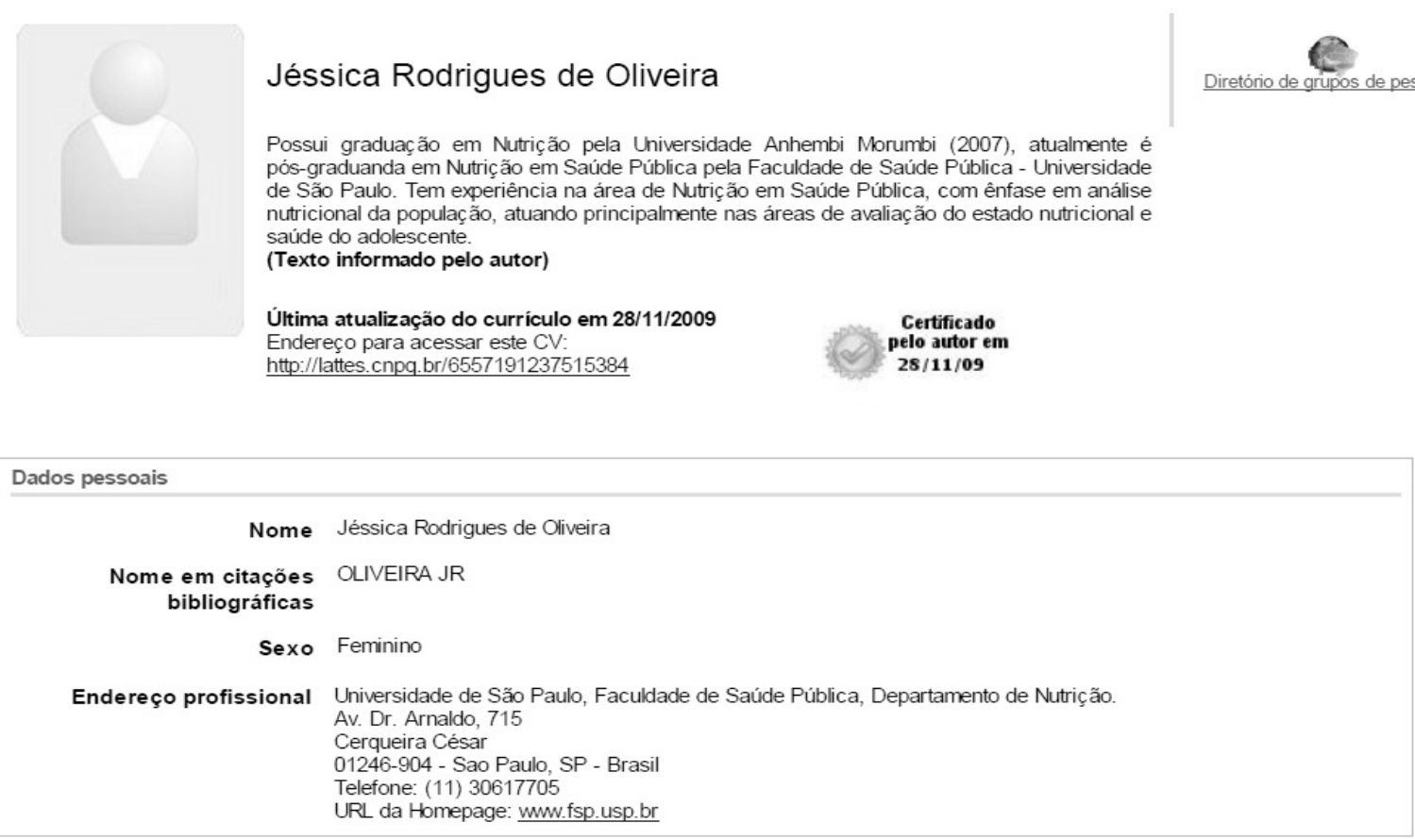

Formação acadêmica/Titulação

2008 Mestrado em andamento em Nutrição em Saúde Pública

Título: A influência do estágio de maturação sexual no excesso de peso e gordura corporal em adolescentes, Orientador: Ana Maria Dianezi Gambardella.

Bolsista do(a): Coordenação de Aperfeiçoamento de Pessoal de Nivel Superior,

Palavras-chave: Adolescentes; avaliação do estado nutricional; índice de Massa Corpórea; Composição corporal;

Estágio de Maturação Sexual; Menarca.

Grande área: Ciências da Saúde / Área: Nutrição.

Grande área: Ciências da Saúde / Área: Nutrição / Subárea: Análise Nưtricional de População.

Grande área: Ciências da Saúde / Área: Saúde Coletiva / Subárea: Epidemiologia.

2005 - 2008 Graduação em Gastronomia

Universidade Anhembi Morumbi, UAM, Brasil.

2004 - 2007 Graduação em Nutrição

Universidade Anhembi Morumbi, UAM, Brasil.

Título: Fatores associados ao excesso de peso em adolescentes.

Orientador: Maria Fernanda Petroli Frutuoso.

Atuação profissional

Universidade de São Paulo, USP, Brasil.

Vínculo institucional

2008 - Atual Vínculo: Pós-Graduação, Enquadramento Funcional: Bolsista, Regime: Dedicação exclusiva.

Atividades

6/2008 - Atual Ensino, Nutrição, Nivel: Graduação

Disciplinas ministradas

HNT 203 - Educação Nutricional

Estágio - Programa de Aperfeiçoamento de Ensino (PAE)

2/2008 - Atual Atividades de Participação em Projeto, Faculdade de Saúde Pública, Departamento de Nutrição.

Projetos de pesquisa

Influência da maturação sexual na adiposidade de adolescentes 


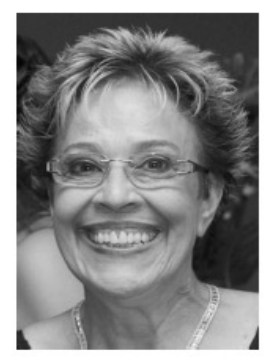

\section{Ana Maria Dianezi Gambardella}

ANA MARIA DIANEZ GAMBARDELLA CONCLUIU O DOUTORADO EM SAUDE PUBLICA PELA UNIVERSIDADE DE SAO PAULO EM 1996. ATUALMENTE E PROFESSOR DOUTOR DA UNIVERSIDADE DE SAO PAULO. PUBLICOU 18 ARTIGOS EM PERIODICOS ESPECIALIZADOS E 48 TRABALHOS EM ANAIS DE EVENTOS. POSSUI 4 CAPITULOS DE LIVROS E 1 LIVRO PUBLICADO. ORIENTOU 11 ALUNOSDE INICIACẼOO CIENTÍFICA, 8 DISSERTACOES DE MESTRADO E 5 TESE DE DOUTORADO NA AREA DE NUTRICAO. RECEBEU 9 PREMIOS E/OU HOMENAGENS. ATUA NA AREA DE NUTRICAO, COM ENFASE EM ADOLESCENTES. EM SEU CURRICULO LATTES OS TERMOS MAIS FREQUENTES NA CONTEXTUALIZACAO DA PRODUCAO CIENTIFICA, TECNOLOGICA E ARTISTICO CULTURAL SAO: ADOLESCENTES, SOBREPESO, CONSUMO ALIMENTAR, ESTADO NUTRICIONAL, MATURACAO SEXUAL, ALIMENTACAO INSTITUCIONAL, ANEMIA FERROPRIVA E GORDURA CORPORAL.

(Texto informado pelo autor)

Última atualização do currículo em 24/05/2010

Endereço para acessar este CV:

http://lattes.cnpq.br/1510248097484351

Certificado

pelo autor $\mathrm{em}$

24/05/10
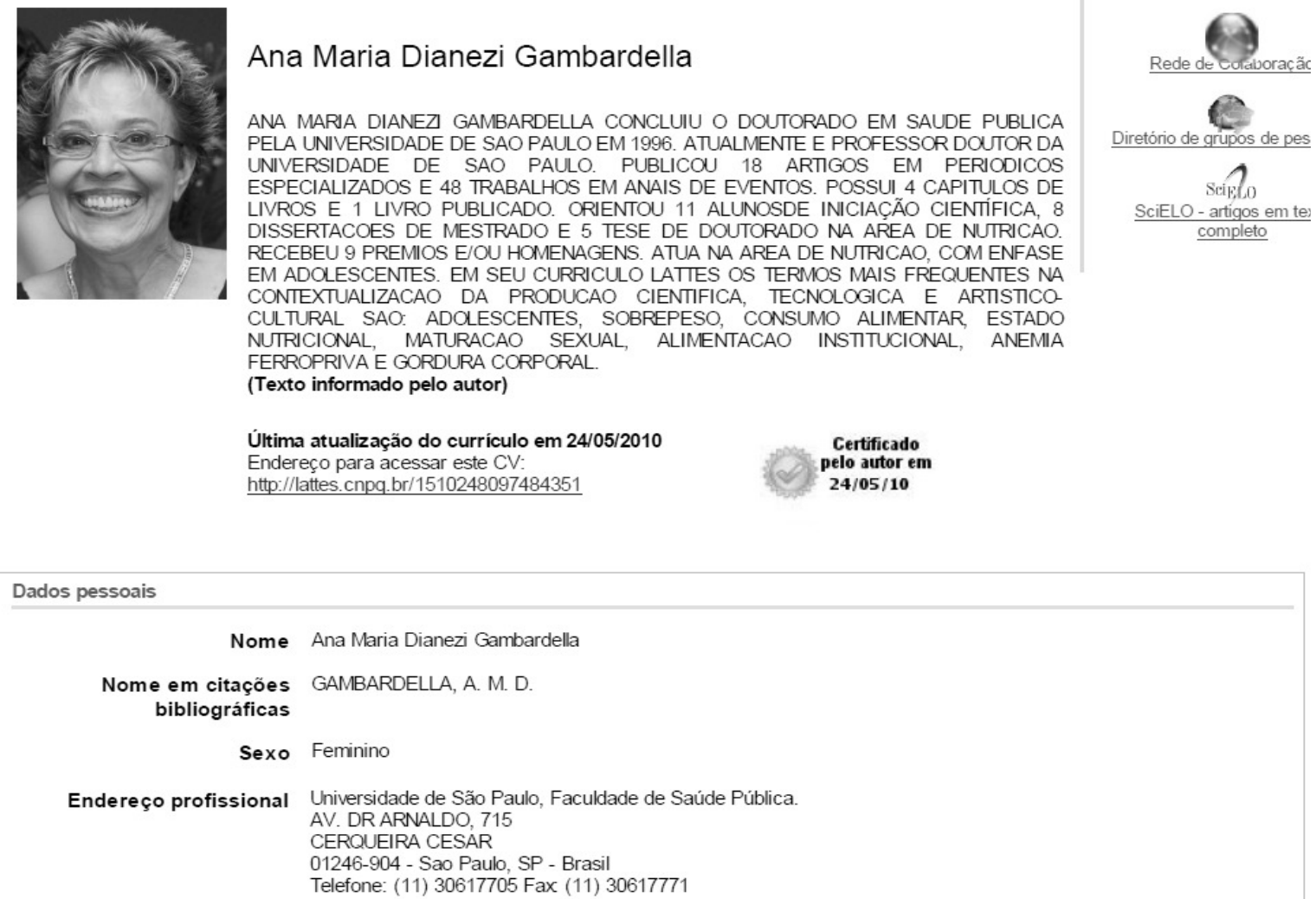

Formação acadêmica/Titulação

1990 - 1996 Doutorado em Saúde Pública (Conceito CAPES 5)

Universidade de São Paulo, USP, Brasil.

Título: ADOLESCENTES ESTUDANTES DE PERIODO NOTURNO: COMO SE ALIMENTAM E GASTAM SUAS ENERGIAS, Ano de Obtenção: 1996.

Orientador: (6) SABINA LEA DAVIDSON GOTLIEB.

Palavras-chave: adolescentes; ALIMENTACAO; DISPENDIO ENERGETICO.

1984 - 1990 Mestrado em Saúde Pública (Conceito CAPES 5).

Universidade de São Paulo, USP, Brasil

Titulo: O PAT FRENTE AS RECOMENDACOES NUTRICIONAIS PARA ESSE SEGMENTO ESPECIFICO DA

POPULACAO, Ano de Obtenção: 1990

Orientador ROSA NILDA MAZZUU.

Palavras-chave: TRABALHADOR; ALIMENTACAO.

1984 - 1984 Especialização em Especializacao Em Saude Publica Universidade de São Paulo, USP, Brasil.

1972 - 1975 Graduação em Nutricao .

Universidade de São Paulo, USP, Brasil.

Atuação profissional

Universidade de São Paulo, USP, Brasil.

Vínculo institucional

1981 - Atual Vínculo: Servidor público ou celetista, Enquadramento Funcional: Professor doutor, Carga horária: 40

Atividades

2007 - Atual Atividades de Participação em Projeto, Faculdade de Saúde Pública, 